\title{
Toward the reconstruction of Proto-Algonquian-Wakashan. Part 2: Algonquian-Wakashan sound correspondences
}

\begin{abstract}
The second part of the present study, continuing an earlier publication by the author in a previous number of JLR, includes: an inventory of Proto-Algonquian-Wakashan phonemes with a list of Proto-Algonquian-Wakashan phonemes with references to Proto-AlgonquianWakashan roots (§2); a comparative Proto-Algonquian-Wakashan dictionary that includes more than 400 root reconstructions, with relevant examples from Proto-Wakashan, ProtoNivkh and Proto-Algic data, also including Proto-Nivkh-Algic roots (§3); an index of lexical meanings for the Proto-Algonquian-Wakashan and Proto-Nivkh-Algic roots $(\S 4)$. The main innovative aspect of the present article is the formal demonstration of genetic relationship between Nivkh, Algic, and Wakashan languages, conducted by means of the standard comparative method, i. e. establishing a system of regular sound correspondences between the vocabularies of the compared languages.
\end{abstract}

Keywords: Algonquian-Wakashan languages, Nivkh-Algonquian languages, Algic languages, Wakashan languages, Chimakuan-Wakashan languages, Nivkh language, historical phonology, comparative dictionary.

\section{Introduction}

In the first part of the present paper (Nikolaev 2015) it was stated that a genetic relationship between Proto-Wakashan, Proto-Nivkh, and Proto-Algic may be demonstrated by means of the standard comparative method, i. e. the establishment of a system of regular sound correspondences between the compared vocabularies. Table 4 in Nikolaev 2015: 30 displays the reconstructed system of Proto-Algonquian-Wakashan phonemes and their reflexes in separate families (PW, PNi, PAlg), but lexical illustration of regular sound correspondences has been limited in that part, for volume reasons, to specific subsets of the "basic" and "cultural" lexicons. Conversely, the second part of the paper will be dedicated to presenting the bulk of the evidence in the form of a comprehensive Proto-Algonquian-Wakashan comparative vocabulary $(\S 3)$.

\section{Proto-Algonquian-Wakashan phonological inventory}

The Proto-Algonquian-Wakashan phonological inventory is shown in Tables 1 and 2.

Definite reconstructions that contain specific PAW phonemes and ambiguous reconstructions where one of 2 alternate protophonemes may have been present (optional variants are divided with the tilde sign) are listed after the Tables $1 \& 2$. Numbers refer to the ProtoAlgonquian-Wakashan vocabulary (§3). Plain and glottalized sonorants $\mathrm{m} / \mathrm{m}$ ', n/n', r/r', etc. (that differ only in PW and perhaps in PChi) and short/long variants of vowels are given jointly. 
Table 1. Proto-Algonquian-Wakashan obstruents and sonorants.

\begin{tabular}{|c|c|c|c|c|c|c|c|c|c|}
\hline Labial & Dental & Alveolar & Palatal & Lateral & Velar & $\begin{array}{l}\text { Labio- } \\
\text { velar }\end{array}$ & Uvular & $\begin{array}{l}\text { Labio- } \\
\text { uvular }\end{array}$ & $\begin{array}{c}\text { Laryn- } \\
\text { geal }\end{array}$ \\
\hline $\mathrm{p}$ & $\mathrm{t}$ & c & $\check{c}$ & $x$ & $\mathrm{k}$ & $\mathrm{k}^{\mathrm{w}}$ & $\mathrm{q}$ & $q^{w}$ & \\
\hline $\mathrm{b}$ & $\mathrm{d}$ & 3 & $\check{3}$ & $\lambda$ & $\mathrm{g}$ & $g^{w}$ & G & $\mathrm{G}^{\mathrm{w}}$ & \\
\hline \multirow[t]{4}{*}{$\mathrm{p}^{\prime}$} & $t^{\prime}$ & $c^{\prime}$ & č & $x$ & $k^{\prime}$ & $\mathrm{k}^{\prime \mathrm{w}}$ & q' & $\mathrm{q}^{\mathrm{w}^{\mathrm{w}}}$ & $?$ \\
\hline & & $\mathrm{s}$ & $\check{S}$ & 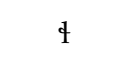 & $x$ & $x^{w}$ & $x$ & $\chi^{\mathrm{w}}$ & $\mathrm{h}$ \\
\hline & $\mathrm{r}$ & & & 1 & $\gamma$ & $\gamma^{w}$ & в & $\mathrm{S}^{\mathrm{W}}$ & \\
\hline & $\mathrm{r}^{\prime}$ & & & l' & & & & & \\
\hline $\mathrm{m}$ & $\mathrm{n}$ & & ń & & $\mathrm{y}$ & & & & \\
\hline $\mathrm{m}^{\prime}$ & $\mathrm{n}^{\prime}$ & & n' & & n' & & & & \\
\hline $\mathrm{w}$ & & & $\mathrm{y}$ & & & & & & \\
\hline$w^{\prime}$ & & & $y^{\prime}$ & & & & & & \\
\hline
\end{tabular}

Table 2. Proto-Algonquian-Wakashan vowels.

\begin{tabular}{ccc}
\hline Front & Mid & Back \\
\hline i i: ü: & i ì: & u u: \\
e e: & ə ə: & о o: \\
ä ä: & & a a: \\
\hline
\end{tabular}

$*$

$13,16,25,31,85,145,183,275,276,277,278,279,280,281,282,283,284,285,286$, $287,288,289,290,292,293,295,296,297,298,299,300,384,417$

${ }^{*} b$ $60,62,63,64,320$

${ }^{*} b \sim{ }^{*} p$

$58,68,69,70,291,294$

${ }^{*} b \sim{ }^{*} p$ '

$59,61,65,65,67,71,153,154,167,242,255,394$

${ }^{*} p$
${ }^{*} t$

$97,98,111,302,303,304,305,306,307,307$ a

$38,53,99,339,340,341,342,343,344,345,346$

${ }^{*} t \sim{ }^{*} t$ ' $142,350,353$

*d 11, 35, 40, 98, 99, 100, 101, 102, 103, 104, 107, 387

${ }^{*} d \sim{ }^{*} t \quad \quad 61,105,106,126,167,278,282,329,360,372$

${ }^{*} t$

$40,86,347,348,349,351,352,354,355,356,357,358,359,361$

${ }^{*} \mathrm{C} \quad 73,116,228,322,403$

${ }^{*} C \sim \check{C} \quad 76$

${ }^{*} C \sim{ }^{*} C$ ' 74, 261, 376

${ }^{*} C \sim{ }^{*} S \quad 75,125,327,388,401$

*3

78, 136, 186, 197, 330, 378, 413, 414, 415, 416, 417

$*_{3}^{*} \sim *^{3} \quad 27$

${ }^{*}{ }^{\prime}$ ' $\quad 77,78,81,95,297,321,323$

${ }^{*} C^{\prime} \sim{ }^{*} \check{C} ' \quad 79,80$

${ }^{*} \mathrm{~S} \quad 4,141,187,326,382$

* $\quad 36,36,84,86,87,88,90,158$

*̌̃ $\sim$ *̌̃ $\quad 52,83,91$

*̌̃ $\sim{ }^{*} \check{S} \quad 85,285$ 


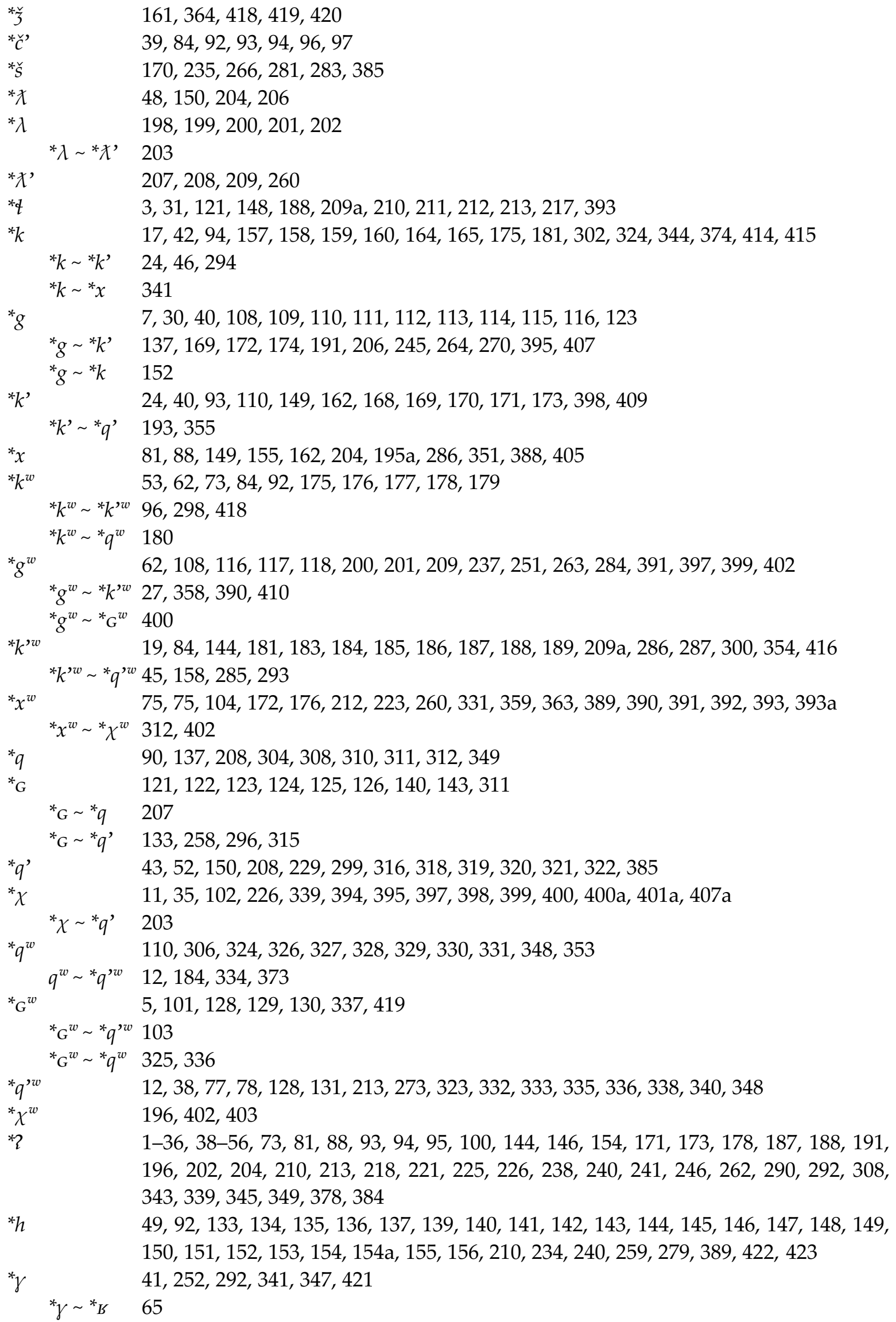




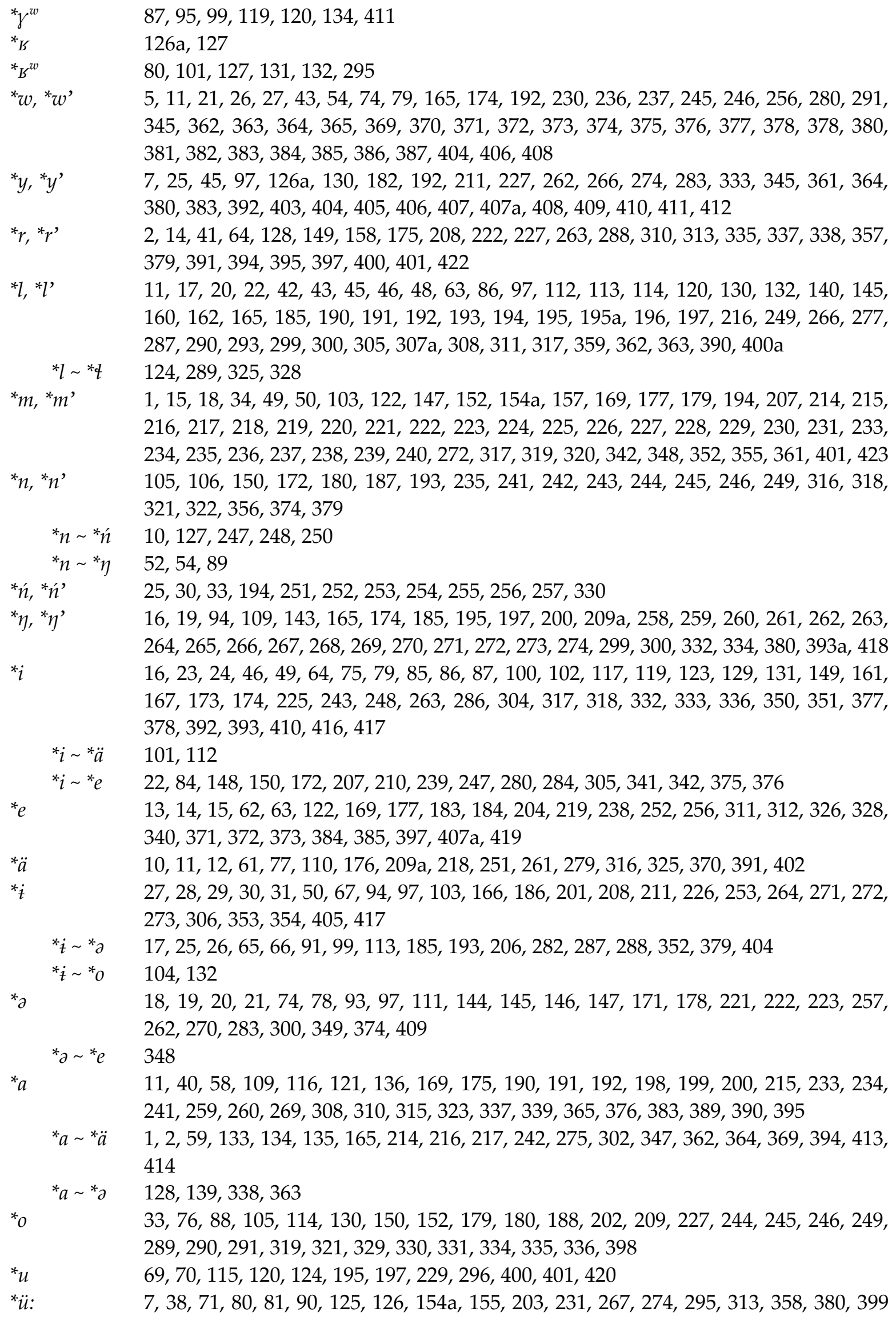




\section{Proto-Algonquian-Wakashan lexicon}

Phonetically, the Proto-Nivkh-Algic (PNA) reconstructions would not differ from the hypothetical Proto-Algonquian-Wakashan (PAW) forms that chronologically precede them; therefore, PNA forms in the list below are interspersed with PAW ones. PNA forms that have their ProtoSalishan counterparts may be considered as PAW forms that were lost in Proto-Wakashan.

The Chimakuan languages (Quileute and the scarcely documented Chemakum) belong to the same phylum as Wakashan. However, the Quileute material still requires further processing in its historical aspect; therefore, only the most important Quileute and Chemakum data are given in the present paper.

There are numerous lexical similarities between Proto-Salishan and PAW, including those within the "basic lexicon" (Nikolaev 2015, §4). However, data for establishing regular sound correspondences between PAW and PS remain scarce, and so the Salish-AlgonquianWakashan relationship stays in the realm of speculation. In the list below I quote Salishan forms as external comparative data.

Whereas modern forms of the Wakashan and Nivkh languages differ insignificantly from the PW and PNi forms, sound changes in the Algic family have been so substantial that cognates are frequently unrecognizable to "the naked eye". For this reason the Proto-Algic and Proto-Algonquian reconstructions are provided below with examples of their reflexes in certain attested languages.

In protoforms the tilde symbol $(\sim)$ denotes alternative variants of reconstruction, rather than actual variance in the proto-language. If reconstruction of two (rarely three) protophonemes in the same position is possible, the alternative variants are given in parentheses. For example, PAW * gilV $\left(\sim \ddot{a}, l\right.$ l') 'three': Quil. $q^{w} \underline{a}: ? l$, PNi *ce-, PAlg *ni-khl- means that attested reflexes permit us to reconstruct either PAW ${ }^{*} i$ or ${ }^{*} \ddot{a}$, either ${ }^{*} l$ or ${ }^{*} l$ '.

Reconstruction of PAW glottal features of stops/affricates (voiceless / voiced / glottalized) in roots containing two stops or affricates is somewhat difficult, due to assimilation/dissimilation of glottal features in the history of many of the concerned languages; therefore, several roots have optional protoforms. This also applies to labialization of velars and uvulars. In such cases alternate protoforms are divided with the tilde symbol. Thus, cf. PAW ${ }^{*} k^{\prime} i: w \eta V \sim$ ${ }^{*}$ gi:w $V$ 'to freeze, cold': here PW * $k$ 'in- 'to feel cold' reflects PAW ${ }^{*} k$ '-, PNi * $k i \eta$ - 'to freeze, cool down' reflects PAW ${ }^{*} g$ - and PA *ko:n- 'snow' may reflect either of the two proto-phonemes; or PAW *bu: *pu: 'to go out, leave', where PW *bu:- 'to leave, flee, abandon' reflects PAW *b-, but PNi *phu- 'to go out/away' reflects PAW * $p$ - and PA *papa:- $m$ - 'to go about, pass by' [reduplication] may reflect PAW * $p-,{ }^{*} b-,{ }^{*} p$ '-

Potential metatheses are represented in the same way; thus, PAW *ho^Vq'A * ${ }^{*} h o q^{\prime} V \star A$

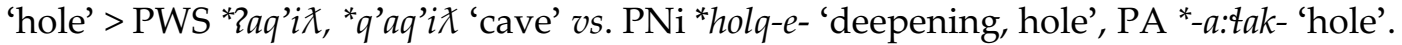

Reflexes of the clusters "sonorant + obstruent" $\left({ }^{*} n C,{ }^{*} l C,{ }^{*} r C\right.$, etc.) are rather unstable, and sometimes I reconstruct them on the basis of their presence in just one of the families.

Within the reconstructed forms, capital letters should be decoded as follows: $A=$ indefinite mid/back vowel, $C=$ any sibilant (alveolar) or hushing (palato-alveolar) affricate, $E=$ indefinite front vowel, $K=$ any velar stop, $L=$ any lateral, $N={ }^{*} n \sim{ }^{*} \dot{n} \sim{ }^{*} \eta, O={ }^{*} u \sim^{*} O\left({ }^{*} \dot{i}\right), P=$ any labial stop, $Q=$ any uvular stop, $S={ }^{*} \sim{ }^{*}{ }^{*}, V=$ any vowel, $X=$ any velar or uvular fricative. This notation is used when sound correspondences are generally regular, but available comparative material is insufficient to definitively choose one particular PAW phoneme over another. Example:

$$
{ }^{*} n^{\prime} \mathrm{OLK}\left({ }^{w}\right) V\left(\sim n^{\prime}\right) \text { 'hand, arm' } \bullet \mathrm{PW}^{*}-n^{\prime} u k^{w} \text { (suff.) 'in hand' } \bullet \mathrm{PA}{ }^{*}-n e t k-\text { 'hand, arm' }
$$


Here either n' or 'n' can be reconstructed (since the Nivkh data are absent); the symbol $O$ denotes a choice between ${ }^{*} i$ and ${ }^{*} u$; the symbol ${ }^{*} L$ denotes the possibility of reconstructing either ${ }^{*} \lambda,{ }^{*} \lambda, \lambda^{\prime}$, or ${ }^{*} l$; the symbol ${ }^{*} K\left({ }^{w}\right)$ denotes a choice between ${ }^{*} k\left({ }^{w}\right),{ }^{*} g\left({ }^{w}\right)$, and ${ }^{*} k^{\prime}\left({ }^{w}\right)$.

Many PAW roots seem to have "inversed" allomorphs * $C V C V$ and *2VCCV (rarely * $h V C C V$ ). The latter structures may represent "incorporated" root forms that were originally used as suffixal variants. Reflexes of the $2 V C C V$-type allomorphs prevail in PNA. The reconstructed allomorphs of both types are divided with the double tilde $(\approx)$ : ${ }^{*} \check{c}^{\prime} A k^{w} V \approx{ }^{*}\left\{A c^{\prime} k^{w} V\right.$ 'earth, dirt', 'č' $\partial k$ ' $E \approx * 2 \partial c^{\prime} ' k$ 'E 'tail (of fish)', etc.

Another type of alternation, namely ${ }^{*} \mathrm{CVCV}-\sim{ }^{*} \mathrm{CCV}$-, is not infrequent in Nivkh (e. g., PNi

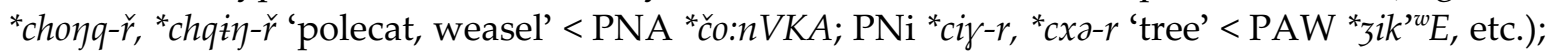
most probably, this is just an internal Nivkh phenomenon, not projectible onto deeper historical levels.

The voiced lateral stop is provisionally denoted here as $\lambda$, as against Nikolaev 2015, where it was marked as $L$. This replacement has been made in order to avoid graphical confusion of $L$ ("voiced lateral stop") and $L$ ("any lateral").

Many of the items below are provided with short comments, although this does not extend to the examples that have already been commented upon in Nikolaev 2015. Some of the PAW and PNA protoforms have been improved upon during the preparation of this part of the article, and are slightly different from those quoted in Nikolaev 2015.

1. PNA * $2 a L V m V\left(\sim \ddot{a}, m^{\prime}\right)$ 'dog' • PNi *ajm 'dog (taboo)' [instead of regular **(a)lam; irregularity of the PNi form may be explained by a "tabooistic" mutation of the original phonetics]; NiY *laama- O 'dog' • PA *atem-w-, -(a)2tem-w- 'dog' [Cree atim, Men. anc:m, Ab. alemós 'dog'; Cree wa:p-astim 'white dog', etc.] II Nikolaev 2015: 47.

2. PAW *2arV ( $\ddot{a})$ 'blood' $\bullet P W N * 2 a l-k^{w}-$ 'blood'; *2al- $x^{w}-$ 'to bleed' - Quil. ti-č- 'blood', ti:'to bleed' • PNi * $\eta$-ar 'blood' $\diamond$ Cf. PSI * $m$-il'-k' 'blood', PS *m-il' 'to bleed' [see PNA* $\eta V$ \#268] II Nikolaev 2015: 36.

3. PAW * $2 A t V$ 'eye' - PW *G-at- 'eye' [with prefix of inalienable possession]; PWS (suff.) *-(k)s-ut, -(k)s-it 'eye' - PAlg *-2et in *čep-2et-, *-čp-2et- 'eyelash' $\diamond$ Cf. PS *-t in *cop-t 'eyebrow, eyelash' II Nikolaev 2015: 38, 48.

4. PAW * $2 A: s V$ 'face' - $\mathrm{PW}{ }^{*} \mathrm{G}-a s^{-}$'eye' [with prefix of inalienable possession]; *-as, *-2aw-as

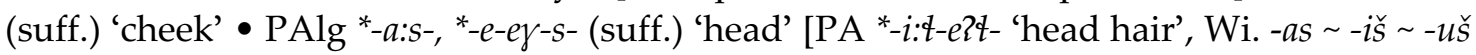
(suff.) 'head'] $\diamond$ Cf. PS * $m$-2us 'face', suff. *-us 'face, eye'.

5. $\quad \mathrm{PAW}{ }^{*} 2 A w V N N^{w} E$ 'duck' • PWN *2anq- 'duck (generic)' • Quil. díq'diq' 'duck, mallard' • PNi *awjk ( a) 'duck sp.' $\diamond$ Cf. PSC *mu?q w ‘duck (generic)’ II Nikolaev 2015: 53.

7. PAW *a:gV *ya:gV ( o:) 'all' • PWN *za:g- 'all, in full, every, any, each' • PA *wi:-yak'some sort, all sorts' [Men. we:yak, Oj. wi:yak, etc.] $\diamond$ Cf. PIS * уәь 'many, all'.

8. PNA *2a:ndVXKE ( ä:, t') 'raven, crow' - PNi *atk, *atk-ak 'raven, crow' P PA *a:nte:hkw'crow' [Oj. a:nte:kkw, Shawnee a:te:kw-a, etc.].

9. PNA * $2 a: X p V(\sim \ddot{a}:)$ 'mouth (of animal)' $\bullet \mathrm{PNi}{ }^{*} a v-\eta$ 'mouth (of animal), palate' • $\mathrm{P}{ }^{*}-a: h p$ itk-an- 'jaw, chin' [Cree -a:p-isk-an, Men. -a:hp-chk-an, Ab. od-s̃pp-ihk-án, etc.].

10. PAW *2äń $V$ 'year, season' • PW *-2in- $\chi$ (suff.) 'year, season'; PWN *hi:-\{an- $\chi$ 'summer' • $\mathrm{PNi}$ *ań 'year'; *h-on-f 'spring (season)' • PAlg *-en- 'season' in PA *ni:p-en- 'summer', Yu. kiš-en- 'be summer; summer' [lit. 'warm season'] $\diamond$ Cf. PS *án-ax ${ }^{w}$ (suff.) 'season, year' \| Nikolaev 2015: 46, 54.

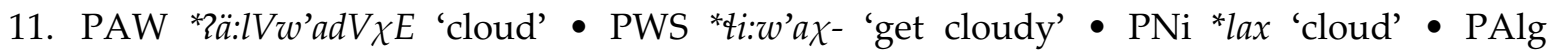
*a:lwadek-w-, *2a:lewdek-w- ( kh) 'cloud' [PA *aletkw- and *watkw- 'cloud', Yu. lewk ${ }^{w}-$, reww ${ }^{w}$ - 'cloudy, misty'; Wi. 2alúk-š 'shadow'] II Nikolaev 2015: 37. 


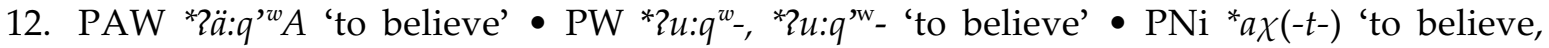
hope'.

13. PAW *2epV 'heart' $\bullet \mathrm{PWN}-2 p(-a:)$ (suff.) 'chest', PWS *t-'ap-at- 'to think' • PNi * $\eta$-if 'heart' $\| \mathrm{PW}^{*} t$ - is a prefix, cf. PWN *qal- $\chi$ - 'egg' *t-'alq- 'roe, spawn' (\#308).

14. PAW *2erV 'to vomit' $\bullet \mathrm{PWS}$ *2at- 'to vomit' $\bullet \mathrm{PNi}$ *er-u- 'to vomit'.

15. PNA *2e: $m V(\sim m$ ') 'to flee' $\bullet \mathrm{PNi}$ * $p h$-im- 'to flee' • PA *a:m-o:- 'to flee, fly' [WOj. en-am-o 'the road goes thither', Fox ki:w-a:mo:-wă 'he flees hither and thither', etc.].

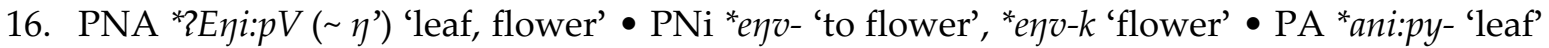
[WOj. eni:pi:-šš 'leaf', Ab. wanib-ákw 'leaf of a tree', etc.] II Nikolaev 2015: 47.

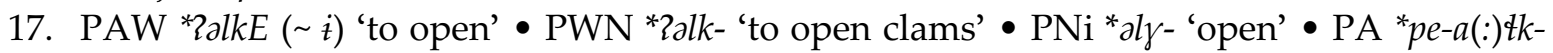
'to open' [Cree p-a:sk-in-am 'she opens it', WOj. p-a:kk-in-ank, Ab. b-óskw-en-á 'to open by hand', etc.]

18. PAW *2amV 'mother, aunt' - PWS *2am(a)- 'mother' • PNi *im(i)- $k$ 'mother; mother's sister; father's brother's wife and her sister; step-father's sister'; *mam 'old woman; wife' • PA *-i:m-at- 'mother' [ ${ }^{*} n-i: m-a t-a$ 'my mother', etc.] $\diamond$ Cf. PS *t-um-a? 'mother, aunt'; PSI *m?am 'woman, wife'.

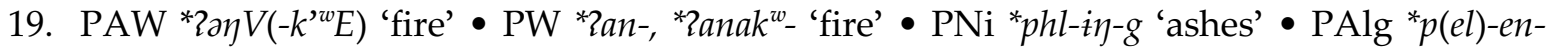

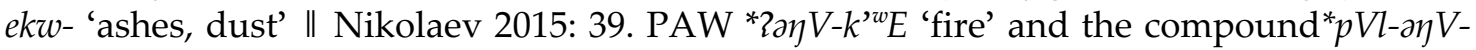

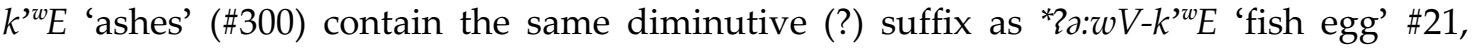
*tä $V-k$ ' $\left({ }^{w}\right) V$ 'woman' \#209a.

20. PNA *2o:lV $(\sim l$ ') 'to think' • PNi *al-m- $(\sim)$ 'to think of', NiY *önmo- 'mind, reason' • PAlg *a:l-, *-e:l- 'to think, feel' [Wi. l-at-bit 'she feels so', l-at-azw 'how she looks', PA *-e:l-em- 'to think, by mind' (cf. PAlg *-Vm- 'by feeling, thought')].

21. PNA *2a: $w V\left(\sim w^{\prime}\right)$ 'egg, brood', *2a: $w V-k^{\prime w} E$ 'fish egg' • PNi * $\eta$-əv- $i$ 'nest'; * $\eta$-əw- $k$ 'fish egg' - PAlg *w-a:w- 'egg' [Wi. w-á-zl 'roe', Yu. w-o:-lew 'spawn', PA *w-a:w-i, Pl. w-a:w-al-i 'egg']; PA *w-a:hkw- 'roe, spawn, fish egg' [Cree $w$-a:hkw-a 'lump of roe', WOj. w-a:kk 'roe', etc.] $\diamond$ Cf. PS * $2 a-k^{w w},{ }^{*} 2 a-q^{\prime w}$ 'fish roe' II Nikolaev 2015: 50.

22. PNA *2ilV $(\sim e)$ 'thus' • PNi *lil- $\eta$ 'indeed that, just that' • PAlg *2el-, *2al-, dim. *2er-, *2ar'thither, thus, that way, like that, that sort' [Wi. t-ala- 'there, then, thus', Yu. s-on 'to be like', PA *et- 'thus, thither', *t-at- 'there', etc.] II Nikolaev 2015: 47.

23. PAW *2i:kV ( k') 'hand' - PW *-i:k-s (suff.) 'in/by hand' • ? PAlg *-e(:)k- ( kh) 'hand' in Yu. pan-ek 'hand measure', pon-ek'-əh 'hand length' $\diamond$ Cf. PS *-ak, *ak-a?, *-ak-is(t) (suff.) 'hand, lower arm' II Nikolaev 2015: 39.

24. PAW *2i:k'V *k'i:2V 'above'・PW *2i:k'- 'above' • PNi *khi- 'above'.

25. PNA *ipwińyV ( o) 'paddle' • PNi *iv(i)ńn 'paddle' • PA *apwiy- 'paddle' [Cree apw-iy, Men. $p$-i:h, etc.].

26. PNA *iw $w\left(\sim \partial, w^{\prime}\right)$ 'to use' $-\mathrm{PNi}{ }^{*} i w-r i-$ 'to use' $-\mathrm{PA}{ }^{*} a w$ - 'to use' [*aw-e:w-a 'he uses him', *aw-ih-e:w-a 'he lends to him', etc.].

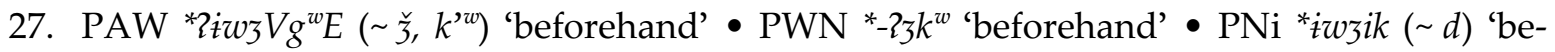
forehand'.

28. PNA *2i:LV ‘kidney' $\bullet \mathrm{PNi}{ }^{*} \eta-\partial l-\check{r}$ 'kidney'; NiY *aĺ-aja- 'liver, kidney’ $\bullet \mathrm{PA}{ }^{*}-o: t-(\sim l)$ 'kidney' [> Ab. -ól-ló, Mic. bug-al-uŏn 'kidney'].

29. PAW *2i:LV 'mouth' - Quil. 2ól-it 'mouth' - PNi *al 'mouth' • PAlg *o:t- 'mouth' [Wi. -ol-ul, Yu. -el-ut 'mouth', mewol-ut-ek' 'I wipe my mouth'] \|| Nikolaev 2015: 41.

30. PNA *iz:ńgE 'face' • PNi * $y$-ińk 'face' • PAlg *-i:ngw-, *-engw- 'face' [Yu. -e2w-ey/-ozw-ey 'face', PA *-i:nkw-e:, *-2kw-e: 'face, look'].

31. PNA*2i:ptV 'lip, tip of tongue' - PNi *avl-(i) $x$ 'lip' • PAlg *-i:pt- 'tongue' [Wi. -it, Yu. -ipt, PA *i:t-an-] II Nikolaev 2015: 50. 
33. PNA *2o:ńk $k^{w} E\left(\sim q^{w}, X^{w}\right)$ 'star' $\bullet P N i * u n ́ \gamma(\dot{t})-r$ 'star' $\bullet \mathrm{PA} * a t-a: n k w$ - 'star' [Cree ata:hk, Men. ana:h, WOj. ena:nk, Ab. alákw-s, etc.] II Nikolaev 2015: 47, 50.

34. PAW *2OmV 'angry' • PWN *2am-s- 'bad luck' • PNi *um- 'angry, be angry'.

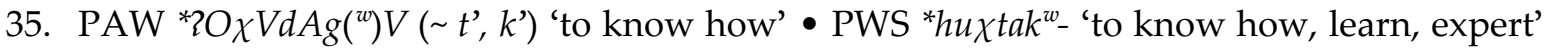
- PA *ketk- 'to know, recognize' [Cree kisk-e:y-im-e:w 'to know, find out', WOj. kekk-e:n-emat 'to know, find out', Ab. o-gáhk-im-j̃ 'he teaches him', etc.].

36. PNA *2O:čk'E 'head, face' • PNi *osk 'face' • PAlg *-o:čk-w-, *-ečk-w-, *-etk-w- 'head' [PA *-etkw- 'head' (suff.), *-a:n-etkw- 'head hair', suff. -šk-y- 'hair; leaf, foliage'; Wi. m-ák ${ }^{w}$-uks 'brains'; Yu m-ot, m-otkw-oh 'head'], PA *-ešk(y)-i:n-š-ekw- 'eye' [in this compound * $-i: n$ maybe corresponds to Wi. -alìd, Yu. -elin 'eye' < PAlg*-li:n-].

38. PAW * $2 u ̈: t O q^{\prime w} E$ 'man' $P \mathrm{PW}^{*}-$-2i:t(a) $\chi^{w}$, ${ }^{*}-2 a t(a) \chi^{w}$ 'man of tribe or residing at; male inhabitant of; people of, where one lives' • PNi *utk- 'man, husband' I| Nikolaev 2015: 41.

39. PNA * $2 V c ̌ c k E(\sim q, X)$ 'foot, leg' • PNi * $\eta-\partial c x$ 'foot, leg' • PAlg *-Včk-, *-Vtk- 'foot, leg' [Wi. -ačk-ač, -itk-ad-, -atk- 'leg', Yu. -eck-ah 'leg', m-eck-es 'track', -a:tk- 'by foot'; PA *-etk-a:t- 'leg', *-ešk-, *-ehk- 'by foot'].

40. PAW *2Vda:k'A *2Vt'a:gA 'belly, abdomen' - PW *da:k'- 'belly' [> PWN *tk'- (<*dak'-), suff. *-(s-)da:k'z(-a:), PWS *tač' 'belly'] • PNi *taq-(a)l 'fish abdomen' • PAlg *2ata: $\gamma-w-$-, *2etay-w- 'belly, stomach' [Wi. tag-ad-a?l 'one's belly', Shawnee hope?kw-ata:w-ilok-e 'she has a stomach ache'] II Nikolaev 2015: 36.

41. PNA *2VyrV 'skin (of animals), scale' • PNi * $y$-ajr, * $y$-ayr 'skin (of animals)' • PAlg *-ajl-, *-ajr- 'skin, scale'. [PA *w-ąl-ak-ay- 'skin, scale', *w-ąš-ak-ay- 'skin', *-tam-eš-k-ay- 'inner skin, membrane'; Wi. $w$-át-k-ay 'skin'; Yu. sr-ahk ${ }^{w}$-oh 'loincloth', sl-ekw 'clothes (a single set)'] $\diamond$ PS * $k$ 'wal' 'skin, feather, porcupine quill' \| Nikolaev 2015: 43.

42. PAW * $2 V k l V$ 'to name' - $\mathrm{PW}{ }^{*}-k t$ - (suff.) 'named' [PWN *-(x) $\lambda(-a:)$ 'named, called'; PWS *-qt(-a:) 'named, called; having as name'], PWN *-kl(-a:) 'to refer to' • Quil. $k^{w} o l-a ́ l$ 'name' - PAlg *-ekl- $(\sim k h, g)>$ PA *-ell- 'narrate (sacred story) [i. e. 'to refer to ancestors' names': *a:t-ell-o:hk-aw-e:w-a 'he tells a sacred story', etc.] II Nikolaev 2015: 41.

43. $\mathrm{PAW}{ }^{*}(2 V: l V-) q$ 'AwV ( l') 'nose' - PWS * q'aw-a:n- 'fish nose, fish nose cartilage' [cf. the same suffix in PWS *q'im-a:n- 'navel'] • PA *e:likw-em- 'nostrils' [Cheyenne -átsitse?-e:m-, Cree -e:yig-um, etc.] II Nikolaev 2015: 42.

45. PNA *2Vlyak'wA ( q'w) 'squirrel' - PNi *laq-r 'squirrel', PNi *olv-ilak 'flying squirrel' • PAlg *alyekw- $(\sim k h)$ 'squirrel' [Yu. hej-oyek 'pine/flying squirrel', $k^{w}$ ec-oyek ${ }^{w}$ 'ground squirrel', PA *anyikw-a 'squirrel'], PA *pel-e:nyikw- 'flying squirrel' [Men. penc:nik, Ab. planíkw, etc.] || Nikolaev 2015: 54.

46. PAW *2O:l'i:kE ( k') 'wolf' - PWN *2u:l'i:k-> Kw. 2ul'ìg-ñ 'wolf' • PNi *lij-ř 'wolf' \| Nikolaev 2015: 54.

48. PAW * $2 V \rtimes V: n Q^{w} V$ ' $\mathrm{k}$. of berries' $-\mathrm{PWN}{ }^{*} \rtimes a n q^{w}$ - 'an unidentified plant with edible red berries' - PA *alo:tk-an- ( tk) 'raspberry' [Cree ayo:sk-an, Men. ano:hk-an, etc.] II PA -tk- in spite of * $n k$ - due to assimilation with the preceding *- $\lambda-$.

49. PAW *2Vmi:hV 'to pray' - PWN *2ami:2-, *2ami:- 'to pray, praise, honour, pay tribute' • PA *al-amih- [Cree ay-amih-a:w, Men. an-a:meh-a:w, Oj. an-amiz-a: 'he goes to church, prays', etc.]; *mamy-a:ntw- 'to pray' [reduplication: Fox mam-a:t-ome:wa 'he prays to him', Men. mami-aht-omew 'he prays to him, etc.].

50. PNA *2VmiyX $X^{w} E\left(\sim m\right.$ ', $\left.K^{w}\right)$ 'spoon' - PNi *mïx 'spoon (wooden)' P PA *e:mehkw-a:n-, *e:meškw-a:n- 'spoon' [Blackfoot háméšk-o, Cree e:mihkw-a:n, Men. e:miskw-ən, etc.].

52. PAW *2E: $q$ ’VnVč $V\left(\sim \eta, \check{c}^{\prime}\right)$ 'k. of shellfish' • PWN * $q^{\prime} \partial n c^{-},{ }^{*} q$ 'ons- 'chitons (sea prunes, Chinese slippers)' • PAlg *2e:hnec- ( ch) 'bivalve shell' [Yu. 2anc-oh 'abalone shell', PA *e:hs'clam, oyster', *e:ns- 'any bivalve mollusk, clam']. 
53. $\mathrm{PAW}{ }^{*} 2 V t O k^{w} A$ 'deer' $\bullet \mathrm{PWN}{ }^{*} t a k^{w}$ - 'deer' $\bullet \mathrm{PNi}{ }^{*} t h o \chi$ 'elk' ${ }^{1} \bullet \mathrm{PA}{ }^{*}$ atehkw- 'caribou' [Cree atihk, Men. atc:h, etc.] $\diamond$ Cf. PS *tiqiw 'deer, elk'.

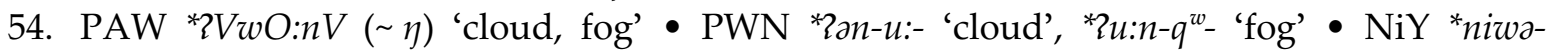
'cloud' [metathesis either in "Northern Nivkh" or in Proto-Yukaghir] - PA *awa(:)n-w'fog' [Cree awan, Men. awa:n, etc.], cf. Yu. -uzway 'cloud' II Nikolaev 2015: 37, 54.

58. $\mathrm{PAW}{ }^{*} b a \sim{ }^{*} p a$ 'to wither' $\bullet \mathrm{PWN}{ }^{*} p \partial-\chi^{w}-$ 'to wither (plant, etc.)' $\bullet \mathrm{PNi}{ }^{*} p a-$ 'to wither'.

59. PNA *baTkE ( p', $\ddot{a}, q, X)$ 'partridge' • PNi *pasi 'partridge' • PA *patk-iw-, *patpatk-iw'partridge' [Cree paspask-iw, Fox pahk-i:wa, Ab. bákk-ess-ó, Miami pahk-i-a, etc.].

60. PAW ${ }^{*} b A: L Q^{w} V$ 'to sever' $\bullet \mathrm{PWN}{ }^{*} b a: q^{w}{ }^{w}$ 'to separate things that are joined together (e.g. a pen and its cap)' $-\mathrm{PA}$ *patk- 'to sever, break' [Fox pahk-wíwin-غ́w-a 'he is shedding his horn', WOj. pekk-on:t 'he skins him', Mic. pěsk-witt 'to shed the feathers', etc.].

61. PNA *bä: $d V\left(\sim p^{\prime}, t^{\prime}\right)$ 'slow' • PNi *pat- 'quiet, slow' • PA*pe:t-, *pe:s- 'slowly' [WOj. pe:s$i k k-a$ : 'to move slowly', pe:č-i:w-i: 'he is walking slowly', etc.].

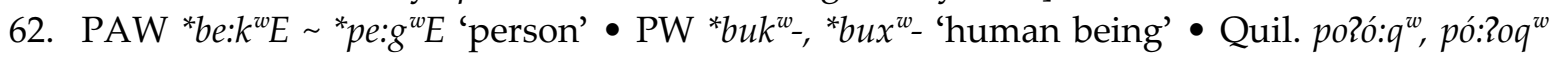

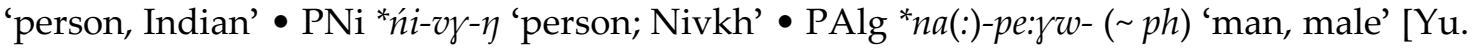

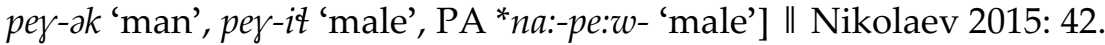

63. PNA *be:lV 'to walk' - PNi *ple-w- 'to go for a walk' - PAlg *ba:l-, dimin. *ba:r- 'to walk, go' [Yu. 2or-oy- 'to walk', PA *-pal- 'to go, move'] II Nikolaev 2015: 47.

64. PAW *bi:rV *pi:rV 'to scatter' - PWN *bi:t- 'to pull apart (moss, etc.), to scatter'; *bal- $\chi$ scatter (feathers, moss, down), to spread (roots)' $\bullet$ PNi *pir- ( a) 'scattered', "phir-i- $(\sim \partial)$ 'spread' $\diamond$ Cf. PS *pil, “pal 'scatter, smudge'.

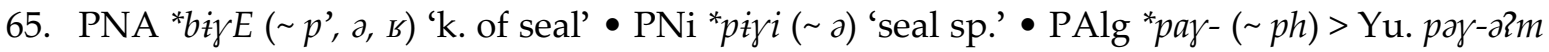
'seal'.

66. PNA *biKE ( p', a, Q,X) 'to throw' - PNi *pay-z- 'to throw' - PA *pak- 'to throw' [Men.

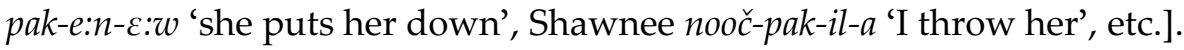

67. PNA *birKE $(\sim p$ ', Q) 'to rot' $-\mathrm{PNi}$ *pirk- 'to rot' $\bullet \mathrm{PA}$ *pek-eškat- 'putrid, rotten' [*eškat 'rot'; Cree pik-iskat-at-iw 'he is putrid, rotten', Oj. pak-aškan-an-i 'be rotten', etc.].

68. $\mathrm{PAW}{ }^{*} b \mathrm{O} \sim{ }^{*} p \mathrm{O}$ 'to bleed' $\bullet \mathrm{PWN}{ }^{*} p a-x$ - 'to bleed sb.' $\bullet \mathrm{PNi}{ }^{*} p u$ - 'to bleed'.

69. PAW *bu: ${ }^{*} p u$ : 'to go out, leave' $-\mathrm{PW}{ }^{*} b u$ :- 'to leave, flee, abandon' $\bullet \mathrm{PNi}{ }^{*} p h u$ - 'to go out/away' - PA *papa:-m- 'to go about, pass by' [reduplication; Cree papa:-m-isk-a:w 'he goes about', Men. papa:-m-esk-aw 'he goes about', etc.].

70. PAW *bu: *pu: 'to blow (with mouth); swell' $\bullet \mathrm{PW}{ }^{*} b u-x^{w}-$ 'illegitimately pregnant'; * $b u$ $s$ - 'to swell (esp. when pregnant)'; 'bu-t-, * $b u-\lambda$ - 'to swell, swelling, to boil (tide), to bud or flower'; “pu:- 'to swell or blow up' • PNi *phu-v- 'to blow (with mouth)'; "pho-ya-, *phoyphoya- 'to swell out' - PAlg *po:-, *pa- $(\sim p h)$ 'to blow with the mouth' [Yu. par-oh, PA *po:taw-]; PA *pa:-kih[š]- 'to swell' [Cree pa:-kis-iw 'he is swelling', Oj. pa:-kišš-i 'be swollen', etc.] $\diamond$ Cf. PS *paw, *puh, * $p u x^{w},{ }^{*} p a x^{w}$ 'to blow, breathe, swell'.

71. PNA *bü:PTV ( p') 'foam' • PNi *poft-r 'foam' • PAlg *pi:pt- ( ph, b) > PA *pi:zt-e:w'foam' [Cree pi:st-e:w, Ab. piht-á 'foam, froth', etc.].

72. $\mathrm{PAW}{ }^{*} b V N ’ V$ 'down' $\bullet \mathrm{PWN}{ }^{*} b a n '-$ 'down, under, below, lower' • PAlg *pen- ( ph) 'down to the ground' [Yu. pen-, PA *pen-].

73. $\mathrm{PAW}{ }^{*} c A: 2 k^{w} V \approx{ }^{*} 2 A: c k^{w} V$ 'seal' $\bullet \mathrm{PWN}{ }^{*} s a: 2 k^{w}-$ 'seal, seal meat' PAlg ${ }^{*} q a: c k w-,{ }^{*} 2 e(:) c k w-$ $(\sim c h, k h)$ 'seal' [Yu. 2ec, 2eck ${ }^{w}-o h$ 'sea-lion', PA *a:sk-ikw-a 'seal'] $\diamond$ Cf. PS *2asx $x^{w}$ 'seal' II Nikolaev 2015: 53.

${ }^{1}$ Borrowed into Proto-Manchu-Tungusic as *tōKī 'elk'. According to Anna Dybo (p.c.), Proto-Mongolic *togij 'grown-up elk' is a Manchu-Tungusic borrowing. 
74. PNA *co:wV ( c', w') 'to open' - PNi *chiw- 'to open' - PA *ta:w-atw- 'to open one's mouth, gape' [with *-atw- 'to turn, round'; Cree ta:w-at-iw 'he opens mouth, gapes', Men. ta:w-an- $\varepsilon w$ 'he holds his mouth open', etc.].

75. $\mathrm{PAW}{ }^{*} c i: x^{w} E(\sim s)$ 'rash' $\bullet \mathrm{PWS}{ }^{*}$ six ${ }^{\mathrm{w}}$ 'rash, sores' $\bullet \mathrm{PNi}{ }^{*}$ chix 'rash'.

76. PAW ${ }^{*} c o: x^{w} E \sim{ }^{*} c o: x^{w} E$ 'to leak, soak' $P W^{*} c a: x^{w}$ - 'to leak' $P N i{ }^{*} z o \gamma-v o r-$ 'to leak' [“incorporated" form of *chox-] $\bullet$ PA *so:k- 'to pour, soak' $\diamond$ Cf. PS *six ${ }^{w}$ 'to pour, spill'.

77. PAW ${ }^{*} c^{\prime} \ddot{a}: q^{\prime w} A,{ }^{*} c^{\prime} V: c q^{\prime w} A$ 'small bird' - PW ${ }^{*} c^{\prime} i: k^{w}-$ 'bird (generic)'; PWN ${ }^{*} c^{\prime} \partial s q^{w_{-},}{ }^{*} c a s q^{w_{-}}$ 'any small songbird' - PNi ${ }^{*} z a q$ 'chickadee' • PAlg ${ }^{*} c o: c k$ - 'small bird' [Wi. cuck-iš, Yu.

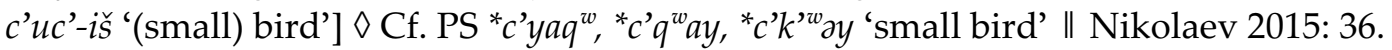

78. PNA ${ }^{*} c^{\prime} \partial q^{\prime w} E \sim{ }^{*} z \partial q^{\prime w} E$ 'to fear' $-\mathrm{PNi}{ }^{*} z \dot{z} g-u-(\sim \partial)$ 'to frighten, punish' $-\mathrm{PAlg}{ }^{*} z e: k(w)-$ $(\sim k h)$ 'be afraid' [Yu. 2ek ${ }^{w}-e t$ 'to be afraid', PA *se:k- 'fright'].

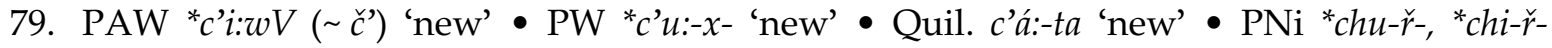
'new', NiY *cirov- 'new' • PAlg ${ }^{*} c i:-,{ }^{*} c i-(\sim c h, \check{c}, c ̌ h)>$ Yu. ca-2an, ci-n- 'new' II Nikolaev 2015: 41.

80. PAW ${ }^{*} c^{\prime} u: s^{w} A\left(\sim \check{c}^{\prime}\right)$ 'to wash, clean' $-\mathrm{PW}{ }^{*} \mathrm{C}^{\prime} u:-$ 'wash' $\bullet \mathrm{PNi}{ }^{*} \mathrm{cu}$ - 'clean, wash', ${ }^{*} \mathrm{ch} \chi 0-j-$ 'wash, launder' $\diamond \mathrm{Cf}$. PS ${ }^{*} c^{\prime} a b^{w},{ }^{*}{ }^{*}$ 'aw 'wash, clean'.

81. PAW *c'ü: $x A \approx$ * $2 \ddot{u}: c^{\prime} x A$ 'sap, blood' $-\mathrm{PWN}{ }^{*} c^{\prime} i: x->$ Kw. c'ix-a 'boiled blood'; ? PWN *c'i:x'lean (meat)' $\bullet \mathrm{PNi}{ }^{*}$ cho $\chi$ 'pitch, sap; blood' $\bullet$ PAlg *-ck-orw-, ${ }^{*}$-tk-orw 'blood; red' [Wi. -atk$a 2 w-i k$, PA * $m-e s k-w-i$ 'blood', etc.] $\diamond$ Cf. PS ${ }^{*} c i s^{w}$ 'to bleed'; ${ }^{*} c i q^{w},{ }^{*} c a q^{w}$ 'to bleed; red' II Nikolaev 2015: 36.

82. PNA ${ }^{*} \mathrm{Ci}(:)(\sim e[:])$ 'to dry' $-\mathrm{PNi}{ }^{*}$ che- 'to dry' $-\mathrm{PAlg}{ }^{*} c e(:)-(\sim c h, \check{c}, \check{c} h)>\mathrm{Yu}$. ce-2l- 'dry (adj.)' I| Nikolaev 2015: 47.

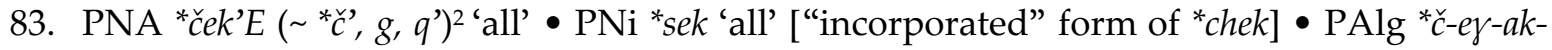

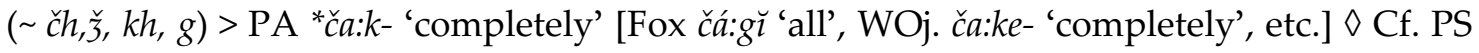
${ }^{*} c u k^{w}$ 'to be all there, be complete' II Nikolaev 2015: 35.

84. PAW ${ }^{*}{ }^{*} i k^{\prime w} E \sim{ }^{*}{ }^{\prime} ' i k^{w} E(\sim e)$ 'big stone, rock' $-\mathrm{PWN}{ }^{*} c a k^{w}-,{ }^{*} c a x^{w}-$ 'rock fence, fish trap made of stones' • PNi *cej-ra- 'rock, cliff' • PAlg *čekw-, *̌c-ej-ekw- ( čh, kh) 'big stone, rock' [PA *ši:kw-an- 'cliff, grindstone'; Yu. cek'w-et 'prayer stone "seat" (semicircular wall of mortared stones)'] I| Nikolaev 2015: 43.

85. PNA *či:pV *pi:čV $(\sim \check{s})$ 'to stretch' - PNi *phez- 'to stretch oneself' PA *ši:p- (pref.) 'to stretch' [Fox ši:p- 'to stretch', Men. se:p-e:w 'he acts long', etc.].

86. PAW *či:t'V(-lV) 'foot, leg' - PWS (suff.) *-cit'-a 'leg, thigh', *-c'i:-t 'foot' - PNi * $\eta \partial-z(\dot{z})-l$ 'foot, sole' - PAlg *-cit-t- 'foot' [PA*-sit- and secondary *-オi才- in Wi. -elit 'foot'] || Nikolaev 2015: 39.

87. PAW ${ }^{*} c i: \gamma^{w} V$ 'adze' $-\mathrm{PWN}{ }^{*} c u: x^{w}$ - 'to chip out with an adze'; *cox ${ }^{w}$ - 'to adze off fine chips';

- PNi *chiw-ř $(\sim-s)$ 'adze' $\diamond$ Cf. PS *cak 'to adze, whittle, carve'.

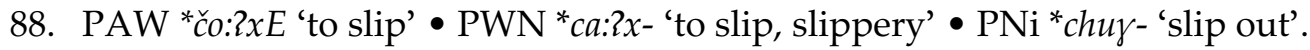

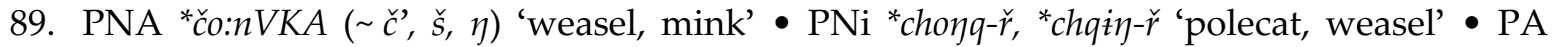
*ša:nkw-e:hs- 'mink'; *šenkw-e:hs- 'weasel' [Cree sa:hkw-e:s-iw 'mink' and sihk-os 'weasel', WOj. ša:nkw-e:šš-i 'mink', šenkw-ass 'weasel', etc.].

90. PAW *čü:qA 'to melt' $-\mathrm{PWN}{ }^{*} c i: q-,{ }^{*} c i: \chi^{-}$'to melt (tallow), to fry' $\bullet \mathrm{PNi}{ }^{*}$ chos- 'to melt, thaw'.

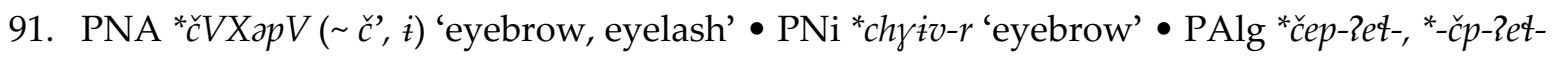
$(\sim p h)$ 'eyelash' [Wi. čapt, Yu. -etp'et] $\diamond$ Cf. PS *cap-t 'eyebrow, eyelash' \|I In PAlg (and PS) compounds with PAW *2AAV'eye’ \#3.

2 Pace Nikolaev 2015: 31, reflexes of PAW hushing sounds in Proto-Wakashan should be amended to the following: *̌c $>c ; * \check{z}>3-, * ;{ }^{*}>c^{\prime}-, c ; * \check{s}>s$. 
92. PAW ${ }^{*} c^{\prime} A k^{w} V \approx{ }^{*} h A c^{\prime} k^{w} V$ 'earth, dirt' $-\mathrm{PW}{ }^{*} c^{\prime} a k^{w}-$ 'dirt' $\bullet$ Quil. c'iq'-á:ti 'ground, land, earth, world, territory' - PAlg *hačk-y-, *hečk-y- ( čh, kh) 'earth, land' [Yu. hetk- 'on land', PA *atky-i 'land', etc.] $\diamond$ Cf. PS *c'iq' 'mud' \|| Nikolaev 2015: 38, 54.

93. $\mathrm{PAW}{ }^{*} c^{\prime} \partial k^{\prime} E \approx{ }^{*} 2 \partial c^{\prime} k^{\prime} E$ 'tail (of fish)' $\bullet \mathrm{PW}{ }^{*} c^{\prime} a x$ - 'tail of a fish' $\bullet \mathrm{PNi}{ }^{*} y \partial-s k$ 'tail fin (of a seal)' • PAlg *-ček-w-an-, *-č-ej-ek-an- 'tail (of fish, bird), rump' [PA *-šekw-an- 'tail of fish' ; *-šyi:k-an- 'rump'; Wi. we-tútk 'ventral fin'; Yu. cak 'bird's tail'; cecek ${ }^{w}$ 'fin of fish'] II Nikolaev 2015: 43.

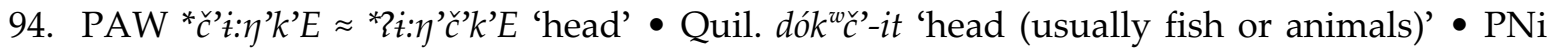
*conj-r 'head' [the Sakh. variant conqr has $-q-$, probably under the influence of PNi *-qar 'neck'] • PAlg *-a:čk-w-, *-ečk-, *-etk- ( čh, kh) 'head' [PA *-etkw-, -ešky- (suff.) 'head', Yu. $m$-otk ${ }^{w}$ - 'head'] II Nikolaev 2015: 39, 50.

95. $\mathrm{PAW}{ }^{*} c^{\prime} \mathrm{O} \gamma^{w} V \approx{ }^{*} 2 \mathrm{O} \gamma^{w} 3 V\left(\sim B^{w}\right)$ 'to give' $-\mathrm{PW}{ }^{*} c^{\prime} u$ :- 'to give' $\bullet \mathrm{PA}{ }^{*}$ ?ahz-, *2ahd-, *2ehž- 'to give' [Wi. Zac-ab- 'give food to', Yu. 2o? 'give', PA *ahš-am- 'to give food' (*-am- 'by mouth, to eat')] II Nikolaev 2015: 39.

96. PAW ${ }^{*} c^{\prime} V k^{w} V\left(\sim k^{* w}\right)$ 'short' $-\mathrm{PWN}{ }^{*} c^{\prime}{ }^{\prime} k^{w}{ }^{w}-$ 'short' $-\mathrm{PAlg}{ }^{*} t e t k w-,{ }^{*} t a t k w-,{ }^{*} t a c ̌ k w-(\sim$ th, čh, $k h)$ 'be short' [Yu. $t k^{w}$ - 'short, low', PA *tatkw-, "tahkw- 'short] $\nabla$ Cf. PSI ${ }^{*} x^{w}$ ic 'short' $\| \mathrm{Ni}$ kolaev 2015: 45.

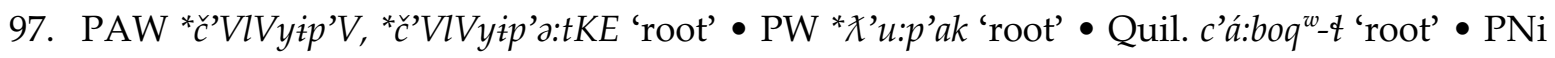
*vizlix ( -řrl-) 'root'; NiY *wadiulu: 'root' [with metathesis] • PAlg *(wre-)dlayep-, *(wre-)dlayepi:t(a)k- ( th, kh) 'root' [PA *we-tye:pitki, *we-tye:piski, ${ }^{*} w e-t y e: p i s ̌ k i, ~ s u f f$. *-tye:petk- 'root'; Wi. 2u-wa-lápitk-a?l, 2u-lápitk-all 'roots'; Yu. 2wo-? 'root(s)', 2wo-2tp-'e?y 'angelica root', 2wa-2tp-itak 'root, willow root', also $2 w o-h p-e \gamma$ 'spruce root']. $\diamond$ Cf. PS ${ }^{*} c^{\prime} a p a \imath \chi$ 'cedar root' I| Nikolaev 2015: 42.

98. PAW *dA: $p$ ' $V$ 'dark (as the night)' - PWN *da:p- 'dark (as the night)', ? PW *p'ad- 'dark' [methatesis ?] - PA *tep-etk- 'night' [lit. 'dark night': Cree tip-isk 'night', Men. tep-e:h 'last night', Ab. deb-ókw 'night', etc.] $\diamond$ Cf. PS *t’op 'dark'.

99. PNA ${ }^{*} d \partial y^{w} V(\sim i)$ 'opening, door' - PNi *thi 'door; ice-hole' - PAlg *thayw-, *theyw'through an opening, passage, space, or door; out' [Wi. thig- 'out', Yur. tew-o2n 'it breaks (of rope or string)', PA *taw- (pref.) 'to open', etc.] $\diamond$ Cf. PS *to $\chi$ 'open up, branch out' ॥ Nikolaev 2015: 55. PNi *th- < ${ }^{*} t(V) X-$.

100. PNA *di $\approx$ *2idV 'to say, tell' - PNi *it- 'to say, tell' • PAlg *the-l-, *tha-l- 'to talk' [Wi.

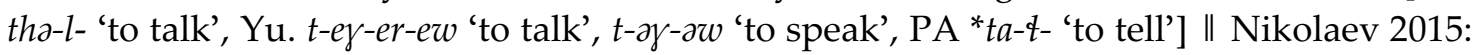
47.

101. PAW *di:s ${ }^{w} V \sim{ }^{*} d i: G^{w} V(\sim \ddot{a}:)$ 'meat, flesh' - PWN *di:q ${ }^{w}$ - 'meat, flesh' in Oo. diq'w my'a 'cheek meat of fish', Ha. dì ${ }^{w} a$ 'diseased fish with white spots in flesh' • PNi *tju- $\check{r}$ 'meat' [Am. cur, Sakh. tur ]; NiY *cu:l 'meat' - PAlg *thew- $(\sim t)>$ Yu. tew-on, -tew 'flesh' || Nikolaev 2015: 41.

102. PAW *di: $\chi V$ 'to defecate, urinate' $-\mathrm{PWN}{ }^{*} d i: \chi$ - 'to defecate (said of an animal)' $-\mathrm{PAlg}$ *dik-, (dim.) ${ }^{*}$ žik- 'to urinate, defecate' [Wi. tik-al- 'to urinate', Yu. 2ahk-ek' 'I urinate, I piss (of men)', PA *šek- 'to defecate, urinate'] $\diamond$ Cf. PSI *tk-ay' 'urine'.

103. PAW *di:mG ${ }^{w} E\left(\sim q^{\prime w}\right)$ 'arm' $P W^{*} d u: m q^{w_{-}}>\mathrm{PWN}{ }^{*} d u: q^{w_{-},}{ }^{*} d a m q^{w_{-}-}$'armpit' PNi *tamk 'hand, arm', NiY * Yirqa- 'hand, finger, paw, sole' II Nikolaev 2015: 39.

104. PAW *dix $A(\sim o)$ 'to jump' • PW *dux $x^{w}$ - 'to jump' • PNi *t $x a-r s a-$ 'to run, gallop'.

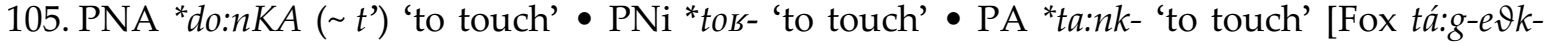
àmw-ă 'he touches it with the foot', Oj. ta:nk-in-ik-e: 'he touches, catches', Mic. tok-am-as-i 'to strike', etc.] .

106. PNA *dO:nXE ( t', K) 'strong' • PNi *tonx- 'strong' • PA *so:nk- 'strong' [Cree so:hk-is-iw

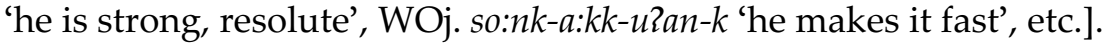


107. PAW ${ }^{*} d V$ 'demonstrative stem' $\bullet \mathrm{PW}{ }^{*} d a$ 'this, that' $\bullet \mathrm{PNi}{ }^{*} t u$ - 'this', *to-n- 'this (visible)' PAlg *ta, * $t i$ 'the one (known but not previously mentioned)' [Wi. ta 'the, some', $c i$ 'that's where, what, why', Yu. tu? 'and then', Cree -te: '(t)hither', -ta '(t)here)', Ab. io-dá 'this one (inanimate)', etc.] Nikolaev 2015: 43.

108. PAW ${ }^{*} g V \sim{ }^{*} g^{w} V$ 'demonstrative stem' • PW ${ }^{*} g a$ : 'this; here' • PNi ${ }^{*} k u$ - 'that (invisible)' • PAlg *kw-Vl- 'he, she, it' [Wi. $k^{w}$-il-áll, Yu. $k^{w}$-el-as, etc.] II Nikolaev 2015: 43.

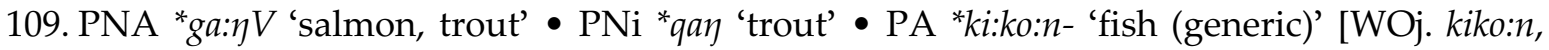
etc.] $\diamond$ Cf. PS *kan-ax ${ }^{w}$ 'salmon (generic term)' II Nikolaev 2015: 39.

110. PAW * ${ }^{*} a ̈ l q^{w} E \sim{ }^{*} k$ 'älq ${ }^{w} E$ 'to urinate' $-\mathrm{PW}{ }^{*} k^{\prime} a l q^{w}$ - 'to urinate (man)' $\bullet \mathrm{PNi}{ }^{*} k i$ - 'to urinate'.

111. PNA *ga:p'V 'to stand' $-\mathrm{PNi}{ }^{*} k a p-r$ - 'to stand, stand up' $-\mathrm{PAlg}{ }^{*} g a: p-(\sim p h)$ 'to stand' [Yu. -ozop, PA *ka:p-, *kap-] $\diamond$ Cf. PSI * fap 'to stand upright' || Nikolaev 2015: 43.

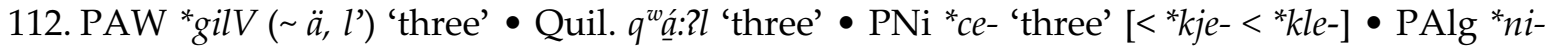
khl-, *ni-khr- 'three' [Wi. dik, dikh-, Yu. nahks-, PA *ne?t-w-] $\diamond$ Cf. PS *ka?t-as 'three' II Nikolaev 2015: 57.

113. PAW *gilV ( a) 'long' - PWN *gal- 'long, tall' • PNi *kil- 'long' • ? PAlg *ken-ew- 'long' [Yu. kn-ew-, PA *ken-w-], where - n- may go back to *-l-n- \|l Nikolaev 2015: 41.

114. PAW *go:l'V 'to suspect' - PWN *ga:l'- 'to suspect sb.' • PNi *qol-o-, *qol-kolv- 'to suspect'; NiY *qolluj- ( ) 'to envy'.

115. PAW *guLA 'to open' - PWS *kuћ- 'to open' • PNi *kul-u-, *kul-kul- 'to open eyes, stare'.

116. PAW ${ }^{*} g A: c V \sim{ }^{*} g^{w} A: c V$ 'to rub' - PWN * $g^{w} \partial s^{-}$'to rub, scrub, wring out (washing)' • PA *ka:s-, *kes- 'to rub, wipe, wash' [Cree ka:s-i:h-am 'to wipe, wash', Men. kes-i:hkw-an 'towel', WOj. kis-i:nkw-e: 'he washes his face', etc.].

117. PAW ${ }^{*} g^{w} i: g^{w} V$ 'leg, foot' • PW ${ }^{*} g^{w} i: g^{w} i: ~ ' l e g$, foot, flipper' • PAlg ${ }^{*}-k i: k-(\sim k h)>Y u .-e k i k$ 'hip(s)' I| Nikolaev 2015: 48.

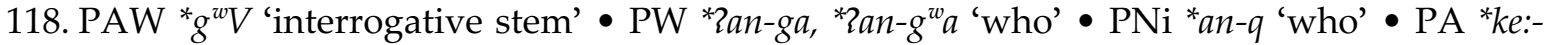
$k w$ - 'something; which?' [Men. ke:k-o:h 'something', WOj. ke:k-o: 'something', etc.]; PAlg *we:-kw- 'what' [Wi. $k^{w}$-átw-a 'what?', PA *we:-kw- 'what is it?'] $\diamond \mathrm{PS} * k a(n)$ 'interrogative stem (do what? do something); (be) where, how?)' II Nikolaev 2015: 45.

119. PAW ${ }^{*} \gamma^{w} i: K V$ 'to dwell' $\bullet P W{ }^{*}{ }^{*}{ }^{w} u: k^{w}$ - 'to live in a place, reside, dwell, settle', ${ }^{*} g^{w} u: x^{w}$ - 'to dwell' • PA *wi:k- 'dwell' [Cree wi:k-iw 'to dwell', WOj. wi:k-uw-a:m 'house', etc.].

120. PAW * $\gamma^{w} u l V$ 'to crawl, go on all fours' • PW *gul- 'to crawl, go on all fours' • PNi *ful- 'to crawl, go on all fours'.

121. PAW ${ }^{*} \mathrm{G} a: t V$ 'to speak' • PWN * $\mathrm{Ga}:$ :t- 'to call sb. names' • PNi *qla-j- 'speak' • PAlg *ga:l-, *ga:t- 'to speak' [Yu. 2ol-oy-e2w 'it calls (e.g. of a bird)', ?ol-oy-ok-e?l 'larynx, vocal chords, throat', PA *kat-aw-, "ket-aw- 'to speak'] $\diamond$ Cf. PS * $q^{w} a l$ 'to speak, think'.

122. PAW ${ }^{*} \mathrm{G} e m V$ 'head' - $\mathrm{PW}{ }^{*}{ }_{-G a m}(-t),{ }^{*}-\mathrm{G}$ Gam 'round thing; mask' [originally perhaps 'head']'; PWN ${ }^{*}{ }^{w} u:-G^{w} m-i$ : 'face' ["head-face", compound consisting of $\mathrm{PW}{ }^{*} \mathrm{G}^{w} u$ :- 'face' and ${ }^{*}$ Gam- 'head'] - PNi *hem-i 'temple' $\diamond$ Cf. PS * ${ }^{*}$ 'w $u m$ 'head, skull, hair on head' II Nikolaev 2015: 39.

123. PAW * ${ }^{*} i: g E$ 'tooth' $\bullet \mathrm{PW}{ }^{*}$ gi:g- 'tooth' $\bullet \mathrm{PNi}$ *khik 'fang' \|l Nikolaev 2015: 44.

124. PAW ${ }^{*} \mathrm{G} u: l V(\sim q)$ 'k. of fish' $\bullet \mathrm{PWN}{ }^{*} \mathrm{G}^{w} u: t$ - 'trout' $\bullet \mathrm{PNi}{ }^{*}$ qhol 'common rud' $\diamond \mathrm{Cf}$. PS *qal 'salmon (generic)' || Nikolaev 2015: 53.

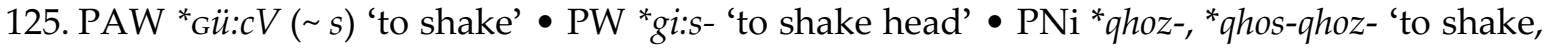
shake head'.

126. PAW *Gü:dV ( t’) 'body' • PW *-gi:t (suff.) 'on body' • PNi *hut 'body, carcass'.

126a. PAW ${ }^{*} B A y V$ 'far' $\bullet$ PWS * $\chi a y-a:-\left(\sim s^{-}\right)$'far' $\bullet$ PA *ay-a:-k(a)w- 'far off' [Men. aya:ki:htaw 'far back in ancestry', Natick aongkóúe 'utmost, farthest off', etc.] II Nikolaev 2015: 45. 
127. PAW ${ }^{*} B V n V \sim{ }^{*} B^{w} V n V\left(\sim\right.$ ') 'to carry' $\bullet \mathrm{PWN}{ }^{*} \mathrm{G} a n$ - 'to carry in the arms' $\bullet \mathrm{PA}$ *wen-ik- 'to

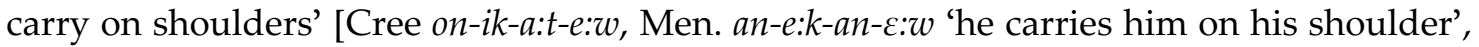
WOj. on-ik-e: 'he carries sth. over a portage', etc.].

128. PAW ${ }^{*}{ }^{w} a:(r) q^{\prime w} V(\sim a:)$ 'raven' $P W{ }^{*} G^{w} a: \chi^{w}$ - 'raven' $-P A l g{ }^{*} k a:(h) k-,{ }^{*} k w a:(h) k w-(\sim k h)$ 'raven' [Yu. $k^{w}-e \gamma-o k w, \mathrm{PA}{ }^{*} k a: h k a: k-i w-a,{ }^{*} k a: k a: k-$ 'raven'].

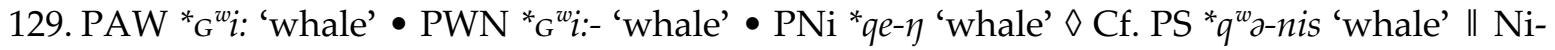
kolaev 2015: 53.

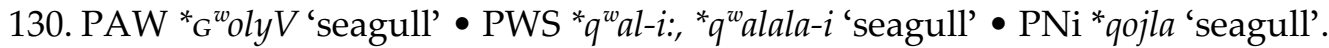

131. PAW ${ }^{*}{ }^{w} i: X q^{w} V\left(\sim r q^{{ }^{w}}\right)$ 'to pull' $-\mathrm{PWN}{ }^{*} G\left({ }^{w}\right) u: q^{w_{-}},{ }^{*} q^{{ }^{w}} u: q^{w}-$ 'to pull, tug, hoist sth. up' • PA *wi:hkw- 'to pull' [WOj. wi:kk-up-in-a:t 'he pulls him in', Ab. o-wíhkw-en-em-én 'to pull in', etc.] $\diamond$ Cf. PS ${ }^{*} x^{w} u k^{w},{ }^{*} x^{w} u k^{w}$ 'pull (out)'.

132. PAW ${ }^{*} B^{w} 0: l V(\sim i:)$ 'fat (n.)' $\bullet \mathrm{PWN}{ }^{*} \mathrm{G}^{w} u: t$ - 'animal fat, tallow, marrow' $\bullet$ PAlg ${ }^{*} w e l-,{ }^{*} w-e \gamma-$ el- 'fat (n.)' [Wi. -wìl-ákh ${ }^{w}-i 2 l-i w$ ' (animal's) fat', Yu. wel 'fat', PA *wi:l-enw-i 'fat'] || Nikolaev 2015: 38, 53.

133. PNA *haGA ( $\ddot{a}, q$ ') 'headdress, cap' • PNi *haq 'headdress, cap' • PAlg *?ek- 'hat' [Wi. $k$ ihy 'basketry cap', Yu. 2ek-ah, Zek-ahp- 'hat, cap'].

134. PAW *har ${ }^{w}(\sim \ddot{a})$ 'to yawn, open the mouth wide' - PW *hox- 'to yawn, open the mouth wide, open sth. jawlike' $-\mathrm{PNi}$ *hava- 'to open the mouth wide' $\diamond \mathrm{Cf}$. PS *haw 'to yawn'.

135. PNA *hapV ( ä) 'lungs' • PNi *hav-[h]af 'lungs' • PA -hp-an- 'lung(s)' [Cree -hp-an, Men. -hp-a:n, Ab. o-hp-án 'lung', etc.].

136. PAW *hazV 'to sneeze' $\bullet \mathrm{PWN}$ *has-, *2as- 'to sneeze' [also PW *haric(x)] $\bullet \mathrm{PNi}$ *hac-hac- 'to sneeze' • PAlg *2a:č- $(\sim 0, c, c h h, c h)>Y u$. 2oc- 'to sneeze'.

137. PAW *hAqAgV ( k') 'k. of berries' • PWN *qak- 'bunchberries (Cornus canadensis)' • PNi *haqaq 'red bilberry' || Nikolaev 2015: 51.

139. PAW *ha: ( a:) 'to go' • PWN *ha:- 'to go, move' • PAlg *ha:- 'to go' [Wi. kitka wi-l-á-th-um 'I'm going with her', l-a-g(i) 'to go'; Yu ho: 'to go, travel', PA *-a:- 'to go', etc.] II Nikolaev 2015: 44.

140. PAW ${ }^{*} h A: l_{G} V$ 'crotch, armpit' $P W N{ }^{*}-h a: q-(i:),-h a: G-i:$ (suff.) 'crotch' $P$ PAlg *-irk-a:w$(\sim k h)>$ Yu. -ark-ow 'armpit' $\diamond \mathrm{Cf}$. PS *-aq, *-aq' (suff.) 'crotch, sexual organs'.

141. PAW *hA:sV 'to breathe' $-\mathrm{PW}$ *ha:s- 'to breathe' • PAlg *has-, *hes- ( 2-) 'to breathe' [PA *-at-amw- 'breath', Yu. s-ew 'to breathe, sigh'].

142. PAW *hA:tV ( t') 'ear' $-\mathrm{PWN}{ }^{*}-h a: t-u$ : (suff.) 'ear' $\bullet$ PAlg *-ht-2l-, *-hč-2r- 'ear; to listen' [PA *-ht-aw-ak- 'ear', suff. *-ht-, *-hš- 'ear; to listen'; Wi. -atb-al-úk 'ear', šáp-ər-uk- 'to listen'; Yu. $c p$-ej-a?r 'ear', cp-e?r-oy- 'to listen', r-e2r-oy- 'to hear sth. as news', cp-ey-u2r 'to tell a story'] || Nikolaev 2015: 38.

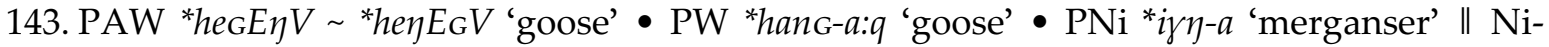
kolaev 2015: 53.

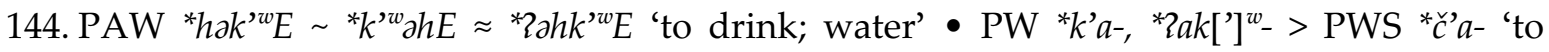
drink'; PWS *č' $a-2 a k^{w}$ 'water' [this PWS compound seems to have meant 'drinking water'] - PChi * ${ }^{\prime}{ }^{w} a: y$-, ${ }^{*} k$ 'a:w- > Quil k'wá:ya, Chem. c'ó:wa, -c'o: 'water' - PNi *oy- 'give to drink, irrigate, pour on', 'ij-r 'creek' • PAlg *-a:hkw-, -ehkw- ( kh) 'to drink' [PA *men-ehkw-, Yu $r-e k^{w}$-ohp- 'to drink']; ${ }^{*}-a: k-a w y-,{ }^{*}-e k$-awy- 'to flow'; PA *akw- (adverbial stem) 'out of/in the water'; *a:k-amy-, *-e:k-amy- (suff.) 'natural body of water', “kwa:-p- 'out of the water' $\diamond \mathrm{Cf}$. PS * $q u q^{w}$ 'to drink; water'; * $q^{w} u$, , $q u-l,{ }^{*} q a-l$ 'water; to drink'; suff. ${ }^{*} q^{w} a,{ }^{*}-k^{w} a$ 'water' II Nikolaev 2015: 44, 51.

145. PAW *hapV(lV) 'hair (body, facial)' - PW *hap- 'hair (body, facial)' - PNi *af 'moustache, beard, tentacles'; ' $\eta-\partial v-r-k-i$ 'body hair' $\bullet$ PAlg *-ep-l, *-ep-r (facial, head) [Wi. - $a p-t-$ 'hair- 
like object', Yu. 2lep 'hair', PA *-i:t-e2-t- 'head hair' ("head+hair”)] $\diamond$ Cf. PSI *wap 'hair, fur, cover of grass, weed' II Nikolaev 2015: 39.

146. PAW *ho:?V *2a:hV 'yes' • PW *ha:(2a) ‘yes' • PNi *hi ( a) 'yes' • PA *e:he ‘yes', Yu. ?ey, 2e:, ใe:y; \{i:; \{i:y 'yes'.

147. PAW *ha:ym'V 'old' • PWN *ha:m'-a: (suff.) 'old, worn-out, useless' • PNi *hajm- $y$ - 'old'.

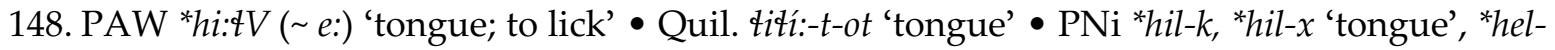
[h]el- 'lick' • PA *-e:t-any- 'tongue' [Cree -e:y-an-iy, WOj. -e:n-en-iw, etc.] $\diamond$ Cf. PSI *t-at-a? 'tongue' I| Nikolaev 2015: 44, 48.

149. PAW *hi:rxk'E 'louse (head)' • $\mathrm{PW}{ }^{*} \mathrm{G}-i: x k$ - 'louse' [with prefix of inalienable possession] • Quil. wí:k'-is 'louse' - PNi *hiřk-r 'nit, body louse' - PAlg *hihk-w- 'louse' [Wi. $k^{w}$ 'louse', Yu. $m$-ohk-oh 'head louse', PA *ehkw- 'louse'] $\diamond$ Cf. PS * $m$ - $x x k-n \sim{ }^{*} m$ - $-x k$ ' $n$ 'head louse' \| Nikolaev 2015: 41.

150. PAW *hinV $(\sim e)$ 'to carry' - PWN *han-q-, *han- $k^{w_{-}}$'to carry in one's apron or blanket' • $\mathrm{PNi}$ *hin- 'to carry on back'.

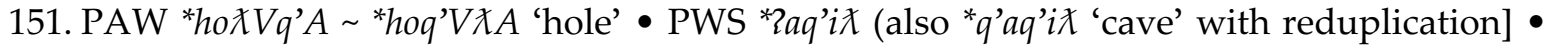
PNi *holq-e- 'deepening, hole' • PA *a:tak- (suff.) 'hole' [Fox mak-a:nak-et-on-wa, Oj. manka:nak-it-on 'he has a large mouth', etc.].

152. PAW *homV 'to carry on back' • PW *ham-, *2am- 'carry on one's back, shoulders' • PAlg *-o:m- 'carry on one's back' [Yu. n-a:m-ew 'grab in one's mouth', n-o:?m 'carry (a load)', PA *o:m- 'carry on back', etc.] II Nikolaev 2015: 55.

153. PAW *hObV $(\sim p$ ') 'to dip' - PWN *hap- 'to dip, immerse, dye' • PNi *hup-u- 'to dip'.

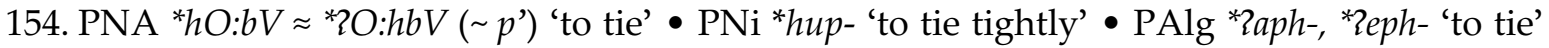
[Wi Zaph- 'to tie', Yu. -(i)p-et- 'bundle; to tie', PA *ahp-it, -it 'to be tied', etc.], PA *a:p- 'cord' [Cree $a h c$ - $a: p$-iy 'bow', Men. kenu-ap-i:k-at 'it's a long string', Mic. $a b-i$ 'cord', etc.].

154a. PNA *hü:mV ( m') 'to hurry' • PNi *mom-jo- 'to hurry' [reduplication] • PAlg *him- 'hurriedly' [Wi. im-aratw- 'hurriedly'; Yu. him-ec-ok' 'I hurry', him-en 'quickly', etc.].

155. PAW *hü:xE 'head, nape' • PWN *hi:x- 'head' • PNi *of-r-i 'nape (of the neck)' I| Nikolaev 2015: 39.

156. PAW * $h V$ 'demonstrative stem' • PW *hi:- 'that (“empty root”)' PNi * $h u-\eta$ - 'this (“a little farther")'; *ho- 'this (remote)' II Nikolaev 2015: 44.

157. PAW ${ }^{*} k A: m V$ 'chief' - PWS *̌a:m-at'a 'chief' [ ${ }^{*} c ̌-<P W{ }^{*} k$-] $\bullet$ PA ${ }^{*}-k e m-a:-~ ' c h i e f$ ' [Cree $u$ kim-a:w 'chief', Fox $\vartheta a$ :-kim-a:hkw-e:w-a 'chieftain-woman', WOj. sa:-kim-a: 'an Indian not belonging to the Grand Medicine, yet knowing medicine well', etc.].

158. PNA *kerčk'w $A\left(\sim q^{\text {ww }}\right)$ 'to fish with line and hook' - PNi *kherqo- 'to fish with line and hook' • PAlg *kačkw-, *kečkw-, *ketkw- ( kh, th, čh) 'to fish with hook' [Yu. kat 'trout fishing pole', katk-ek' 'I go trout fishing', PA *kwetkw- 'to fish with a hook', *me-kesk-an- 'fish hook', etc.].

159. PAW *kE( g) 'along with' • PW *ki $\sim g)>$ PWS *-č $i$ (suff.) 'along with' • PA *kek- 'along, with' [Cree, WOj. kik-i 'having such and such a thing', Fox kek-ap-iw-a 'he sits having sth.', etc.].

160. PAW *kElV 'to fear' - PWN *kat- 'to be amazed, afraid' - PNi *khl-u- 'to fear' $P$ PA *kwa:l-,

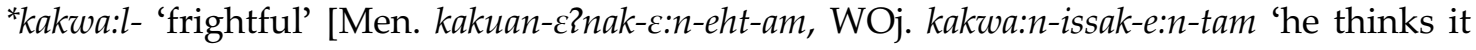
terrible', Ab. gwáhl-ial-ew-á 'he startles someone', etc.].

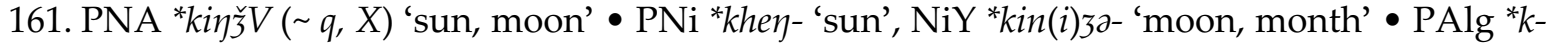
ef-ečh- 'sun, moon', *kečh- 'sunshine, daylight' [Wi. kačh-ály 'day', Yu. kec-i? 'it is daylight', PA *ki:š-e?twa 'sun/ moon/ month', etc.] $\diamond$ Cf. PS * $k^{w} u s a n$ 'star' \| Nikolaev 2015: 43.

162. PAW ${ }^{*} k O l x V \sim{ }^{*} k^{\prime} O l k ' V \sim{ }^{*} k^{\prime}{ }^{w} i: l k$ ' $V$ 'round' $-\mathrm{PWN}{ }^{*} k a l x$ - 'round, round thing, to turn (wheel), to make sth. round' $-\mathrm{PNi}{ }^{*} k u l k u-\check{r}$ 'wheel' $\bullet \mathrm{PA}{ }^{*} k w e: t k$ - 'to turn, return' [Cree 
kwe:sk-in-am 'he turns it about', Men. ko:hk-aw-ew 'to tip over, upset', Penobscot kósk-sw-e 'to tip over, upset' etc.] II Nikolaev 2015: 42.

164. PAW *kV 'you (sg.), thou' • PChi *ki-> Quil. či, Chem. ce:ya 'thou' • PNi *chi 'thou' • PAlg *ke?- (prefix) 'thou, thee, thy', "kerila 'thou' $\diamond$ Cf. PS ${ }^{*} n-k^{w}$ a, ${ }^{*} n-\gamma^{w}$ a 'thou (independent pronoun)', '2an $\left[\gamma^{w}\right]-$ '2nd singular possessive prefix' * $-a x^{w}$ '2nd singular transitive subject suffix', * $k-\partial x^{w}$ '2nd singular intransitive subject affix', etc \|| Nikolaev 2015: 44.

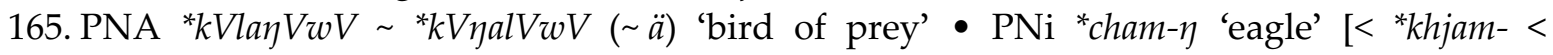
*khlayw-], NiY *como- ( ) 'raven' • PAlg *ken-ej-lew- $(\sim k h)$ 'a sp. of brownish hawk' [Yu. knu:-u 'hawk', PA *kenliw-a 'eagle'] II Nikolaev 2015: 54.

166. PNA *KičV $(-K E)(\sim Q, X)$ 'wild cat' • PNi *khis-k 'cat' • PAlg *ka: ̌c-, *ket- ( kh, th, čh) 'wild cat' [Yu. k-ej-et 'puma', PA *kaš-ak-e:ns- 'cat'].

167. PNA ${ }^{*} K V d i b V\left(\sim t\right.$ ', $p$ ') 'thick (cloth), tight (fabric)' $\bullet \mathrm{PNi}{ }^{*} t i p-i\left(\sim{ }^{*} c^{-}\right)$'tight (fabric)' $\bullet \mathrm{PA}$ ${ }^{*} k e t p-,{ }^{*} k e c ̌ p-$ 'thick (e.g., cloth)' [Yu. ketp-e?n 'it is thick (cloth, etc.)', PA *ketp- 'thick'].

168. PAW *k'ä: 'negative stem' • PWN *k'i:-, * ${ }^{\prime}$ ' $\partial$ - 'negative stem', PWN *-k(a:) (suff.) 'un-` • $\mathrm{PNi}{ }^{*} q h a-u$ - 'no, there isn't' $\bullet$ PAlg ${ }^{*} k a$ - 'negative stem' [Wi. ko- (pref.) 'negative', Yu. k-en$i m-i$ 'emphatic negative'; $k$-im- $i$ 'negative with reference to time'; PA * $k a$ - 'negative stem'] II Nikolaev 2015: 42.

169. PAW *k'e:ma:kw $\left.A{ }^{*} g e: m a: k^{\prime}{ }^{{ }^{w}}\right) A$ 'ring' • PWS *k'a:ma:kw 'ring' • PNi *kemqa 'iron ring on the rim of shaman's tambourine'.

170. PAW *k'E:šV 'loose' • PWN *k'as- 'loose, to loosen' • PA *ke:hš-aw- 'loose' [Men. ke:hs-awe:hn-en, WOj. ke:šš-aw-iss-in 'to be loose on the handle', etc.].

171. PAW * $k^{\prime}$ : $\approx$ *2a: $k^{\prime} E$ 'to reach' $\bullet$ PWN *-ka: (suff.) 'to reach, manage to do, get to or exceed limit' $\bullet \mathrm{PNi}$ * $a k$ - 'to reach'.

172. PAW ${ }^{*} k^{\prime} i n x^{w} V \sim{ }^{*} g i n x^{w} V(\sim e)$ 'curly' $-\mathrm{PWN}{ }^{*} k$ ' $\partial n x^{w}$ - 'to be curly (hair), to be curled up (in chair)' $\bullet \mathrm{PNi}{ }^{*} k e v-k e v-$ 'curly'.

173. PAW * $k$ ' $i: \approx * 2 i: k$ ' $V \bullet \mathrm{PW} * 2 i: k$ '- 'above' $\bullet \mathrm{PNi}{ }^{*} k h i-$ 'above'.

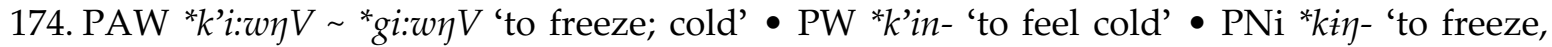
cool down' • PA *ko:n- 'snow' [Cree ko:n-a, Men. ko:n, etc.] $\diamond$ Cf. PS *k'im 'cold, to freeze' \| Nikolaev 2015: 37, 54.

175. PAW ${ }^{*} k^{w} a: r k A$ 'dry' $-\mathrm{PW}{ }^{*} k^{w} a: k-\left(\sim g^{w}\right)>$ PWS (suff.) $-k^{w} a: k-t,-k^{w} a: s^{2}-t$ 'dried' • Quil. q'i:x'dry' - PNi *qharxa-harsa- 'hard, dry' - PA *ka:hk- 'dry' [Cree ka:hk-e:w-ak 'dried meat', Men. ka:hk-ek-Es-ow 'to dry', WOj. ka:sk-iw-ak 'dried meat', etc.] ॥ Nikolaev 2015: 37, 50 (compared with PWN * $q$ ' $a k$ - 'to dry and pound salmon eggs').

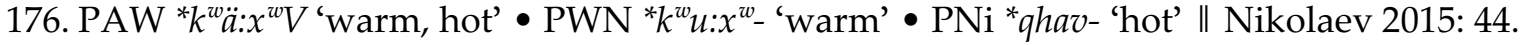

177. PAW * $k^{w} e: m V$ 'to know, understand' - PW * $k^{w} a m-\left(\sim g^{w}\right)>$ PWS *kam-at 'known' • PNi ${ }^{*} h i m-,{ }^{*} k h i m$ - 'to know, understand, realize' • PAlg. ${ }^{*} k(w) a: m-(\sim k h, o:)>$ Yu. kom- 'to understand, feel' || Nikolaev 2015: 40 (PW * $x a m$ - > PWS * $\chi a m$ - 'to know, know how, recognize' and Quil. $\chi a b$ - 'to know how' are compared instead of PWS *kam-at 'known').

178. PAW ${ }^{*} k^{w} \partial 2 V \approx{ }^{*} 2 a k^{w} V$ 'to jump' $\bullet$ PWS *kar-axkat- 'jump'; PWN *2ak- 'to jump on the surface of the water (said of whales, dolphins, fish)' $\bullet \mathrm{PNi}{ }^{*} k h i-(\sim \partial)$ 'to jump, jump on the surface of the water' - PA *kwa:š-kwa:š- 'to jump' [Cree kwa:s-kwa:s-kwanip-i:hk-e:w 'the big vein from the heart, “jumper”', Oj. kwa:k-kwa:š-konip-i:kk-a:n? 'kangaroo, grasshopper', etc.].

179. PAW * $k^{w} o m V$ 'to stoop' $\bullet \mathrm{PWN}{ }^{*} k^{w} a m$ - 'to stoop, to bend the body down' $\bullet \mathrm{PNi}{ }^{*} k h u n-t k u-$ 'round-shouldered'.

180. PNA * $k^{w}$ onV $\left(\sim q^{w}, n^{\prime}\right)$ 'light; day' • PNi *khun-u 'dawn'; *khun-u- 'light, transparent' • PA *-wi-kwen- 'day' ["net-wi-kwen-ak-es-iw-a 'he is three days old'; *nye:w-wi-kwen-i 'four days'; *meta:ht-wi-kwen-i 'ten days', *-taht-wi-kwen-ak-atw-i 'it is so many days old', etc.]. 


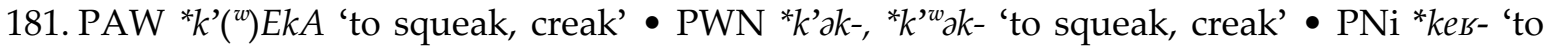
squeal'.

182. PNA ${ }^{*} k^{\prime w} E y V\left(\sim q^{w}, g^{w}\right)$ 'owl' $-\mathrm{PNi}{ }^{*} k i k u$ 'owl' $\bullet \mathrm{PAlg}{ }^{*} k w a y-(\sim k h)>Y u . k^{w} \partial y k^{w} \partial y-\partial c$ 'screech owl'.

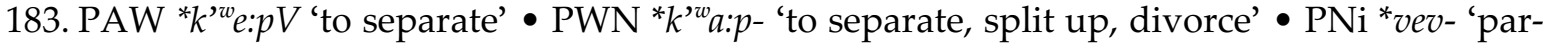
ticular', *vev-u- 'to separate'.

184. PAW ${ }^{*} k^{\prime w} e: T q^{w} V\left(\sim q^{\prime w}\right)$ 'lichen' $\bullet$ PWN ${ }^{*} k^{\prime w} a: 2 q^{w}$ - 'lichen' $\bullet$ PAlg ${ }^{*} k i: k w-t-(\sim k h)>Y u . k i k^{w} t-$ en- 'moss; rotten wood' II Nikolaev 2015: 47, 55.

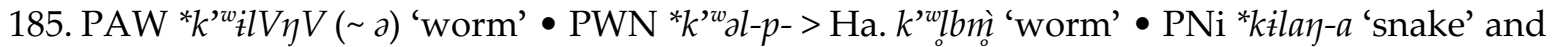

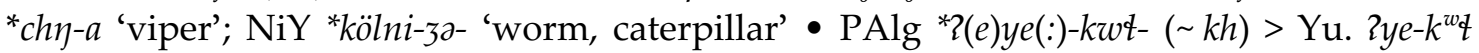
'maggot, worm' $\diamond$ Cf. PS *q'ya ‘'an 'snail, slug' II Nikolaev 2015: 46.

186. PAW ${ }^{*} k^{3 w} i: 3 V$ 'to bend, fold' $-\mathrm{PW}{ }^{*} k^{\prime w} u$ :s- 'fold, bend' $\bullet \mathrm{PNi}{ }^{*} k h i c-(\sim t)$ 'bend, bow' $\diamond \mathrm{Cf}$. PS * $k^{\prime w} a c$ ' 'to bend, twist'.

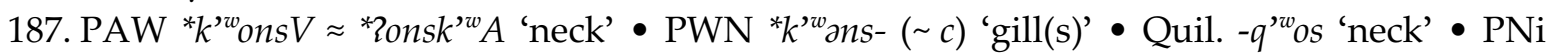
*qhos- $\eta$ 'neck, Adam's apple' • PAlg *-sk-w- 'neck' [PA *-tkw-e:-k-an-, suff. *-Vtkw-/*-Vkw'neck'; Wi. -asw- 'neck' in hi-ták ${ }^{w}$-asw-al-it 'she fell and broke her neck', (hu)w-ásw-itk-ad-all 'her neck'] $\diamond$ Cf. PS *k’as-pan 'neck' \|| Nikolaev 2015: 41.

188. PAW ${ }^{*} k^{\text {wo }} 0 t V \approx{ }^{*}\left\{0 t k^{\prime w} A\right.$ 'to sleep' - $\mathrm{PW}{ }^{*} k$ 'at- 'to sleep, to dream' - PNi *qho- 'to sleep' • PAlg *-i:tkw-, *-etkw- ( kh) 'to sleep, dream' [Yu. ka:m-itkw-ok' 'I dream a bad dream about sth.', etc., PA *-enkw 'sleep' < *en-etkw-] II Nikolaev 2015: 43.

189. $\mathrm{PAW}{ }^{*} k^{\prime w} \mathrm{OcV}(\sim s, \breve{s})$ 'wolf, wolverine' $\bullet \mathrm{PWN}{ }^{*} k^{\text {ww }}$ as- 'wolf' $\bullet \mathrm{PNi}{ }^{*} k h u z-r$ 'wolverine', NiY *khöře( $\gamma) e l$ 'wolf'.

190. PAW *la 'to be in a position, be such as' $\bullet \mathrm{PW}{ }^{*}$ la- 'to be in a position' $\bullet \mathrm{PNi}$ *-la (suff.) 'to be such as'.

191. PNA *la:gA $\approx{ }^{*} 2 a: \lg A(\sim l$ ', k', G, q') 'snowshoe, ski' • PNi *laq 'ski' • PA *a:k-em- 'snowshoe' [Cree -a:k-im, Men. a:k-em, WOj. a:k-im, etc.]

192. PAW *la:yVwV 'wind; to blow (wind)' $\bullet \mathrm{PW}{ }^{*} y u$ :- 'wind; to blow (wind)' [<*l(V)yew-] $\bullet$ $\mathrm{PNi} * l a$ 'wind'; NiY *ilija- 'wind' • PAlg *lo:yew- 'wind, to blow' [Yu. ro:- $k^{w}$ s 'wind', PA *lo:w-< *lo:yew- 'wind, to blow'] $\diamond$ Cf. PS *al-aq (suff.) 'wind, weather' II Nikolaev 2015: 45, 54.

193. PNA *link'E ( l', a, q') 'to shake' - PNi *lik-lik- ( a) 'to shake, tremble' • PA *nenenk- 'to shake' [Fox nenenk-ešk-a:w-i 'it moves up and down', Oj. ninink-ač-i 'shiver, tremble with cold', etc.] $\diamond$ Cf. PS *lax $x^{w},{ }^{*} x^{w} a l$ 'to shake, hurry'.

194. PNA *lOńmV ( l', n', m') 'salmon, trout' • PNi *lojm(-r) 'trout' • PA *nam-e:- 'trout, stur-

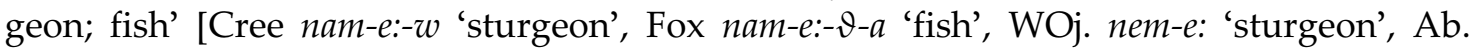
nam-á-(o)kw 'trout', etc.].

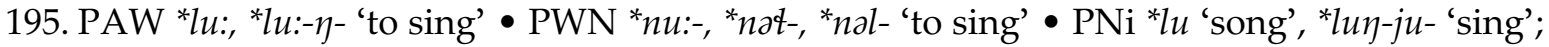
$\mathrm{NiY}{ }^{*} l o \eta-d \partial^{-},{ }^{*} l o j u-d \partial-$ 'to dance' $\diamond \mathrm{Cf}$. PS *lul 'to sing'.

195a. PAW *lVxE 'to slip, slide' $\bullet \mathrm{PWN}{ }^{*}{ }^{*} a x$ - 'to slip, slide' [probably from PW ${ }^{*} t-l V x$-] $\bullet \mathrm{PNi}$

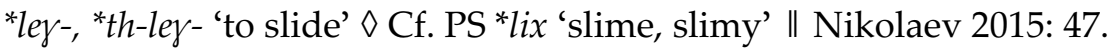

196. PAW *l'E $\chi^{w} A \approx{ }^{*} 2 E \chi^{w} l$ ' $A$ 'to cough' $\bullet \mathrm{PWN}{ }^{*} l ' a \chi^{w}$ - 'to cough' $\bullet \mathrm{PNi}{ }^{*} q h j-e v$ - 'to cough' $\nabla \mathrm{Cf}$. PS *2a $\chi^{w} u 2$ 'to cough'.

197. PAW *l'u:y'3V 'moon' • PWN *n'u:?s-i: ‘moon, month' • PNi *lon- ‘moon', NiY *jä-lon:za 'sun' II Nikolaev 2015: 41.

198. $\mathrm{PAW}{ }^{*} \lambda a$ 'near' $\bullet \mathrm{PW}{ }^{*} \lambda a$ - 'near' $\bullet \mathrm{PNi}{ }^{*} l a-{ }^{-}$- 'near', -le- (postpos.) 'near' \|| Nikolaev 2015: 45.

199. PAW * $\lambda a$ : 'to stand' $\bullet \mathrm{PW}{ }^{*} \lambda a$ :- 'to stand' $\bullet \mathrm{PNi}{ }^{*} l a-r$ - 'to get up on the back paws' $\bullet \mathrm{PA}$ *ta-m-at- 'to stand up, erase' [ ${ }^{*} w e-t a m-a c ̌-i-~ ' h e ~ s t a n d s ~ e r e c t ', ~ * n e-t a m-a t-e n-e: n-i$ 'I erect it, erase it', etc.] I| Nikolaev 2015: 43. 
200. PAW ${ }^{*} \lambda a: \eta g^{w} V$ 'to borrow' $P W N{ }^{*} \lambda a: k^{w}-\left(/ \lambda i: k^{w}-\right)$ 'to borrow' $\bullet \mathrm{PNi}{ }^{*} l a \eta-r-$ 'to borrow'.

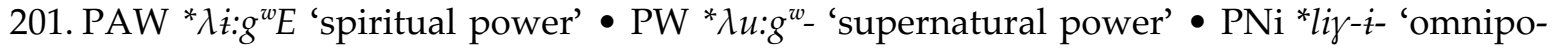
tent (shaman)'.

202. PAW ${ }^{*} \lambda o 2 V$ 'together' $\bullet \mathrm{PW}{ }^{*} \lambda a \imath u(:)$ '(with) another' $\bullet \mathrm{PNi}{ }^{*}$ rolo 'mutually, together' [reduplication?].

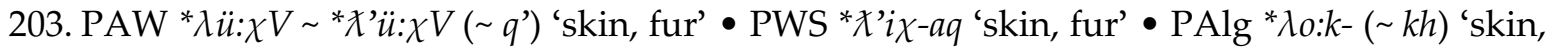
feather' [Yu. $r$-e -o? 'feather', PA *-to:k- 'hide, skin'] II Nikolaev 2015: 43.

204. PAW * ${ }^{*}: x E \approx{ }^{*} 2 e: \rtimes x E$ 'to look for, watch' $P W N{ }^{*} \rtimes a: x$ - 'to look for lice' $P$ PNi *khi- 'to wait' - PAlg *2ekt-, *2etk- 'to watch' [Wi. kt- 'to watch', Yu. $4 k-y$ - 'to look at, watch', PA *atk- 'to wait, lie in ambush'] II Nikolaev 2015: 47.

206. PAW *オik'E $(\sim \partial, g)$ 'to notch' $\bullet \mathrm{PWN}{ }^{*}$ オak- 'to notch' $\bullet \mathrm{PNi}{ }^{*}$ tək- 'to notch' [cf. borrowed PIt *lọk'-al 'notch, mark'].

207. PAW *X'imqA $(\sim e, \mathrm{G})$ 'to hop on one foot' $\bullet \mathrm{PWN}{ }^{*}$ 'amq- 'to hop on one foot' $\bullet \mathrm{PNi}^{*}$ tes$(\sim c)$ 'hop on one foot'.

208. PAW ${ }^{*} \chi ' i: r q E$ 'cold, to freeze' $-\mathrm{PWN}{ }^{*} \chi^{\prime} u: \chi^{w}$ - 'ice; to ice up, to freeze, to congeal' $\bullet \mathrm{PNi}$ *lakri- 'to chill'; NiY *lerko- ( j-) 'to shiver with cold' $-\mathrm{PA}{ }^{*}$ tahk- 'cool, cold' [Cree tahk-a:k 'when it is cool', Fox tahky-a:w-i 'cold', Men. tahk-i:k 'when it is cool', etc.] $\diamond$ Cf. PS * ${ }^{*} x^{w}$ 'cold (object)' I| Nikolaev 2015: 37.

209. PAW ${ }^{*}{ }^{\prime} \circ g^{w} E$ 'to kneel' $-\mathrm{PW}{ }^{*} \chi^{\prime} a k^{w}$ - 'to kneel, to lean in the elbow, to push with the knee or elbow' $\bullet \mathrm{PNi}$ *luk- 'to kneel, bow'.

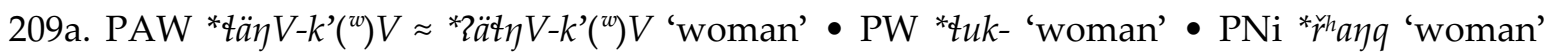

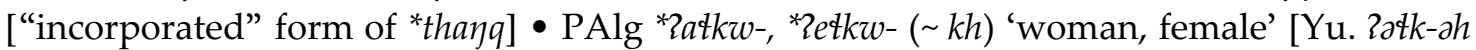
'bitch', PA *etkw-e:w- 'woman'] $\diamond$ Cf. PS *tan-ay' 'woman' II Nikolaev 2015: 45. PAW *tä $V$ $k^{\prime}\left({ }^{w}\right) V$ contains the same diminutive (?) suffix as \#\#19, 21, 19, 300.

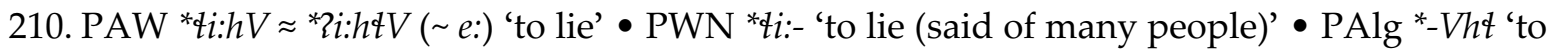
lie, fall' [Wi. -t-, PA *-ht- 'to fall, lie'] II Nikolaev 2015: 40.

211. PAW *ti:yV 'thunder' $\bullet P W S * t u:-t-$ 'thunder' $\bullet P N i * l i j$ 'thunder'.

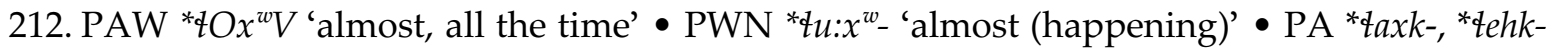
'all the time, long time' [Cree tahk-i 'all the time', Fox nehk-i 'so long a time as', etc.].

213. PAW ${ }^{*} q V q^{\prime}\left({ }^{w}\right) E \approx{ }^{*} ? V q q^{\prime}\left({ }^{w}\right) E$ 'bone' $-\mathrm{PWN}{ }^{*} z \partial q^{w_{-},}{ }^{*}{ }^{*}{ }^{\prime} \partial q^{w_{-}-}$'pit (in fruit); inside of sea eggs (urchins); brain' • PNi * $\eta$ - $z k$ 'gristle' $\bullet$ PAlg *-Vtk- 'bone' [Wi. w-atk-ad-át, Yu. 2w-atk-a2, PA *w-etk-an-, *-k-an-] II Nikolaev 2015: 36, 48.

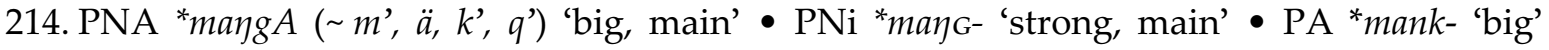
[Cree mama:hk- 'big', WOj. menkw-akk-em-ik-ess-in 'it has mounds', mema:nk-e- 'big', etc.] II Nikolaev 2015: 47.

215. PAW *ma: 'near' • PWN *ma:- $k$ - 'near, next to, close' • PNi *ma- 'near, close'; NiY *mi(ä)-ka 'near' • PA *ma:-t- 'side by side, in a row' II Nikolaev 2015: 45.

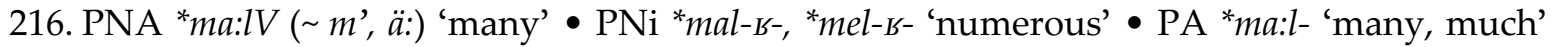

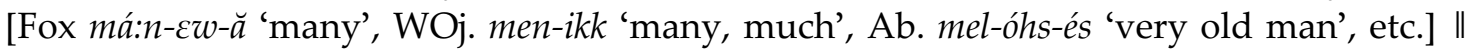
Nikolaev 2015: 47.

217. PAW *ma:lV ( ä:) 'berry, fruit' • PWN *ma:t- 'fruit', *mal-k- 'berry' • PAlg *mal-o:-, *mel-o:'k. of berry; wild rice (Zizania sp.)' [Yu. men-o-men 'Juneberry', Fox man-o:-min-i 'rice', Men. man-o:-men-an 'wild rice; oats', Ab. mal-o-mõn 'wheat', etc.] II Nikolaev 2015: 51.

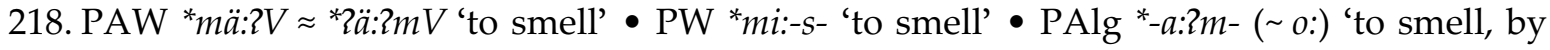
smell' > Yu. -orm- 'to smell'; PAlg *mey-a-> PA *mya:- 'to smell' [Men. wi:ki-mya:kwat 'it smells good'; Cree wi:hki-ma:me:w 'he likes the smell of him', etc.] $\diamond$ Cf. PS *hum' 'to smell, sniff'.

219. PAW *me: 'two' • PW *ma:2ta 'two', PWN *mo-t- 'twins' • PNi *mi-, *me- 'two'-, NiY *mä:l'two' || Nikolaev 2015: 44. 
220. PAW * $m E$ : 'to flame, fire' - PWN *mi:- 'to flame' - PAlg *me-hs- 'fire' [with diminutive suffix: Wi. bo-s, Yu. me-c, PA *me-ht-] II Nikolaev 2015: 39.

221. PAW *marV $\approx$ *2am?V 'to hear', *2amE-lV 'ear' - PWS *-2amit (suff.) 'ear' - PNi *m-la 'ear', * $m \dot{z}$ - 'hear, listen' $\bullet$ PAlg * Vim- 'by hearing (also 'by thought') in Yu. $k$-o(?)m- 'hear' (also 'understand, feel'), Wi. $k$-an-i?m-it 'hear', PA *pe:m-t-, *no:m-t- 'hear' (< *pe-em-, "no(:)-Vm-) II Nikolaev 2015: 40.

222. PAW *ma: $r V$ 'to swim' - PWN *ma:t- 'to swim' - PNi *mrz- 'to swim (human, animal), bathe'; NiY *mör(i)- 'to swim' • PAlg *-o:l- 'to swim' [Wi. -úl-, Yu. -ur-] || Nikolaev 2015: 43.

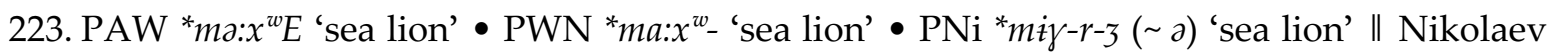
2015: 53.

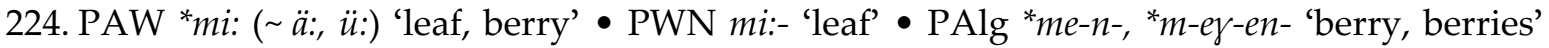
[Yu. men-o-men 'Juneberry', PA *mi:n-, -min- 'berry'].

225. PNA *mi: $\approx$ *2i:mV $\left(\sim m\right.$ ') 'to give' $\bullet \mathrm{PNi}{ }^{*} k h$-im-, *im- 'to give, hand over' $P$ PAlg *mi:-l- 'to give' [Wi. bi-l- 'to divide and distribute', PA *mi:-l- 'to give to sb.'] II Nikolaev 2015: 47.

226. PAW *mix $\approx \approx$ *im $\chi E$ 'hair, feather' $-P W N{ }^{*} m \partial \chi$ - 'long feather of eagle' $\bullet$ PNi * $\eta$-amx 'head hair; animal hair' $\bullet$ PAlg *mekw-, *m-ej-ekw- $(\sim k h, g)>$ PA *mi:k-w-an-, ${ }^{*}[m] i k-w$-an'feather' [WOj. mi:(n)kw-an, Ab. migw-én, etc.] II Nikolaev 2015: 39.

227. PNA *mo:ryV ( m') 'to die' • PNi *mu-, *muj-v- 'to die' • PAlg *ma:hy- 'to die', *meh[y]-t'to kill' [Yu. moy-k-ek' 'I die', PA *mer-t-ekw-a:py- 'bow, bowstring', *mi:-tkw-ahw-e:w-a 'he

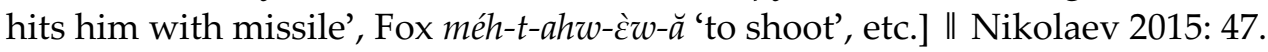

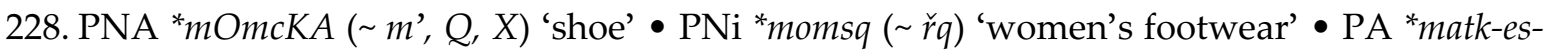
en- 'shoe' [Cree mask-is-in, WOj. mekk-is-in, Arapaho woz-óh 'moccasin, shoe', etc.] II Nikolaev 2015: 55.

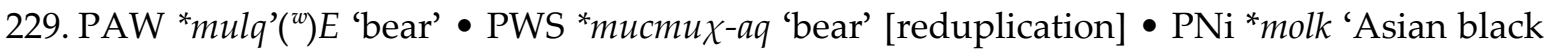
bear'3 • PA *matk-w- 'bear' [Cree maskwa, Fox máhkwă, Mic. -skw, etc.) $\diamond$ Cf. PS *mixat 'black bear'.

230. PAW *mu:wV ( o:) 'deer, elk' PWS *muw-ač 'deer’ $\left[-\check{c}<\mathrm{PW}{ }^{*}-k\right] \bullet$ PAlg *mo:w-, ${ }^{*} m e w-$ 'elk' [PA *mo:-sw- 'elk, moos', Yu mew-it 'elk'].

231. PAW *mü: 'dirt(y)' $-\mathrm{PWN}{ }^{*} m i:-q^{w}-$ 'dirty, muddy (said of water)' $\bullet \mathrm{PA}{ }^{*} m y-e: y-i$ 'piece of dung, dropping'; PA *mo:w- 'dirt, dung' [Fox mo:w-a:w-i 'soiled', WOj. -mo:w-an 'droppings', Shawnee mo: $w-i$ 'manure', etc.].

232. PNA * $m V N V C V(\sim m$ ', N') 'spiritual power' • NiY *mönca 'spiritual power' • PA *maneto:'spirit' [Cree manito:w, WOj. menito: 'manitou', Fox máneto:w-i- 'sacred', etc.] $\diamond$ PS *na?m 'shaman (power)'.

233. PAW * $m$ 'a 'to touch with the hands' - PW * $m$ 'a- 'to touch with the hands' - PNi * $m a$, *ma- $n$ - 'big span (distance between toe and little finger)'.

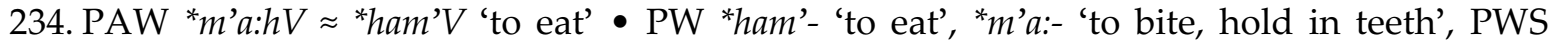
*m'a:- 'to bite'; *ma:-c-, ${ }^{*} m a(:)-s^{-}$'to eat as side dish' $-\mathrm{PNi}{ }^{*} a m$ - '(fish)bait'; *am-x, *am-k 'mouth' - PAlg *2am-w- 'to eat', *-Vm- (suff.) 'by mouth, eating, biting'; PA *mo:[h]w-, *mi:t- 'to eat' $\diamond$ Cf. PS *2um-, *2am-, * $m$ - 'to feed, food'; *ma-l '(fish)bait'; PSC *ma- $k^{w}$ 'to eat, put into mouth, chew' || Nikolaev 2015: 38.

235. PAW *(2V)m'A:nšV 'flower, berry' - PW *ma:s- > PWN *ma:s- 'blossom, flowers'; Noo. m'aš-, m'a:yi 'young green shoots of salmonberry bush' • PA *eminšy- 'fruit, berry, or nutbearing tree' [Fox -emiš-i, -(e)mišy-, Men. -emeh, -Emehsy-, etc.].

${ }^{3}$ Cf. such Manchu-Tungusic forms as Evenki mōdikā, Manchu možix́an, Negidal, Ulchi monoko(n) 'Asian black bear', which have no Altaic etymologies. 
236. PAW *m'A:w'V 'to load' • PW *m'aw'-u 'to load, transport, deliver' • PAlg *-[m]i:w-er, *-[m]i:w-ar (suff.) 'load, burden' [Wi. -ul-aw-, Yu. -u:l-, PA *-i:w-at-, *i:wet-].

237. PAW * $m$ 'äwg ${ }^{w} E$ 'blue' • PWS * $m$ 'uk ${ }^{w}-$ 'blue' • PNi * mawka- 'dark blue'.

238. PAW *m'e: $\approx$ *2e:m'V 'earth, land' • PWS *nis-m'a-k 'land, country', PWN *-G-m'a:- 'tribe' • PNi *mi-f 'land, place'; *mami 'clay', *or-mi 'clay' • PA *a:m-ehkw- 'earth, soil' [Fox -a:m$e h k(w)-$, Shawnee -a:m-e?k, etc.] $\diamond$ Cf. PS *-mi- $x^{w}$ 'earth, land, ground' \| Nikolaev 2015: 38.

239. PAW *m’i ( e) ‘we'•Quil. lo-bá:za, Chem. má:za-t' 'we' • PNi *me- 'we' $\diamond$ Cf. PS *n-Zim- 'we' $\|$ Nikolaev 2015: 45.

240. PAW * $m$ 'O: $2 V \approx{ }^{*} h O: 2 m$ ' $V$ 'below' $\bullet \mathrm{PWN}{ }^{*}-(a:) m^{\prime} u$ : 'underlying or implicated in' • PAlg *hirm-eli 'below' [Wi. irm-al-, Yu. him-ar].

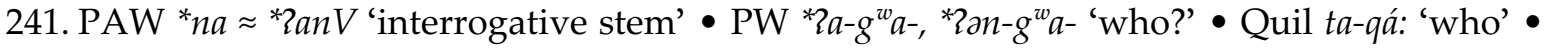
PNi *an-q 'who', *an- 'who; where', *na-r 'who' $\diamond$ Cf. PS *2in-wa-t, *2in-wa-n- 'to say what? (interrogative verb)'.

242. PNA *nabV ( n', ä, p') 'early' • PNi *nap- 'early' • PAlg *neP-t- > PA *nez-t-am- 'earliest, first in time' [Cree nis-t-am, WOj. net-t-am 'first', etc.].

243. PAW ${ }^{*} n i: K^{w} V ' k$. of fur game' $P \mathrm{PWN}^{*} n u: k^{w}-$ 'fur seal' $\bullet$ PAlg ${ }^{*} n i: k w-(\sim k h)>\mathrm{Yu} . n i k^{w}-e c$ 'grizzly bear'

244. PAW *no: 'to hear' - PW *na:- 'to hear' > PWN *na:- in Kw. nanaGiga 'to obey'; PWS *naza:'to hear; sense'; *nayi- 'echo' • Quil. \{ò:-lá:- $x$-at, suff. -la- $x$ 'ear' • PNi *no-s 'ear' • PAlg *no(:)-Vm-t- > PA *no:-nt- 'to hear' [Men. n-o:ht-am, WOj. n-o:nt-am, etc.] $\diamond$ Cf. PS *t-Zan-i?, *t-2an-a? 'ear', suff. *-an-iz, *-an-a? 'ear(side)'; ? * $q(-) a n$ 'to hear'.

245. PAW *nowgE ( $\left.k^{\prime}\right)$ 'to wait' $\bullet \mathrm{PW}{ }^{*}$ nawk- 'to be anxiously expecting sb. who is late, to be worried when sb. is late' $\bullet \mathrm{PNi}$ *nuk-nuk- 'wait for'.

246. PAW *nowV $\approx{ }^{*}$ *onwV 'to suck; breast' - PWS *2anma 'breast; to suckle' • PNi *mo-mo- 'to suck' [reduplication]; *mo-c- 'to suck, kiss', 'mo-c 'breast (female)' • PAlg *new- 'to suck' [Wi. du-n-ač- 'to suckle', Yu. new 'breast milk', PA *no:-n- 'to suck, suckle'] \|| Nikolaev 2015: 47. PNi *mo-<**nwo-.

247. PAW *n'i: ( n', e:) 'down' • PW *-n'i-(2)i:s, *-ni-c-'i(:)s (suff.) 'down to beach' [cf. PW *-hi:s 'on beach'] - PA *ni:-ht- 'down' [Cree ni:-ht-in-am 'to lower', WOj. ni:-ss-ey-ar-i: 'below the place', Ab. le-ss-ín 'he lies down', etc.].

248. PAW *n'i:n’V ( ń') 'k. of bird' • PWS *n'i:n'-i(:)̌c-, *n'ayn'-ays- 'small bird' • Quil. dí:d-o?os 'bird (generic)' - PA *nen-emeXk- 'small bird' [Fox nen-emehk-i:w-a 'thunderbird', WOj. $n e: n-o: k k-a: s s-i$ 'hummingbird', etc.] $\diamond$ Cf. PS *ninar 'great horned owl' \| Nikolaev 2015: 36.

249. PAW *n'o:lV 'to fly' $-\mathrm{PWN}{ }^{*} n$ 'al- 'to fly' > Kw. n'l-xiid, nl-xiid 'to fly' $-\mathrm{PNi}$ * $n u l-j o-$ 'to hurry' • PAlg -[n]a:l-, *[n]el- 'to fly' [Wi. -al-, Yu. -ol-, -el-; PA *-iz-l 'to fly' with incorporated PAlg *-ip- 'speed'] II Nikolaev 2015: 39.

250. PAW * $n^{\prime} O L K\left({ }^{w}\right) V\left(\sim n^{\prime}\right)$ 'hand, arm' • PW * $n^{\prime} u k^{w}$ (suff.) 'in hand' • PA *-netk- 'hand, arm'

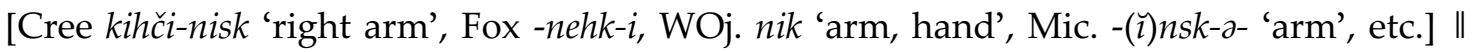
Nikolaev 2015: 39.

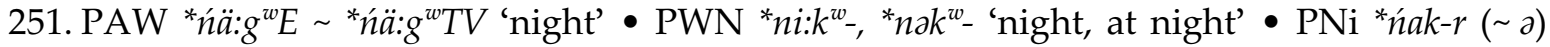
'night' • PAlg *neyt-, *neyč- 'last night' [Wi. dac-aw- 'night', Yu. nahsc- 'night, evening'] Cf. PS *nat 'night; 24 hour period' \|| Nikolaev 2015: 41, 48.

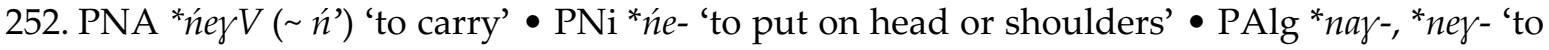
carry' [ ${ }^{*}$ naj-o:m- > Yu. na:-m- 'to carry'; nonow- 'to fetch, invite'; PA *nay-'to carry', "na:-t-, *nena:-t- 'to fetch', etc.].

253. PNA * ${ }^{\prime} i:(\sim$ '́) 'to eat' • PNi *ńi- 'to eat' • PAlg *no:-n-> Yu. nu-n- 'to feed, food' \| Nikolaev 2015: 47. 
254. PAW *ńV 'I' • PW *nu:- 'I; we' • Quil. lá:-b, Chem. lá:-2at • PNi *ńi 'I'; *ńi- $\eta$ 'we (excl.)' • PAlg *ne?- (pref.) 'I, me, my', *ner-il-a 'I (independent pronoun)' $\diamond \mathrm{Cf}$. PS ${ }^{*} n-c a,{ }^{*} c a-n a$ ? [with deictic particle * $c$ ] 'I (independent pronoun)'. II Nikolaev 2015: 40.

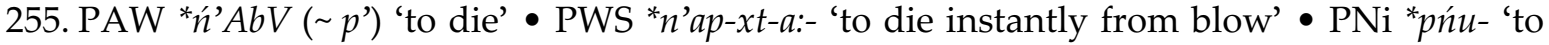
die (about twins)' [metathesis of “np-u-] • PA *nep- 'to die' [Cree nipiw, Men. nepuah, WOj. nempo, etc.] || Nikolaev 2015: 37.

256. PAW *n'e:(wV) 'to see, look' - PW *n'a:- in *n'a:-k- 'to look', PWS suff. *-in'aw- $\chi$ 'seeking', PWN *n'u:- 'to aim' - Quil. da-q'wó: 'eye' - PNi *nu- 'to look, watch', “n-ř́t- 'to see; find',

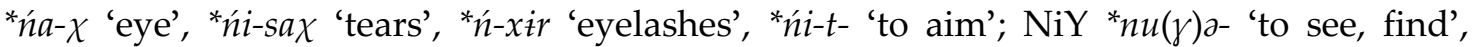
*nojdi- 'watch, guard' • PAlg *ne:-w-, *na-w- 'to see' [Yu. new, PA *ne:w-, "naw]; *nen?- 'to look for' [Yu. ni:2n]; "na-, "ne- 'by sight' [PA *-n- 'by sight', *na-t(a)w- 'seek, hunt'], etc. II Nikolaev 2015: 42.

257. PAW *ń’ 'one' - PW *n'a-m 'one' - PNi *nít, *ńz-ń 'one'; *nuyi 'first, fore' • PAlg *nekweht- *ne-kwehc- 'one' [compound “one+half”], PA *ne-hš-ihk-e:w- 'alone', *na-y- 'only; all in one place', " $n a-w$-at- 'first' $\diamond$ Cf. PS * $n a-k$ ', * $n-k$ ' $u$ 'one, another', *na-qas 'one' II Nikolaev 2015: 42.

258. PAW * $\eta A_{G} A(\sim q$ ') 'snow' • Quil. laq- 'to snow' • PNi * $y a q-r$ 'snow'.

259. PAW * $\eta a: h V$ 'beast of prey' $-\mathrm{PW}$ *na:n(a) 'grizzly bear' • PNi * $\eta a$ 'animal, beast' • PA *mah- 'wolf' [Cree mah-i:hk-an, Men. mah-w-e:w, etc.] $\diamond$ Cf. PS * $m \gamma$-aw 'large feline or canine (fox, coyote, lynx, cougar)' \|| Nikolaev 2015: 53.

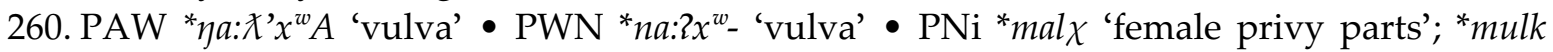
'privy parts of a girl' [PNi * $m$ - instead of ${ }^{*} y$ - perhaps due to "tabooistic" mutation of the original phonetics].

261. PNA * $\eta \ddot{a}: c V\left(\sim c^{\prime}\right)$ 'track, trail' • PNi * $\eta a z-i-f(\sim)$ 'track' • PA *ma:t- 'track, trail' [Cree ma:č$i: w$ 'he hunts', WOj. ma:t-e?-att-o:t 'he starts to follow its trail', etc.].

262. PAW * ya:?yV 'valley, shoal' • PWN *na:2-x- 'swampy, soggy underfoot, quicksand' $P \mathrm{PNi}$ * $\eta$ ij 'valley; shoal, sandbank'.

263. PAW * $\eta i: r g^{w} V$ 'k. of berries' $-\mathrm{PWN}{ }^{*} n \partial k^{w}$ - 'salal berry' • PAlg *mihkhw- 'salal berry' [Wi. bíkhw'-al, Yu. mahkew 'salal', mahk-ut 'salal berry'].

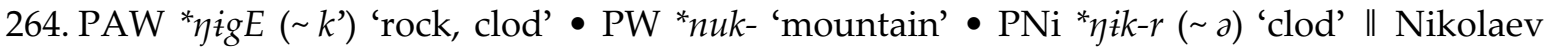
2015: 43, 54.

265. PNA * $\eta O k^{w} A\left(\sim \eta^{\prime}, q^{w}, X\right)$ 'fat, grease' • PNi * $\eta o \chi$ 'fat (n.)', * $\eta \dot{i} \gamma-l-$ 'fat (adj.)' • PA *makw'grease' in *makw-ehš-e:w-en-i 'feast, banquet' II Nikolaev 2015: 38.

266. PNA * $\eta \mathrm{Oly} V(\sim \eta$ ') 'path, road' • PNi * $\eta$ ol 'path' • PAlg *mey-e:- > PA *mye:- 'road, trail' [Cree me:-sk-an-a:w 'trail, road', WOj. mi:-kk-an 'road', etc.] II Nikolaev 2015: 47.

267. PAW * $\eta \ddot{u}: s ̌ V$ 'full' • PWS *nis- 'be full, satiated' • PA *mo:š-k- 'full, to fill' [Cree mo:s-k-i-, Fox mo:(h)š-k-i-, WOj. mo:š-k-i- 'to fill', mo:š-k-e?-an 'it is flooded', etc.] II Nikolaev 2015: 39.

268. PNA * $\eta V-\left(\sim \eta\right.$ ') 'prefix: inalienable possession' $\bullet \mathrm{PNi}{ }^{*} \eta(a)-/ \eta(a)$ - prefixal morph in many body part terms ${ }^{4} \bullet$ PAlg ${ }^{*} m(V)$ - 'indefinite possessor of inalienable nouns (body parts, tree, close relatives, louse and dog)' [Wi. $b$-, Yu. $m$-, PA * $m$-] $\diamond$ Cf. PS * $m(\partial)$ - 'prefixal morph in many body part terms and "inalienable" nouns' ("ma-qsn 'nose', 'm-axk'n 'louse', etc.).

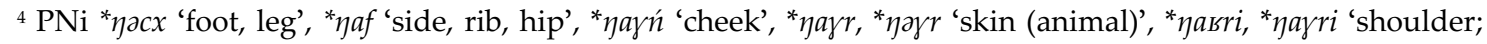

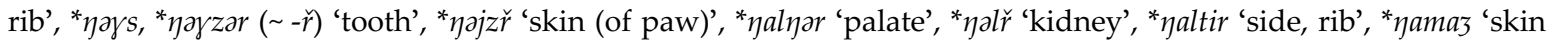

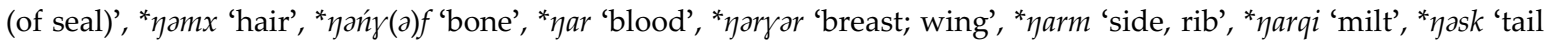

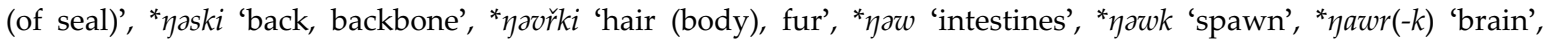

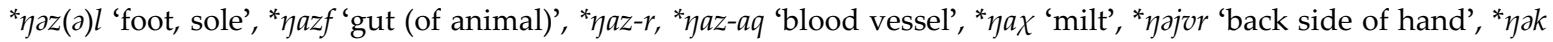
'gristle', *yam 'belly', *yańk 'face', * yazij 'hind paws (of seal)', * yif 'heart', etc. 
269. PAW * $\eta$ 'a: 'to go with, go and do' $\bullet \mathrm{PW}{ }^{*} n^{\prime} a$ :- 'go (with)' $\bullet \mathrm{PNi}{ }^{*} \eta a-$ 'go (for some purpose)' • PAlg *ma, *me 'to go and do' [Wi. $b$ - 'to go to do', Yu. me- 'went and did', PA *ma$w$ - 'to go and do sth.'].

270. PAW * $\eta^{\prime}$ a:gE ( k') 'tail' • PW *na:k- ( n') 'tail of fish or bird' • Quil. -doq ${ }^{w}$ 'fishtail' • PNi * $\eta$ əki 'tail'; NiY *laqi-l, *l- 'tail of animals' $\diamond$ Cf. PS *-anak (suff.) 'tail, anus, buttocks' II Nikolaev 2015: 43.

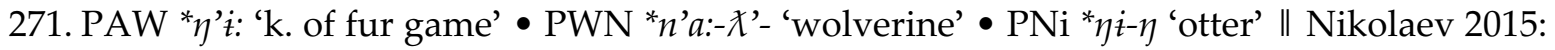
54.

272. PAW * $\eta$ 'i:m'V *m'i:y'V 'all' • PWS *n'u:m'(a)- 'all' • PNi *min- ( a) 'wholly' \| Nikolaev 2015: 35, 50.

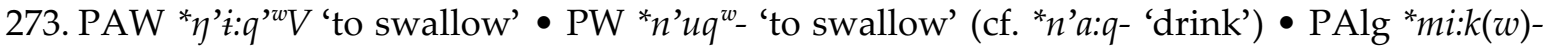
$(\sim k h)>$ Yu. mik-'olum- 'to swallow' $\diamond$ Cf. PS *maq', *maq'w 'to swallow, eat one's fill'.

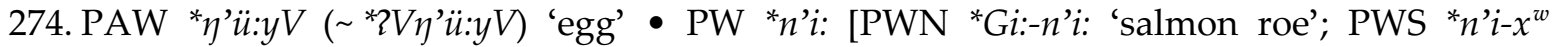

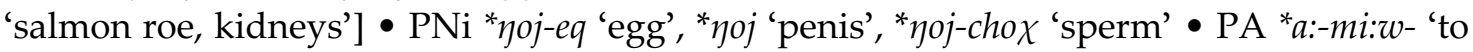
spawn' [Cree a:-mi:w 'she spawns', Oj. a:-mi: '(fish) is spawning', etc.] II Nikolaev 2015: 38.

275. PNA *pa $(\sim \ddot{a})$ 'to miss' - PNi *pha-r-u- 'to miss' - PA *pa-t-, *pa-t- 'to miss, pass by' [Fox pa-n-a- 'to miss, to fail to', Ab. o-ba-lh-ám 'he errs', etc.].

277. PAW * $p A l$ ' $V$ 'thin and flat' - PW *pat- 'flat'; PWN *pal'-, *pol- 'thin and flat (as a layer or sheet of sth.)'; *pal-q- 'to flatten with a hammer, to be somewhere (said of a flat obj.)' • PAlg *pel- 'flat (and wide)' [Wi. pal- 'flat', par- 'little and flat', Yu. pl- 'wide and flat'] $\diamond \mathrm{Cf}$. PS *pal 'flat, thin', * $p$ 'il, * $p$ 'al 'flat'.

278. PNA *pedV $\left(\sim t^{\prime}\right)$ 'to cover' $\bullet \mathrm{PNi}$ * phit- $i-(\sim c)$ 'to be covered with sth.' $\bullet$ PA *pet- 'to cover' (Haas 1958: 244).

279. PNA *pehV 'to run' - PNi *phe- $\gamma-0$ - 'to hurry', *ve- 'to run (animal)' • PAlg *pah-, *poh$(\sim p h)$ 'to run' [Yu. pah-c- 'to move one's body', PA *-pah-, *pah-t- 'to run'].

280. PAW *pewV ( i) 'deep' - PW *pu- 'deep' • PNi *vev- 'deep' [“incorporated” form of *phew-].

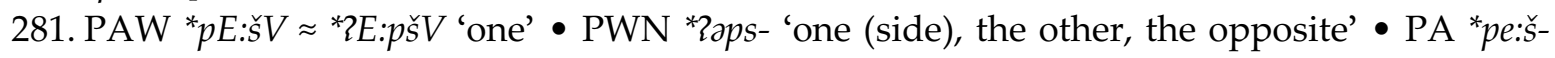
ekw- 'one' [WOj. pe:š-ik, Ab. baz-ékw, etc.].

282. PAW *padV $\left(\sim \dot{i}, t^{\prime}\right)$ 'to split' $\bullet$ PWN *pat- 'to split dry oolachens in two' - PNi *phit- 'to split'.

283. PAW *payšV 'to peel' • PW “pays- 'to peel off inner bark' • PA *pe:hš- 'to peel, husk' [Fox

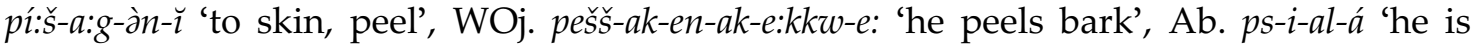
skinning', etc.].

284. PNA *ping ${ }^{w} E(\sim e)$ 'fly, gnat' • PNi *pheng-r 'fly (n.)'; NiY *pugucee 'midge' • PA *penkw'gnat' [Cree pihk-os 'gnat', Oj. pink-ošš 'sandfly', etc.] II Nikolaev 2015: 54.

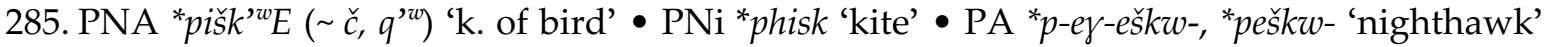
[Cree pi:skw-a 'nighthawk', Men. pe:sk-i? 'mosquito hawk', Shawnee peškw-a 'nighthawk', etc.] $\diamond$ Cf. PS *p'ọsk'a 'hummingbird'.

286. PAW ${ }^{*} p i: x k^{\prime w} E$ 'tree, willow' $P W{ }^{*} p u: x k^{w}->\mathrm{Kw}$. $p u x^{w}$-as 'willow tree' $P \mathrm{PNi}{ }^{*} p h x-i$ 'mixed wood (taiga)' • PAlg *pihkw- $(\sim p h, k h)>$ Yu pahk ${ }^{w}-o$ ? 'willow, red willow'.

287. PNA *piLVlVk' $\left({ }^{w}\right) E(\sim a)$ 'stone suitable for making tools' • PNi *valk-i 'chain' ["incorporated” form of *phalk-] • PAlg *peletk- 'stone suitable for making tools' [PA *-a:-petkw-, *-petkw'stone/metal'; Yu petk- 'gravel, pebbles'; Wi. ptátk'rock, stone'] II Nikolaev 2015: 55.

288. PAW *pirV ( a) 'to spread' - PWN *pol-k- 'to be somewhere (said of flat obj.), to spread out' $\bullet$ PNi *phiri- ( a) 'to spread'.

289. PAW *po:lV ( t) 'to flood' - PWN *pa:t- 'to rise, flood, overflow (river)' - PNi *phol-x 'whirlpool, deep place'; NiY *palaja- ( - -) 'to flood' $\diamond$ Cf. PS * $p$ 'ịl 'overflow'. 


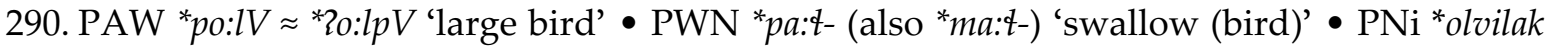

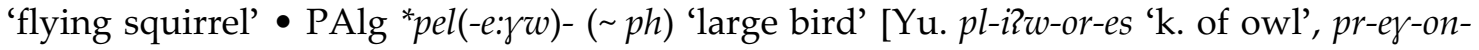

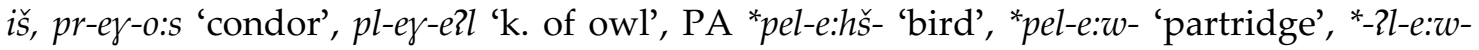
'bird' (-2l- <*-pl-); *pel-e:nyikw- 'flying squirrel'] $\diamond$ Cf. PSC *parl 'large bird' II Nikolaev 2015: 36.

291. PAW *po:wV ( b) 'to dream' - PWS *pu(:)w-'is- 'dreaming' - PA *pa:w-, *a:h-paw- 'to dream' [Cree pa:w-a:m-iw 'to dream', EOj. pa:w- $\varepsilon$ : 'he gains insight through vision or dream', Fox a:h-paw-e:w-a 'he dreams', WOj. puw-a:n-a:t 'he dreams of him', etc.].

292. PAW ${ }^{*} p O \gamma\left({ }^{w}\right) V \approx{ }^{*} 2 O p \gamma\left({ }^{w}\right) V$ 'to heat, burn' - PWN ${ }^{*} p a x$ - 'to heat, hot (like metal)' $-\mathrm{PNi}$ *phu-, * $p h u j-$ 'to set fire; shine (sun)' $\bullet$ PAlg * $p o: w-,{ }^{*} p e w-,{ }^{*} p u$ - 'to heat, put on the fire' [Wi. pu 'to cook', hi-piy-ágad-at-il 'I scorched my face'; Yu. pew 'to cook', PA *po:n- 'to put on the fire']; PA *apw- 'to heat, roast, bake' [Cree apw-a:n, Men. apu-an 'a roast', Ab. ab-ว̃n-ak 'cake', etc.] $\diamond$ Cf. PSI * $p$ 'әь 'to burn (esp. of forest fire)' \|| Nikolaev 2015: 37.

293. PNA ${ }^{*} p O l k^{w} A\left(\sim q^{s w}\right)$ 'to pierce' $-\mathrm{PNi}{ }^{*} p h o l q-o$ - 'to pierce' $\bullet \mathrm{PAlg}{ }^{*} p e k w-,{ }^{*} p a k w-(\sim p h, k h)$ 'to pierce through an obstacle' [Yu. $p k^{w}$ - 'out of a hole'; to bring/come out, PA *pakw-, *pekw- 'to pierce; hole'] $\diamond$ Cf. PS *pạl' $k^{w}$, * $p a t k^{w}$ 'to pierce', " $p a ̣ l x^{w}$ 'to pierce, pop out'.

294. PAW *pO:kV ( b, k’) 'thin (flexible obj.)' - PWS *pu:k- 'thin (flexible obj.)' P PA *pepak-

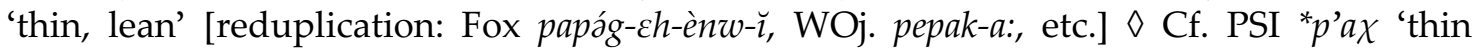
(layer)' || Nikolaev 2015: 45.

295. PNA *pü: $s^{w} V$ 'k. of seal' • PNi *pho, *phov-k 'seal (small species)' • PAlg *pe(:)yw- ( ph)> Yu. pe?w-iš 'lake porpoise'.

296. PAW *puq'A ( G) 'fish bladder' • PWS * $q^{\prime w} u q^{w}-a c$ 'bladder' • PNi *phoqi 'fish bladder' \| PWS * $q^{\prime w}$ - instead of ${ }^{*}{ }^{\prime}$ - due to assimilation.

297. PAW * $p V c$ ' $V$ 'to be hot, to warm' $-\mathrm{PWN}$ * $p a c$ '- 'to warm oneself by the fire' • PA *pas-et- 'be hot' [Cree pas-it-e:w 'it is on fire', Fox pas-et-e:w-i 'it is hot, burnt', etc.] II Nikolaev 2015: 44.

298. PAW ${ }^{*} p V k^{w} V\left(\sim k^{\prime w}\right)$ 'edible root' - PWN * $p a k^{\mathrm{w}}$ - 'cedar roots (edible)' • PAlg *pekw-an-e $(\sim p h, k h)$ 'Indian rhubarb (a plant with edible roots)' [Yu. pok $k^{w}-\partial n-\partial 2$ 'Indian rhubarb', PA *pekw-an- 'wild rhubarb, burdock', etc.].

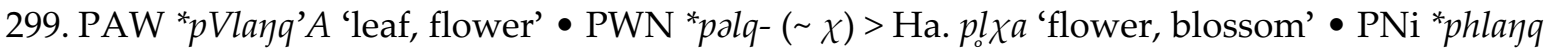
'leaf, branch of broad-leaved tree' • PAlg * $p(e l) a k-w$ - $(\sim p h, b, k h, g)>$ PA *-pak-w- 'leaf' [Fox

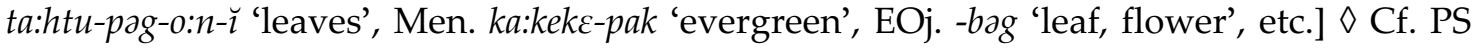
*packl [<*palk-c] 'leaf' II Nikolaev 2015: 40.

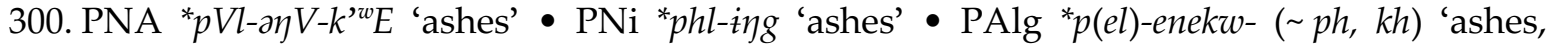
dust' [Yu. penk ${ }^{w}$ 'acorn flour', PA *penkw- 'ashes, powder'] \|| Nikolaev 2015: 36, 48. A

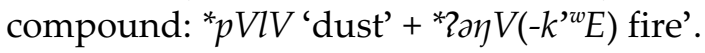

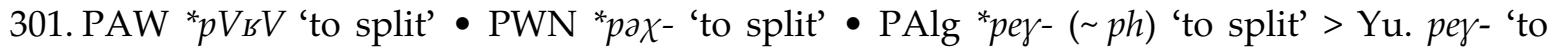
split'.

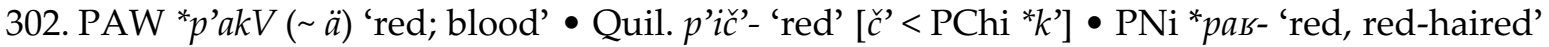
- PAlg *pek-, *pak- ( ph, kh) 'red; blood' [Yur. pek-, pak- 'red', PA *pek-, *ni:-/*ne-pek- 'blood; red'] II Nikolaev 2015: 42.

303. PAW * $p^{\prime} E$ 'along' $\bullet \mathrm{PW}{ }^{*}-p^{\prime} i$ - 'along with' • PA *pe-m- 'along (in space or time)' [Cree $p i$ $m$-ih-a: $w$ 'to fly along', WOj. pe-m-i- 'movement on, along, past', etc.].

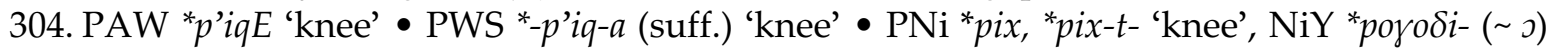
'knee' II Nikolaev 2015: 40.

305. PNA *p'i:lV ( e:) 'big' • PNi *pil- 'big' • PAlg *pe:l-, *pel- ( ph) > Yu. pel-, pl- 'big' \|| Nikolaev 2015: 47.

306. PAW * ${ }^{\prime}$ 't:Tq ${ }^{w} E$ 'to break' - PWN * $p^{\prime} u: q^{w}$ - 'to break off with the hands (dried fish, leaves, etc.)' • PNi *pay- 'to break' - PA *po:tkw- 'to break' [Cree po:skw-a:w 'he breaks it by tool', 
Men. pu:hkw-ah-am 'to break', Ab. boskw-en-á 'to break', etc.] $\diamond$ Cf. PSI *p'ac'q'w, * $p a c ' q^{\prime w}$ 'break/tear off'.

307. PAW *p'OLV 'to blink, close eyes' - PW *p'at- 'to blink, close eyes' • PNi *pol-m- 'blind'; NiY *pilom- 'foolish'.

307a. PAW *p'OlV $\approx$ *2Op'lV 'moss' • PW *p'ul- 'moss' • PAlg *2apt- ( b, ph) > PA *azt-a:xk-am$i k$ - '(ground) moss' [Men. a?n-a:hk-am-ek, WOj. ass-akk-am-ik, etc.].

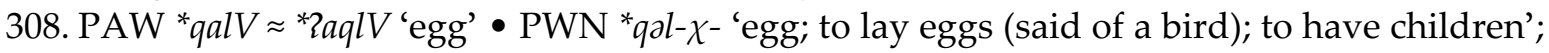
PWN *t-'alq- 'roe, spawn in fish' • PNi *t-qhla- 'to spawn' \|l Nikolaev 2015: 38.

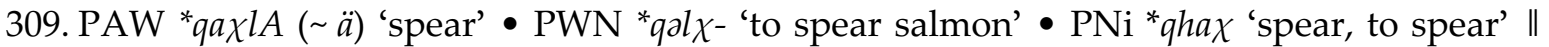
Nikolaev 2015: 55.

310. PAW *qa:rV 'to walk' • $\mathrm{PW}$ * qat- 'to walk, to leave (walking)' $-\mathrm{PNi}{ }^{*} k h r i-$ 'to follow'.

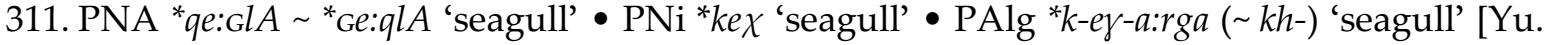

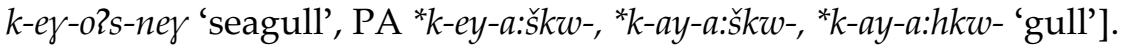

312. PAW ${ }^{*} q e: x^{w} A\left(\sim \chi^{w}\right)$ 'to hear' $-\mathrm{PWN}{ }^{*} q a: \chi^{w}-\left(\sim-x^{w}-\right)$ 'to hear, listen' $\bullet$ Quil. $q^{w} o q^{w}-a l-$ 'to hear' $\bullet \mathrm{PNi}$ *he $\chi$ - 'to hear about, feel' II Nikolaev 2015: 40.

313. PNA *qü: $r V(\sim x, \chi)$ 'throat' $\bullet \mathrm{PNi}$ * qhor-qr 'throat' $\bullet$ PAlg *ke:l- $(\sim k h)>$ Yu. kelokell 'throat'.

314. PAW * $q$ 'amV $~{ }^{*} \mathrm{Gam} V(\sim 0, o)$ 'to sing' • PW * $q$ 'am-at- 'to sing (for dancers)' • PAlg *negam-, *na-gam- 'to sing' [Yu. na:m-əy 'to sing songs', PA *ne-kam- 'to sing'].

315. PAW ${ }^{*} q$ 'anz $V \sim{ }^{*}$ Ganz $V(\sim c, s)$ 'to eat, bite' • PW * $q$ 'Vns- $>$ PWN *q'ons- 'to eat meat'; * $q$ 'os'to eat meat or fat'; * $q$ 'วs (suff.) 'eat, put in mouth'; PWS -'i:-ks 'to eat, consume' - PNi *haz- 'to bite' II Nikolaev 2015: 38.

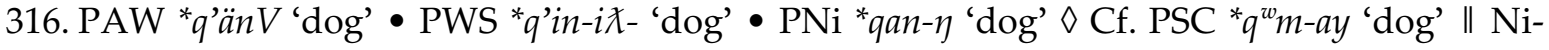
kolaev 2015: 37.

317. PAW *q'ilmV *qilmV ( G) 'navel' - PWS *q'im-a:n(a) 'navel' [the same derivation as in *q'aw-a:n- 'nose'] • PNi *khilm-řr 'navel' \|| Nikolaev 2015: 47.

318. PAW * $q^{\prime} i:(n V) \approx{ }^{*}(n ' i:) q^{\prime} V$ 'to sew' $P \mathrm{PW}^{*} q^{\prime} i:-n-,{ }^{*} n-' i: q-$ 'to sew' $\bullet \mathrm{PNi}{ }^{*} k n e-$ 'to sew (dress, footgear)' $\bullet$ PAlg ${ }^{*} k a-,{ }^{*} k i-(\sim k h)$ 'to sew' [Yu. $k a-h c-$, PA *ka-šk-; ${ }^{*} k-w-a:-$, etc.].

319. PAW * $q^{\prime}$ omV $\left(\sim q^{\text {ww }}\right)$ 'green' $\bullet \mathrm{PW}{ }^{*} q^{\prime} a m-\left(\sim q^{\text {ww }}\right)$ 'green, unripe' $\bullet \mathrm{PNi} * q o \eta-\mathrm{G}-r$ 'green', NiY *qomo- 'green' I| Nikolaev 2015: 39.

320. PAW * $q$ 'OmbV 'sand' • PWN *q'วp- 'sand' • PNi *qom-r ( -ř $)$ 'sand' $\diamond$ Cf. PSI * $q$ 'ap-ar 'sand' II Nikolaev 2015: 42.

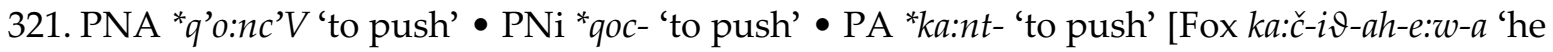

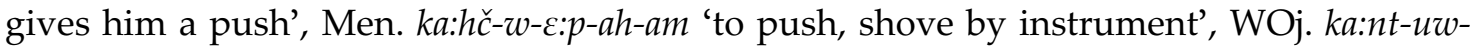
a:t 'he pushes him', etc.].

322. PAW * $q$ 'V:ncV 'to fold' - PWN * $q$ 'ons- 'to fold, to wrap up' • PA *ke:s-ip- 'to fold' [Men. $k \varepsilon: s-e p-\varepsilon n-\varepsilon: w$ 'he folds him up uselessly', WOj. ke:s-ep-i:k-en-ank 'to make, fold up', etc.].

323. PAW ${ }^{*} q^{w} a K c$ ' $V$ 'half, one of a pair' - PW*qakc'a 'other, following' > PWS *qakc'a 'three' ("another number [after two]") $\bullet \mathrm{PNi}{ }^{*}$-vasq 'half, one of a pair'5 $\bullet$ PAlg *ne-kwehc-, *nekweht- 'one' [Wi. kuc- 'one', Yu. kaht-, “kahc- 'one', PA *ne-kwet- 'one'] II Nikolaev 2015: $47,57$.

324. PAW * ${ }^{w} A T k A$ 'hard, tough' $-\mathrm{PW}{ }^{*} q u t k$ - 'to be hard or tough' $\bullet \mathrm{PNi}^{*}$ qhas- 'hard, tough'.

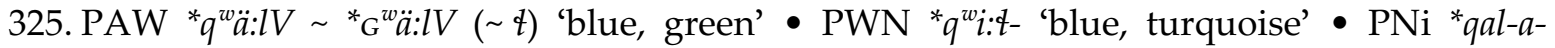
'green, unripe', NiY *qola- $(\sim k)$ 'green, yellow' $\diamond \mathrm{Cf}$. PS ${ }^{*} k^{w}$ ạl 'green, yellow' and * $q^{w} a y$ 'blue, green; bruise' I| Nikolaev 2015: 39.

\footnotetext{
${ }^{5}$ The isolated foms pasq, paz ${ }^{-} r$ with irregular ${ }^{*} p$ - have been derived (with hypercorrection) from the incorporated forms *-vasq, ${ }^{*}$-fasq after numerals: $n$-vasq, me-vasq, c-fasq, etc.
} 
326. PAW * $q^{w} e s V \approx{ }^{*} h e q^{w} s V$ 'mouth, nose, throat' $-\mathrm{PW}{ }^{*}$-(h)aqs- (suff.) 'mouth' • PNi *hes 'larynx', *hes-qr 'throat, gullet' • PA -t-kwet-, *-kwet- 'nose' [Cree timi-kut-e:w 'he has a short nose', etc.] II Nikolaev 2015: 41.

327. PAW ${ }^{*} q^{w} E: c V(\sim s)$ 'to worry' $\bullet \mathrm{PWN}{ }^{*} q^{w} u: s-$ 'to worry' $\bullet \mathrm{PNi}{ }^{*} q h e z-$, *qhoz- 'to worry, suffer'.

328. PAW * $q^{w} e: l V(\sim q)$ 'to burn to cinders' - PWN $q^{w} a: t$ - 'to burn to cinders' - PNi *hil-m-, *helm-[h]elm- 'to blaze', *hi[l]m-ř 'cinders' $\diamond$ Cf. PS * ${ }^{\text {'w }} a l$, * $q$ 'w ay 'to scorch, (burn to) ashes,

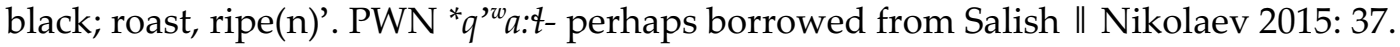

329. PAW * $q^{w} o d V(\sim t$ ') 'to cut in two; middle, other' - PW *qa:t- 'to cut in two' - PNi *hut-i

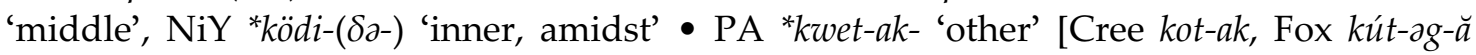
'other, another', etc.] II Nikolaev 2015: 50.

330. PAW * $q^{w}$ ońzV 'to sink' - PWN * $q$ 'alc- 'to sink a weighted object; heavy', * $q$ 'als- 'to drop anchor' • PNi *qhońz- 'to sink' • PA *kwes- 'to sink' [Cree kos-a:p-e:w 'it sinks', Oj. kos-a:p-i: 'to sink', etc.].

331. PAW * $q^{w} 0: x^{w} A$ 'to freeze' $-\mathrm{PWS}{ }^{*} q u: x^{w}-$ 'to freeze' $\bullet \mathrm{PNi}$ *hos- $a$ - 'to freeze'.

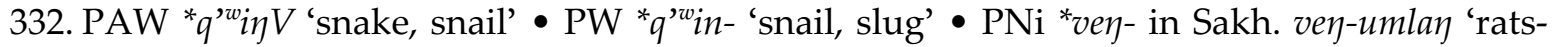
nake (?)' • PA *kenw-e:p-ikw- 'snake', *keny-ęp-ikw- [Cree kin-e:p-ik, Men. ken-u:p-ik] - PA ${ }^{*} k e n w$ - instead of ${ }^{* *} k w e n$ - under the influence of *kenw- 'long'; PA *keny-e?p-ikw- 'spider' [Shawnee kiny-ęp-ikw-a, Ab. mams-eláb-ihk-á] $\diamond$ Cf. PS *k'ínk’w 'snake' \|I Nikolaev 2015: 45.

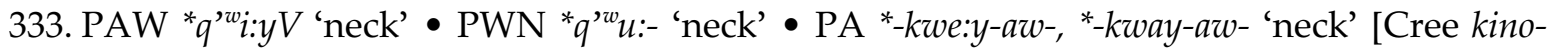
kway-aw-e:w 'he has a long neck', Oj. kino-kway-aw-e: 'to have a long neck', Men. pi:me-kiy$a w-\varepsilon n-\varepsilon: w$ 'she wrings her neck', etc.] II Nikolaev 2015: 41.

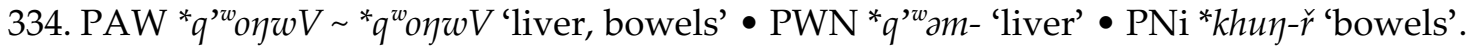

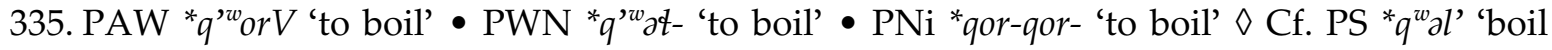
(food), cook'.

336. PAW ${ }^{*} q^{{ }^{w} o} 0: q^{{ }^{w}} E\left(\sim-G^{w}-\right)$ 'dark' $\bullet \mathrm{PWN}{ }^{*} q^{\prime w} a: q^{w}-$ 'to darken (by smoke, heat)' $P \mathrm{PNi}{ }^{*} v u k-v u k-$ 'dark' $\diamond$ Cf. PS * $q$ 'wi ix 'dark color'.

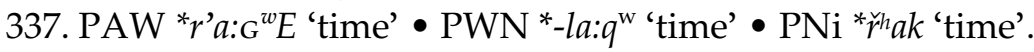

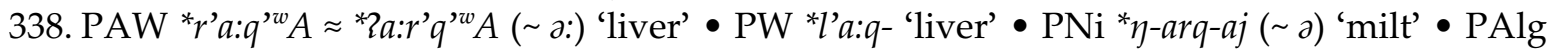
*-Vtkw- 'liver' [Wi. $w$-átw-ad, Yu. $\left\{w\right.$-atk-un, PA *w-etkw-alen-, -tkw-an-] $\diamond \mathrm{Cf}$. PS *tiq ${ }^{w}$ 'flesh, meat' II Nikolaev 2015: 40.

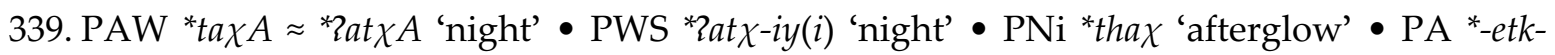
'night' [in *tep-etk- '(dark) night'; *l-etk-an- 'it is evening; by night'] II Nikolaev 2015: 41.

340. PAW ${ }^{*} t e: X q^{\text {ww } E}$ 'to hold' $-\mathrm{PW}{ }^{*} t a: q^{w}$ - 'hold or squeeze' $\bullet \mathrm{PNi}{ }^{*}$ thik- 'to carry in armful' • PAlg *tahkw-, "tehkw- ( th, kh) 'to hold, grasp' [Yu. tek-on-ek' 'I wear (clothes)', PA *tahkw'to hold'] $\diamond$ Cf. PSI ${ }^{*} t$ ' $u q^{\prime w}\left(\sim k^{\prime w}\right)$ 'hold/carry in the arms, hug, get an armful of'.

341. PAW *tijV $(\sim e)$ 'liver, gall' $\bullet \mathrm{PWN}{ }^{*} t a x-(\sim k)$ 'bile, gall' $\bullet \mathrm{PNi}{ }^{*} t h i u-\check{r}$ 'liver, kidney' II Nikolaev 2015: 40.

342. PAW *timQV $(\sim e)$ 'to kick' - PW *timq- $\left(\sim q^{w}\right)$ 'to wade or kick in water' - PA *tank- 'to kick' [Cree tahk-isk-am, Men. tahk-e:sk-am, Ab. o-dák-sk-am-én 'to stamp, kick', etc.].

343. PNA ${ }^{*} \mathrm{O} \approx{ }^{*} 2 \mathrm{O} t V$ 'to carry' $-\mathrm{PNi}{ }^{*}$ tho- 'to carry' $-\mathrm{PA} *$-at- 'to carry' [Cree aw-at-a:w 'he carries it off', Men. aw-a:t-a:w 'he takes it away with him', Oj. aw-at-o:n 'to carry', etc.].

344. PAW *tOkA 'to press' - $\mathrm{PWN}{ }^{*}$ tok- 'to press; tight (shoe, etc.)' • PNi *thou- 'to press' • ? PA *tamakw- 'to press, squeeze'.

345. PNA *tOyViwV 'to burn (trans.)' • PNi *thuv- 'to burn' • PAlg *teye?w- 'to burn' [Wi. tuwán-izl 'it is burned out', Yu. tye?w-ol-ok' 'I burn (trans.)'] I| Nikolaev 2015: 47.

346. PNA * $t V$ 'interrogative stem' • PNi *thu- > Am. si-, Sakh. řh $u^{*}$ 'what?' [“incorporated” allomorphs of Am. *chi, Sakh. *thu], "tha- 'who?' • PA *tV- 'interrogative stem' [Blackfoot $t$-, 
Cree $t$-a:n-, Miami $t$-an-, etc.] $\diamond$ Cf. PS *ta-m? 'what?' (and perhaps *wa-t 'who?') \| Nikolaev 2015: 45.

347. PNA *t'arV ( ä) 'spotted' • PNi *taj- 'spotted' • PAlg *ter-, *tay- $(\sim$ th $)>$ Yu tef-ek-en-i 'spotted', tajaryk'arary 'it is spotted'.

348. PAW ${ }^{*} t^{\prime} \partial m q^{w} E(\sim e)$ 'dance' $-\mathrm{PWN}{ }^{*} t^{\prime} \partial n q^{w}->\mathrm{Kw} t^{\prime} \eta_{0} q^{w} a$ 'a dance of some kind' $\bullet \mathrm{PNi}{ }^{*} t i \gamma-$ 'female dance, to dance'.

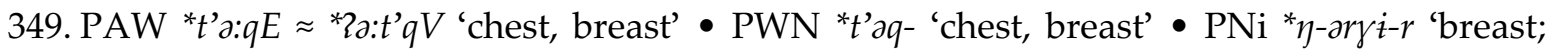
wing' • PAlg ${ }^{*} t e(:) k-w-l-$, dimin. ${ }^{*} c ̌ e: k-w-r-$ 'heart' [Wi. -atw-, Yu. cek ${ }^{w}-s$ 'heart', tek ${ }^{w}$ 'chest', dim. tek ${ }^{w}$-s-a?r 'heart of salmon, uvula'; PA -te:h- 'heart'] \| Nikolaev 2015: 37.

350. PAW ${ }^{*} t^{\prime} i: q^{\prime w} V \sim{ }^{*} t i: q^{\prime w} V$ 'to sit' $\bullet \mathrm{PWS}{ }^{*} t^{\prime} i: q^{w}$ - 'to sit, to lie back' $\bullet \mathrm{PNi}{ }^{*}$ thiv- 'to sit, sit down

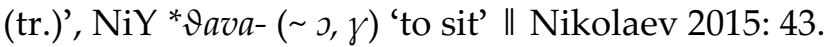

351. PAW *t'i:xE 'to carry' $-\mathrm{PWN}{ }^{*} t$ ' $i: x$ - 'to carry a bulky thing on the shoulder' $-\mathrm{PNi}{ }^{*}$ thik'to carry in armful'.

352. PAW *t' $i m V$ ( a) 'k. of berries' - PWN *t'am-s- 'bunchberry (Unifolium dilatum)' • PNi *tam 'cranberry' $\diamond$ Cf. PS *t'am- $x^{w}$ 'gooseberry' II Nikolaev 2015: 51.

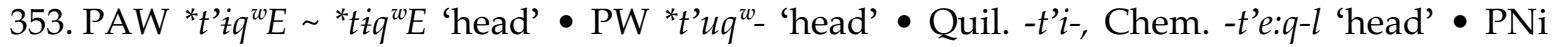
*thox 'forehead' • PAlg *tekw-, -č-tekw-, -T-tekw- ( th, kh) 'head' [Yu. to:k-un 'fish head', PA *-2-tekw-a:n-, ${ }^{*}$-š-tekw-a:n- 'head'] II Nikolaev 2015: 39.

354. PAW ${ }^{*} t^{\prime} i: k^{\prime w} E \sim{ }^{*} k^{\prime w} i: t^{\prime} V$ 'nail, claw; peg' $-\mathrm{PWN}{ }^{*} k^{\prime w} u: t-$ 'to nail' $\bullet \mathrm{PNi}{ }^{*} t a k n$ 'claw, fingernail', NiY *tuk-no- 'nail (peg)' $\bullet$ PAlg *-tk-an-, ${ }^{*}-c k$-an-, *-čk-en- 'claw, hoof, finger-, toenail'

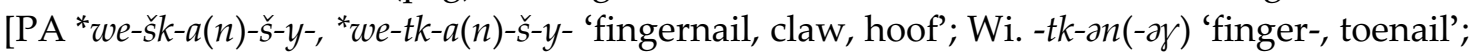
Yu. 2we-tk-e-tej 'fingernail, toenail, claw'] II Nikolaev 2015: 37.

355. PNA *t'Omk'A ( q') 'elbow' - PNi *tomq 'elbow' - PAlg -čekw- 'elbow' [Wi. cacukad-, watuk, PA. *-škw-an-].

356. PAW *t'OnCV ( S) 'cold' • PWN *t'ans- 'cold' • PNi *tuz- 'cool' II Nikolaev 2015: 37.

357. PAW *t'OrV 'to jump' $\bullet \mathrm{PWN}$ *t'at- 'to jump (said of fish)' $\bullet \mathrm{PNi}$ *thur-i- 'jump over'.

358. PAW *t'ü: $g^{w w} E\left(\sim k^{{ }^{w}}\right)$ 'to dig' • PWS *t' $i: k^{w}-$ 'dig with digging stick' • PNi *tok-l- 'dig up'.

359. PAW * $t^{\prime} V l x^{w} V$ 'to pound' - PW *t'ulx ${ }^{w}$ - 'shred cedar bark by pounding' - PAlg *tekw-, *takw- 'to break, pound' [Wi. tok ${ }^{w}$ - 'to break', Yu. tek ${ }^{w_{-}}$'to chop, break', PA *takw- 'to pound fine'].

360. PNA *t'VPOt'V $(\sim d)$ 'arm' • PNi *tot 'forearm, arm' • PA *-tpetw- 'arm' [Cree -spit-un, Ab. -hped-ín, etc.].

361. PAW *t'VyOmV 'raft' - PWN *t'am- , ${ }^{*} t$ ' $a m-s-$ 'old, worn-out canoe' - PNi *com 'raft'; *combi-zombi- 'to paddle in turns'; NiY *cam-za 'paddle' • PAlg *teyim- ( th, $d)>$ PA *ci:m'to paddle' [Cree či:m-a:n 'canoe; to paddle, swim', Men. ise:-čim-ew 'he paddles thither', etc.] II Nikolaev 2015: 55.

362. PNA *wa:lwV ( w', ä:) 'back, behind' - PNi *al(-ь)-, -al 'behind' - PA *wa:lw- 'back, around' [Cree. way-o:n-i- 'back', Oj. wa:n-in- 'around, circle', etc.].

363. PAW *walx ${ }^{w} E(\sim a)$ 'to find out' $\bullet \mathrm{PWN}{ }^{*} w a l x^{\mathrm{w}}$ - 'to do sth. at short notice' $-\mathrm{PNi}$ *aly - 'find out, learn' || Nikolaev 2015: 50.

364. PNA *walyV $V(\sim w$ ', ä) 'to cheat' - PNi *valc- 'to cheat'; NiY *ju(u)liza- O 'sly' - PA *waye:š- 'to deceive' [Cree waye:s-im-e:w 'he deceives him with talk', Oj. waye:š-im 'to cheat so.', etc.] $\diamond$ Cf. PS *mac' 'cheat, trick, lie'.

365. PNA *waNXKA ( w') 'box' • PNi *vaq-aj 'box' • PA *mahk-ahkw- 'box, barrel, tub' [Cree mahk-ahk 'box, barrel, tub', Fox máhk-ahkw-̌̆ 'box', Men. mahk-a:h 'box, chest, trunk', WOj. mekk-akk 'box', etc.].

${ }^{6}$ Admittedly from *t(V)jom-, cf. PChK loan *tijmi- 'to paddle'. 
366. PNA *waTVrk'ańV ( w') 'fork' • PNi *marqań 'fork' • PAlg *watehkan-, *wacehkan- ( th, kh) [PA *watehkwan- 'fork (of tree)'; Yu cki:ka? 'fork, table fork'; ckəkə:? 'to pierce, spear, pitcfork, fork (utensil)'].

367. PAW *wa:kV ( a:, k') 'to bend' - PWN *wa:k- 'to bend sth., to be bent, to be ring-shaped, to be around sth.' • PA *wa:k- 'to bend, crook' [Blackfoot é-vóhk-o 'it's bent', Cree wa:g-a:w, Miami wak- 'to bend', etc.].

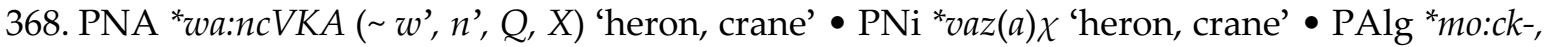
*mack- 'heron, crane' ( ch, kh) [PA *mo:sk-aho:siw- 'bittern, heron'; Yu. mok 'crane, heron'].

369. PNA *wa:XK'v ( w', ä:, $\left.Q^{w}\right)$ 'moss, lichen' - PNi *vas[ $\left.\eta\right]$ 'moss' • PA *wa:hkw-en-ak- 'lichen' [Cree asini:-wa:hk-on-ak 'lichen', Men. wa:hk-on-ak 'tree lichen', etc.].

370. PAW *wä: 'river, flowing water' $\bullet \mathrm{PWN}$ *wa:- 'river, stream, flowing water' $\bullet \mathrm{PNi}{ }^{*} i$ 'river'.

371. PAW *we: *2e:wV 'voice; to call' • PW *2a:-da:- 'call, ask for' • PNi *aw 'voice’ • PAlg

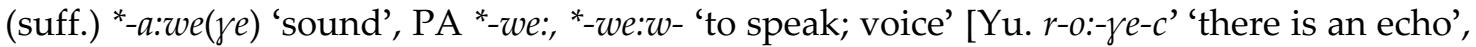
tolow-o:-c-ek' 'I speak Tolowa', Cree it-we:- $w$ 'he speaks so', etc.] $\diamond$ Cf. PS * $2 a b^{w}$, * $2 a w$ 'to call, howl'.

372. PNA *we:dV $\left(\sim w^{\prime}, t^{\prime}\right)$ 'to dress' - PNi *veta- 'to dress' - PA *wawe:š- 'to dress up, ornament' [Cree wawe:s-i:h-e:w 'he dresses him up', Oj. uwe:š-e?-a:t 'he dresses him up', etc.].

373. PAW *we: $q^{w} E\left(\sim q^{\text {ww }}\right)$ 'nose, cape' • PWN *wa: $q^{w}$ - 'cape' • PNi *vix 'nose' || Nikolaev 2015: 42.

374. PAW *wa:nkE 'to bark (dog)' - PWN *wa:k- 'to bark (dog), to woof' - PNi *ay- 'to bark (dog)' • PAlg *ma:k-, *mek- ( kh) 'to bark' [Yu. mok ${ }^{\mathrm{w}}-$, PA *mek-].

375. PAW *wi ( e) 'to walk, go' $\bullet \mathrm{PWN}$ *wa-n- 'to go, go ahead' $\bullet \mathrm{PNi}$ *vi- 'to walk, go' $\bullet \mathrm{PAlg}$ *we-ht- 'to walk' [Wi. šamit-ó-r-it yo 'did you come on foot?', Yu. n-o-?r- 'to run', ?o:-2r 'run behind or in front of someone else', PA *we-ht- 'to walk'] II Nikolaev 2015: 44.

376. PNA *wiXca:rV ( w', e, q', c') 'to slip' • PNi *ezsar- 'to slip' • PA *wekca:2r- 'slippery' in PA *we?sa:2̌s-ikwepy- 'slippery elm bark' [Men. osa:2s-ekop 'slippery elm bark' , Oj. ussa:šš-ekop 'slippery elm', etc.].

377. PAW *wi:LV 'horn' - PWN *waᄎ- 'horn, antler' - PA *-wi:t-, *-wiwi:t- 'horn' [Cheyenne vevêsce, -évesé-, Arapaho hini:n-is, Delaware wi:l-a:w-an, Kickapoo -wi:n-, Miami wi:wi:l-a 'horn', Fox pahk-wíwin-غ́w-a 'he is shedding his horn', etc.] $\diamond$ Cf. PS *wið' *wil' 'horn': Bella Coola wi才'-ax, Shuswap wl-aps 'horn' II Nikolaev 2015: 40.

378. PAW *wi:3V $\approx{ }^{*}$ *i:w3V 'body, belly' - PWN *-2i:s (suff.) 'body, belly' - PNi *vic 'body (of human)' ; NiY *wizie body' - PA *wi:s- 'belly fat' [Cree wi:s-ih 'belly fat', EOj. wi:nz-i 'fat', Mic. us-ak 'fat on the kidneys', etc.] $\diamond$ Cf. PS *-iws (suff.) 'body' \| Nikolaev 2015: 36.

379. PNA *wirKE *winKE ( w', a) 'scab' • PNi *vary-i, *varx 'scab' • PA *mek-y- 'scab' [Men. $o-m \varepsilon: k-e: w$ 'he has a scab/ scar', Oj. o-mik-i: 'have scabs; have leprosy', etc.].

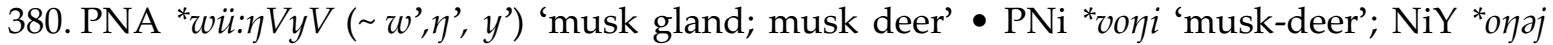
'wild reindeer' $\bullet$ PA *wi:niy- 'musk-gland' [Cree, Men. wi:n-iy, etc.].

381. PAW * $w V\left(\sim w^{\prime}\right)$ 'interrogative stem' - PW *way $(a)\left(\sim w^{\prime}\right)$ 'interrogative stem' - PA *we:$k w$ - 'what', *a-we:-na 'who' $\diamond$ Cf. PS *wa-t 'who?' \|| Nikolaev 2015: 45.

382. PAW *w'APsV $(\sim K s)$ 'to cough' $\bullet$ PWS *w'as-aq- 'to cough' • PAlg *wept- ( kt) > PA *we?t'to cough' [Cree ost-ost-ot-am 'he coughs', WOj. uss-ass-et-am 'to cough', etc.].

383. PAW *w'a:yV 'to bark (dog)' - PWN *w'a:- 'to bark'; *w'a:(-s)- 'hunt with dogs', *w'a:-s'dog' • PNi *vaj- 'to bark (dog)' • PAlg *way-e(h)c- 'dog' [Wi. wáy-ic 'dog', Yu. way-c-'ək 'puppy'] $\diamond$ Cf. PS *wuh, *wah 'to bark (at)' II Nikolaev 2015: 37.

384. PAW *w'e:pV *pe:w’ 'water, liquid' - PWN *w'a:p- 'water' • PNi *fi 'dew' ["incorporated” allomorph of *phi] • PAlg ${ }^{*}$-[w]a:p- $(\sim p h)$ 'liquid' [Yu. -op- 'water, liquid'; PA *-a:p'liquid, water']; PAlg *pi-\{ihk-> Yu. pa-2ah 'water, juice; be/get wet' II Nikolaev 2015: 44. 
385. PAW *w'e:šq'V 'to produce or use smoke' • PWN *w'a: $\chi$ - 'to produce or use smoke' • PNi *th-usk- 'to smoke fish' [compound with *thu- 'smoke'] • PA *wi:škw- 'to smoke (leather or meat)' [Cree wi:skw-as-am 'he smokes it (leather)', Men. wi:skw-art-cw 'it gets smocked', Oj. wi:šk-oss-a:n 'to smoke (meat)'] ॥l Nikolaev 2015: 43.

386. PAW * $w$ ' $V$ 'demonstrative stem' - PWN * w'a- 'this (“empty root”)' • PNi *iv- $\eta$ 'he', *av- $\eta$ 'he (honor.)' • PAlg *we?- '3rd person'; *we 'this (nonpersonal, extended)'; *wa 'this (personal, extended)' II Nikolaev 2015: 43.

387. PAW * $w^{\prime} V d V$ 'cold' - PWN * w'ad- 'cold, to be cold' - PA *at- 'cold' [Fox kep-at-enw-i, Men. kep-a:t-en, WOj. kep-at-in 'to freeze', etc.].

388. PAW * $x E c V \approx{ }^{*} 2 E x c V(\sim s)$ 'tooth' $-\mathrm{PWN}{ }^{*}-x s-i:(2 a:)$ (suff.) 'tooth' • PNi * $\eta \partial-\gamma s,{ }^{*} \eta \partial-\gamma z-i r$ $(\sim-\check{r})$ 'tooth' || Nikolaev 2015: 44.

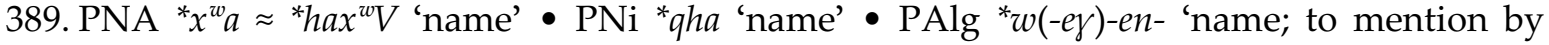
name' [Wi. wan- 'to mention by name', Yu. w-ej-en- 'to name', PA *wi:n- 'name']; *he(:)w-> Yu. hew 'name' $\diamond$ Cf. PS ${ }^{*} k^{w} a-\sim{ }^{*} k^{w} i$ - 'name, to name' \|l Nikolaev 2015: 41.

390. PAW ${ }^{*} x^{w} a: \lg ^{w} V\left(\sim-k^{w_{-}}\right)$'boat' $\bullet \mathrm{PWN}{ }^{*} x^{w} a: k^{w}$ - 'canoe' $\bullet \mathrm{PNi}$ *halk 'boat, barge'.

391. PAW ${ }^{*} x^{w} \ddot{a}: r{ }^{w} A \sim{ }^{*} g^{w} \ddot{a}: r{ }^{w} A$ 'k. of edible root' $-\mathrm{PWN}{ }^{*} x^{w} u: k^{\mathrm{w}}$ - 'Indian rice, rice root (Fritillaria, chocolate lily)' $\bullet$ PNi * qarq 'wild lily with blue flowers'.

392. PAW ${ }^{*} x^{w} i: y V$ 'to whistle' $-\mathrm{PW}{ }^{*} k^{w} i:-,{ }^{*} x^{w} i$ :- 'to whistle' $-\mathrm{PNi}{ }^{*}$ phev- 'to whistle' $-\mathrm{PAlg}$ *kwey-, *kwa:hk-, *kwa:y- ( kh) 'to whistle' [Yu. k'eyk eyur-'to whistle', kw ${ }^{w}$ hk $k^{w}$ oyrcek', $k^{w}$ ayawek' 'I whistle', PA *kwi:škwih $\vartheta$ - 'to whistle'] $\diamond$ Cf. PS * $x^{w}$ iw 'whistle'.

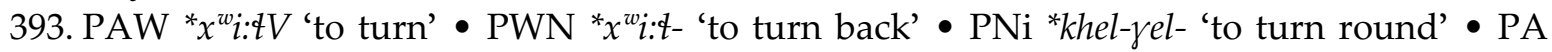
${ }^{*} k w e: t-$ 'to turn, return' [in *kwe:t-k-, *kwe:t-ap- 'over, round', cf. also PAlg *kel-om- 'turn'] $\diamond$ Cf. PS * $x^{w} u l$ 'to turn, spin, drill, wrap around; round' and ${ }^{*} \chi^{w} a l a q^{\prime w}$ 'round, to roll'.

393a. PAW * $x^{w} O: \eta V \sim{ }^{*} \eta O: x^{w} V$ 'bee' $P W N{ }^{*} x^{w}$ zm- 'bee' $\bullet P N{ }^{*} v u \eta$ 'bee' $P$ PA *a:-mo:w-, *a:maw- 'bee' [Cree a:mo:w, Oj. a:mo:, Miami amaw-ia, etc.] II PA - $m$ - is an irregular medial reflex of ${ }^{*} \eta\left(\mathrm{PA}{ }^{*} n\right.$ - is expected). Perhaps PA $a$ :- is a secondary prefix, cf. PA * $a$ :-mi:w- 'to spawn' from PAW * $\eta$ 'ü:yV 'egg' (\#274).

394. PAW * $\chi a r b V(\sim \ddot{a}, p$ ') 'to scratch, scrape' - PWN * $\chi$ alp- 'to rake, scrape with the fingers, shovel, scrape' $\bullet \mathrm{PNi}$ * qharp- 'to scratch, scrape'.

395. PAW * $\chi a: r g A\left(\sim k\right.$ ') 'backbone' $-\mathrm{PWN}{ }^{*} \chi a: k$ - 'backbone of fish' $-\mathrm{PNi}$ *harq, *har $($ s $) r(\sim-\check{r})$ 'dried fish backbone' • PA *-tapta-ka:k-w- 'backbone' [Fox -tahta-ka:kw-an-, Oj. -tatto-ka:wakan, WOj. tatta-ka:k, etc.] II Nikolaev 2015: 47.

397. PAW ${ }^{*} \chi e: r g^{w} A \sim{ }^{*} g e: r \chi \chi^{w} A$ 'bark (of tree)' $\bullet \mathrm{PWN}{ }^{*} \chi a: k^{w}{ }_{-},{ }^{*} \chi a: x^{w}{ }_{-}$'bark; scab' $\bullet \mathrm{PNi}{ }^{*} k e r \leq a-\check{r}$ 'birch bark (with fine scales), "black birch"' || Nikolaev 2015: 36.

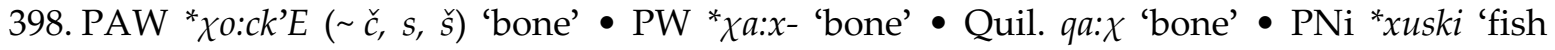
bones' || Nikolaev 2015: 37, 48.

399. PAW ${ }^{*} \chi \ddot{u}: g^{w} E \sim{ }^{*} g^{w} \ddot{u}: \chi E$ 'to scratch, scrape' $-\mathrm{PW}{ }^{*} k i: \chi^{w}$ - to 'scratch, rip' $\bullet \mathrm{PNi}{ }^{*} h u k-u$ - 'to brush off, peel' $\diamond$ Cf. PS * $\chi i k^{w}$ 'to scratch, crunch'.

400. PAW ${ }^{*} \chi u \mathrm{uG}^{w} E \sim{ }^{*} \chi \mathrm{urg}^{w} E$ 'hollow' $-\mathrm{PW}{ }^{*} \chi u l q^{w}$ - 'hollow inverted object', PWN * $\chi$ alk- 'hollow-shaped surface, warped, concave; ridgepole, central point of the sides of a vault or of one's ribs' $\bullet \mathrm{PNi}$ *hurk-i- 'hollow'.

400a. PAW ${ }^{*} \chi V l V \approx{ }^{*} ? V l \chi V \bullet P W N{ }^{*} 2 a l \chi$ - 'to kill, murder, beat up' $\bullet \mathrm{PNi}{ }^{*} k h-u$ - 'to kill' [also passive ${ }^{*} k h-u$ - 'to perish (in the battle)'] $\diamond$ Cf. PS * $\chi$ way 'to perish (pl.), disappear' $\| \mathrm{Ni}$ kolaev 2015: 40.

401. PAW * $\chi$ Vru:mcV $(\sim s)$ 'to $\operatorname{rot}^{\prime} \bullet \mathrm{PWN}^{*} \chi u: m s-$ 'rotten' $\bullet \mathrm{PNi}{ }^{*} k r u \eta z-$ 'rot'.

401a. PAW * $\chi V t V \bullet P W N *-\chi t-a: m$ 'u: 'knee' [with the specificatory suffix *-(a:)m'u: 'underlying or implicated in'] - PAlg *ket- ( kh, th) 'knee' [PA *ket-ekw-, Yu. 2a:-kat, (suff.) -eket- 'knee'] I| Nikolaev 2015: 40. 


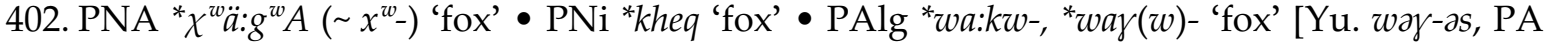
$\left.{ }^{*} w a: k w-\right] \diamond \mathrm{Cf}$. PSI * $\chi^{w} \partial s^{w}$ 'fox'.

403. PAW * $\chi^{w} a: y V c V(\sim a:, o:)$ 'ready' $\bullet \mathrm{PWN}^{*} \chi^{w} a$ :s- 'to get ready, to prepare (for anything)' • PA *kwayat-, 'kwayat-k- 'ready/good, fixedly' [Cree kwayask 'properly, good straight', Fox kwaya:š- $i$ 'good, definitely, fixedly', Men. kwaya:k 'properly, good straight; in the right place', etc.] $\diamond$ Cf. PS * $\chi \partial c$ 'ready, completed'.

404. PNA *yizwV ( y', a, w') 'body, intestines' • PNi * $\eta$ - aw 'intestines' • PA *-i:-yaw- 'body; flesh, meat' [Cree -i:ya:w 'body', wi:ya:-s 'meat, flesh', etc.].

405. PAW *yixA 'quick, fast' • PW * $y u x$ 'fast' • $\mathrm{PNi}$ * $е$ s- $^{\text {' }}$ quick, hurry'.

406. $\mathrm{PAW} * \mathrm{yOLwV}$ 'to roll, wrap' $-\mathrm{PWN}{ }^{*} y \partial x$ - 'to wrap or tie around (rope, bandage, strap), to bandage' PA *at-w- 'round' [cf. Yu. ho:l- 'around'] $\diamond$ Cf. PS *yạl, *yul, *hayl 'to roll, turn over; round'.

407. PAW * $y O g E(\sim k$ ') 'to limp, lame' • PWN *yok- 'to limp' • PNi *hok-l- 'lame, to limp'.

407a. PAW *y'e: $\chi E \approx{ }^{*} 2 e: y$ ' $\chi E$ 'to suffer' - PWS * ${ }^{*}$ ' $i: \chi-a$ (suff.) 'to suffer from excess or die from' $\bullet \mathrm{PNi}{ }^{*} i j \gamma$ - 'to suffer, grieve'.

408. PAW *y'E:wV '?' in *n't-y'E:wV, * $m V-y$ 'e:wV 'four' - PW *mu: 'four' • Quil. bázyas 'four',

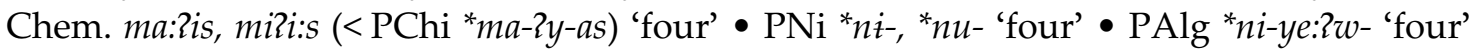
[Wi. di-yazw-, PA *n-ye:w-] $\diamond$ Cf. PS mu-s 'four' (from Wakashan?) \|l Nikolaev 2015: 57.

409. PAW *y'ว:k'E *k'ว:y'E 'bad' • PW * $y^{\prime} a k$ - 'bad, spoiled, evil, vicious, sick, not as it should be'; “ $y^{2}{ }^{w}-$ 'bad' $\bullet$ PNi *ik-i- 'bad' • PAlg *ki:- ( kh) 'bad' [Yu. ka:-m-, PA *ki:-] $\diamond$ Cf. PS *k'i$s$ 'bad'.

410. PAW * $y^{\prime} i l g^{w} E\left(\sim k^{w w}\right)$ 'to carry' $\bullet \mathrm{PWN}{ }^{*} y^{\prime} \mathrm{llk}^{w}$ - 'to carry a long, stiff object on the shoulder' - PNi *ilk- 'carry behind the belt' $\diamond$ Cf. PSI * $2 u k^{w}$ 'carry, haul, take/bring somewhere'.

411. PAW * $y^{\prime} \mathrm{O}: \gamma^{w} E$ 'rain' • $\mathrm{PWN}{ }^{*} y^{\prime} u: g^{w_{-}}$'to rain'; * $y^{\prime} u: g^{w}-a$ 'rain' • PNi *ju 'dew' II Nikolaev 2015: 42.

412. PAW * $y$ 'V 'demonstrative stem' - PW *y'i(:)- 'that yonder'; * $y$ 'a: 'that'; * $y$ ' $u(:)-$ 'that (near

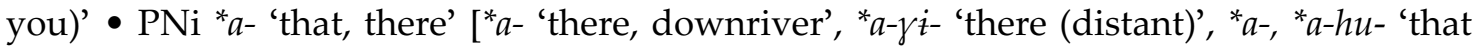
(visible distant)'] - PAlg *ya 'that (personal, extended); then'; *yo 'that (restricted)' [Wi yo 'then', Yu. yo? 'he, she, it'; yu? 'there', etc.] II Nikolaev 2015: 44.

413. PNA * $3 a K E(\sim \ddot{a}, X)$ 'to stick in' $\bullet \mathrm{PNi}{ }^{*} c a \gamma$-a- 'to stick in' $\bullet \mathrm{PA}$ *sa:k- 'to protrude, emerge' [Men. sa:k-a:p-et-cw 'to teethe', WOj. sa:k-ekk-i 'it grows forth', etc.].

414. PNA *3aXkA ( $\ddot{a})$ 'cradleboard' - PNi *caq 'cradleboard' • PA *tehk- 'to tie on the cradleboard', *tehk-in-a:-kan- 'cradle board' [Cree tihk-in-a:-kan, WOj. tekk-in-a:-kan 'cradle', Men. tchk-e: $w$ 'he is tied to the cradleboard', etc.].

415. PAW ${ }^{*} 3 A$ : $k E$ 'bear' $\bullet \mathrm{PWN}{ }^{*} s a: k$ - 'grizzly bear' $\bullet \mathrm{PNi}{ }^{*} c x i-f$ 'brown bear'.

416. PAW ${ }^{*} 3 i k^{\prime w} E$ 'tree' - PW *suk'- 'tree' - PNi *cij-r, ${ }^{*} c x a-r$ 'tree' $\diamond$ Cf. PSI *caq 'tree' \|| Nikolaev 2015: 44.

417. PAW *3i:pV *3i:pV 'k. of bird' • PWN *su:p-, *cu:p- 'robin (Turdus migratorius)' • PNi *cev$r-q$ 'bird (singing, generic)' $\bullet$ PAlg ${ }^{*} c-e \gamma-e p-(\sim c h, p h)>$ PA *si:p-e:hs- 'bird (generic)' [Ab. sib-es, etc.] II Nikolaev 2015: 36.

418. PAW ${ }^{*} \breve{z} A: \eta k^{w} V\left(\sim k^{w}\right)$ 'straight, extended' - PWN *3a: $k^{w}$ - 'to straighten out, extend (leg, knife), to spread apart with the hands' $\bullet$ PA *šenk- 'straight, extended (lying)' [Cree sihkis-em-e:w 'to lay down', Fox še:k-iš-ik-a 'one who lies down', WOj. šenk-ǐšs-in 'to lay down', etc.].

7 P. Proulx (1994, \#370) traces PA *i:yaw- 'flesh; body' and Yu. tew-on, -tew 'flesh' to PAlg *we-Tewi, *w-eyeTawi '(her) flesh, body'. Here, however, sound correspondences are "reverse", because PAlg *T=*d regularly changes to $2 / \varnothing$ in Yurok and Wiyot and not in Proto-Algonquian. 
419. PAW *ร̌ $[e:] G^{w} A$ 'spear, point, knife' $\bullet \mathrm{PWN}^{*} 3 i: q^{w}$ - 'spear, point, prong' • $\mathrm{PNi}{ }^{*} c a q-o$ 'knife'. 420. PAW * *̌ $u$ : 'fish, salmon' • PW * $3 u:-x^{w}-$ 'cohoe salmon' • PNi *cho 'fish' $\diamond$ Cf. PS *caw'i-n 'cohoe salmon' || Nikolaev 2015: 39.

421. PAW *-Vy- 'infix: plural' $\bullet$ PWS *-ay'- or *-ay- 'plural infix' $\bullet$ PAlg *-ej- 'plural infix'.

422. PNA *-VhrV 'diminutive suffix' - PNi morphs ${ }^{*}-r$ and ${ }^{*}-\check{r}$ in animal names : *qhot- $r$ 'bear',

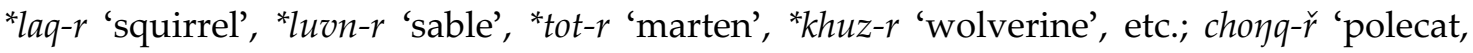
weasel', * lij-řr 'wolf', etc. • PA *-e:hš- 'diminutive suffix, esp. in animal and bird names': *wa:kw-e:hš-a 'fox', *penkw-e:hš-a 'gnat', ‘̌̌a:nkw-e:hša 'mink', "ko:hko:-hš-a 'pig', also *makwehš-e:w-en-i 'feast, banquet' (from *makw- 'grease').

423. PAW *-VhmV 'diminutive suffix' - PWN *-hm 'diminutive suffix' • PAlg *-Vm-c- (suff.) 'diminutive suffix' [Wi. -ác-, -íc-, Yu. -os-, -es-, PA *-ens-].

\section{Index of lexical meanings}

ABDOMEN - PAW *?Vda:k'A *2Vt'a:gA 'belly, abdomen' 40

ABOVE - PAW *2i:k’ $\sim{ }^{*} k^{\prime} i: ? V 24 \bullet \mathrm{PAW}{ }^{*} k^{\prime} i: \approx * 2 i: k ’ V 173$

ADZE - PAW *či: $\gamma^{w} V 87$

ALL - PAW *2a:gV *ya:gV ( a:) $7 \bullet$ PNA *ček’E ( *̌c', g, q') 83・PAW * $\eta^{\prime} \dot{t}: m^{\prime} V \sim{ }^{*} m^{\prime} \dot{t}: \eta^{\prime} V 272$

ALL THE TIME , ALMOST - PAW * $₹ O x^{w} V$ 'almost, all the time' 212

ALONG - PAW * $p^{\prime} E 303$

ALONG WITH - PAW * $k E(\sim g) 159$

ANGRY - PAW *2OmV 34

$\mathrm{ARM}-\mathrm{PAW}{ }^{*} d \dot{t}: \mathrm{mG}^{w} E\left(\sim q^{\prime w}\right) 103 \bullet \mathrm{PAW}{ }^{*} n^{\prime} \mathrm{OLK}\left({ }^{w}\right) V\left(\sim n^{\prime}\right)$ 'hand, arm' $250 \bullet \mathrm{PNA}{ }^{*} t^{\prime} V P O t^{\prime} V$

$(\sim d) 360$

ASHES - PNA * $p V l-\partial \eta V-k^{\prime w} E 300$

AUNT - PAW *2amV 'mother, aunt' 18

BACK (ADV.) - PNA *wa:lwV ( w', ä:) ‘back, behind' 362

BACKBONE - PAW * $\chi a: r g A(\sim k ’) 395$

BAD - PAW * $y^{\prime} ə: k^{\prime} E \sim{ }^{*} k^{\prime} \partial: y^{\prime} E 409$

BARK (DOG) - PAW *wa:nkE $374 \bullet$ PAW * w'a:yV 383

BARK (TREE) - PAW * $\chi e: r g^{w} A \sim{ }^{*} g e: r \chi^{w} A 397$

BE IN A POSITION, BE SUCH AS - PAW *la 'to be in a position, be such as' 190

BEAR (N.) - PAW *mulq' ${ }^{*}$ ) $E 229 \bullet$ PAW ${ }^{*} 3 A: k E 415$

BEAST OF PREY - PAW * $y a: h V 259$

BEE - PAW * $x^{w} O: \eta V \sim{ }^{*} \eta O: x^{w} V 393 a$

BEFOREHAND - PAW * ${ }^{2} i w z V g^{w} E\left(\sim \check{z}, k^{w}\right) 27$

BEHIND - PNA *wa:lwV ( w', ä:) 'back, behind' 362

BELIEVE - PAW *2ä: $q^{\prime w} A 12$

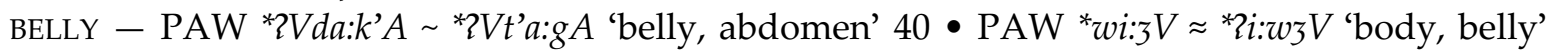
378

BELOW - PAW * $m$ 'O:?V $\approx{ }^{*} h O: 2 m^{\prime} V 240$

BEND - PAW * $k^{\prime w} i: 3 V$ 'to bend, fold' 186

BERRIES (KIND OF) - PAW *2VオV:nQ $Q^{w} V 48 \bullet$ PAW ${ }^{*} h A q A g V\left(\sim k^{\prime}\right) 137 \bullet$ PAW ${ }^{*} \eta i: r g{ }^{w} V 263 \bullet$

PAW *'t'mV $(\sim) 352$

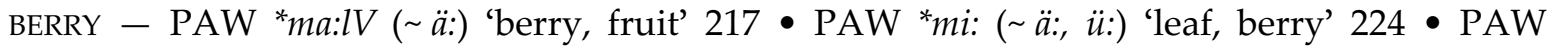

*(2V)m’A:nš $V$ 'flower, berry' $235 \bullet$

BIG - PNA *mangA ( m’, ä, k’, q’) 'big, main’ 214・PNA *p'i:lV ( e:) 305 
BIRD (KIND OF) - PAW *n'i:n’V( ń') $248 \bullet \mathrm{PNA}{ }^{*} p i s ̌ k^{\prime w} E\left(\sim \check{c}^{\prime}, q^{\prime w}\right) 285$

BIRD (LARGE) - PAW * $p o: l V \approx * 20: l p V 290$

BIRD (SMALL) - PAW ${ }^{*} c^{\prime} \ddot{a}: q^{w} A,{ }^{*} c^{\prime} V: c q^{\prime w} A 77 \bullet$ PAW * $3 i: p V \sim{ }^{*} z i: p V 417$

BIRD OF PREY - PNA * $k$ Vla $V w V \sim{ }^{*} k V \eta a l V w V(\sim \ddot{a}) 165$

BITE - PAW * q'anz $V \sim{ }^{*}$ Ganz $V(\sim c, s)$ 'to eat, bite' 315

BLADDER (FISH) - PAW *puq'A ( G) 'fish bladder' 296

BLEED - PAW ${ }^{*} b O \sim{ }^{*} p O 68$

BLINK - PAW *p'OLV 'to blink, close eyes' 307

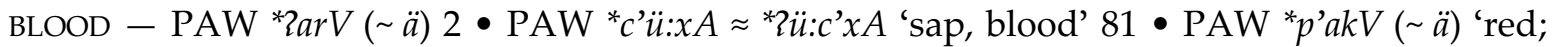

blood' 302

BLOW (WIND) - PAW *la:yVwV 'wind; to blow (wind)' 192

BLOW (WITH MOUTH) - PAW *bu: *pu: 'to blow (with mouth); swell' 70

BLUE - PAW * $m$ 'äwg ${ }^{w} E 237 \bullet P A W{ }^{*} q^{w} \ddot{a}: l V \sim{ }^{*}{ }^{w} w \ddot{a}: l V(\sim q)$ ‘blue, green' 325

BOAT - PAW ${ }^{*} x^{w} a: \lg ^{w} V\left(\sim-k^{w_{-}}\right) 390$

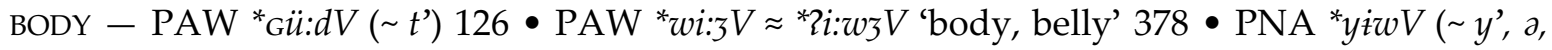

$w$ ') 'body, intestines' 404

BOIL (VB.) - PAW * $q^{\prime w}$ orV 335

BONE - PAW *qVq'( $\left.{ }^{*}\right) E \approx *^{*} 2 V q q^{\prime}\left({ }^{w}\right) E 213 \bullet P A W{ }^{*} \chi o: c k ' E(\sim \check{c}, s, \check{s}) 398$

BORROW - PAW ${ }^{*} \lambda a: \eta g^{w} V 200$

BOWELS - PAW ${ }^{*} q^{\text {wwo}} 0 \eta w V \sim{ }^{*} q^{w}$ o $w w V$ 'liver, bowels' 334

BOX - PNA *waNXKA $\left(\sim w^{\prime}\right) 365$

BREAK - PAW * ${ }^{\prime} \dot{t}: T q^{w} E 306$

BREAST - PAW *t'ə:qE $\approx{ }^{*}$ ?z:t' $q V$ 'chest, breast' 349

BREAST (FEMALE) - PAW *nowV $\approx$ *?onwV 'to suck; breast' 246

BREATHE - PAW ${ }^{*} h A: s V 141$

BROOD - PNA *2o: $w V\left(\sim w^{\prime}\right)$ 'egg, brood' 21

BURN (TRANS.) - PAW ${ }^{*} p O \gamma\left({ }^{w}\right) V \approx{ }^{*} 2 O p \gamma\left({ }^{w}\right) V$ 'to heat, burn' $292 \bullet$ PNA *tOyViwV 345

BURN TO CINDERS - PAW ${ }^{*} q^{w} e: l V(\sim q) 328$

CALL - PAW *we: *2e:wV 371

CAP - PNA *haGA $(\sim \ddot{a}, q$ ') 'cap, headdress' 133

CAPE - PAW *we: $q^{w} E\left(\sim q^{\text {ww }}\right)$ 'nose, cape' 373

CARRY - PAW ${ }^{*} B n V \sim{ }^{*} B^{w} V n V\left(\sim\right.$ ń) $127 \bullet \mathrm{PAW} * h i n V(\sim e) 150 \bullet \mathrm{PNA}$ *ńegV $\left(\sim n^{\prime}\right) 252 \bullet \mathrm{PNA}$

${ }^{*} t O \approx{ }^{*} \mathrm{O} t V 343 \bullet \mathrm{PAW}{ }^{*} t^{\prime} i: x E 351 \bullet \mathrm{PAW}{ }^{*} y^{\prime} i l{ }^{w}{ }^{w} E\left(\sim k^{* w}\right) 410$

CARRY ON ONE'S BACK - PAW *homV 152

CAT (WILD) - PNA *Kǐc $V(-K E)(\sim Q, X) 166$

CHEAT - PNA *walyV̌̌V $(\sim$ w', ä) 364

CHEST - PAW *t'ว:qE $\approx$ *2ว:t'qV 'chest, breast' 349

CHIEF - PAW * $k A: m V 157$

CLAW - PAW * ${ }^{\prime} ' t: k^{\prime w} E \sim{ }^{*} k^{\prime w} i: t^{\prime} V^{\prime}$ 'nail, claw; peg' 354

CLEAN (VB.) - PAW ${ }^{*} C^{\prime} u: b^{w} A\left(\sim \check{c}^{\prime}\right)$ 'to wash, clean' 80

CLOD - PAW * $\eta$ igE $(\sim k$ ') 'rock, clod' 264

CLOSE EYES - PAW *p'OLV 'to blink, close eyes' 307

CLOUD - PAW *2ä:lVw'adV $\chi E 11 \bullet$ PAW *2VwO:nV $(\sim \eta)$ 'cloud, fog' 54

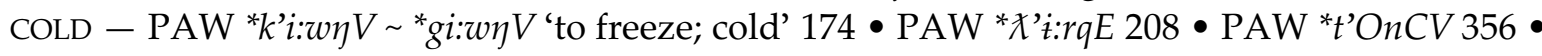

PAW * $w^{\prime} V d V 387$

COUGH $-\mathrm{PAW}{ }^{*} l^{\prime} E \chi^{w} A \approx{ }^{*} 2 E \chi^{w} l^{\prime} A 196 \bullet \mathrm{PAW}{ }^{*} w^{\prime} A P s V(\sim K s) 382$

COVER (VB.) - PNA *pedV ( t’) 278

CRADLEBOARD - PNA *3aXkA $(\sim \ddot{a}) 414$ 
CRANE - PNA *wa:ncVKA ( w', n', $Q, X)$ 'heron, crane' 368

CRAWL - PAW * $\gamma^{w} u l V$ 'to crawl, go on all fours' 120

CREAK - PAW * $k$ ' $\left({ }^{w}\right) E k A$ 'to squeak, creak' 181

CROW - PNA *2a:ndVXKE ( $\left.\ddot{a}:, t^{\prime}\right)$ 'raven, crow' 8

CURLY - PAW ${ }^{*} k^{\prime}$ in $x^{w} V \sim{ }^{*}$ ginx $x^{w} V(\sim e) 172$

CUT IN TWO - PAW * $q^{w}$ odV $\left(\sim t^{\prime}\right)$ 'to cut in two; middle, other' 329

DANCE - PAW ${ }^{*} t^{\prime} \partial m q^{w} E(\sim e) 348$

DARK - PAW ${ }^{*} q^{s}{ }^{w}: q^{\prime w} E\left(\sim-G^{w}-\right) 336$

DARK (AS THE NIGHT) - PAW * $d A: p ' V 98$

DAY - PNA * $k^{w}$ onV $\left(\sim q^{w}, n\right.$ ') 'light; day' 180

DEEP - PAW *pewV $(\sim i) 280$

DEER - PAW *2VtOk ${ }^{w} A 53 \bullet P A W{ }^{*} m u: w V(\sim o:)$ 'deer, elk’ 230

DEFECATE - PAW *di: $\chi V$ 'to defecate, urinate' 102

DEMONSTRATIVE STEM - PAW * $d V 107 \bullet \mathrm{PAW}{ }^{*} g V \sim{ }^{*} g^{w} V 108 \bullet \mathrm{PAW}{ }^{*} h V 156 \bullet \mathrm{PAW}{ }^{*} w^{\prime} V 386$

- $\mathrm{PAW}{ }^{*} y^{\prime} V 412$

DIE - PAW *'́'AbV ( p') 255・PNA *mo:ryV ( m') 227

DIG - PAW ${ }^{*} t^{\prime} \ddot{u}: g^{w} E\left(\sim k^{* w}\right) 358$

DIMINUTIVE SUFFIX - PAW *-VhmV $423 \bullet$ PNA *-VhrV 422

DIP - PAW *hObV $\left(\sim p^{\prime}\right) 153$

DIRT - PAW *̌c' $A k^{w} V \approx{ }^{*} h A \check{c}^{\prime} k^{w} V 92$

$\operatorname{DIRT}(\mathrm{Y})$ - PAW *mü: 231

DOG - PAW *q'änV 316・PNA *2aLVmV $\left(\sim \ddot{a}, m^{\prime}\right) 1$

DOOR - PNA *day ${ }^{w} V(\sim \dot{t})$ 'opening, door' 99

DOWN - PAW *bVN'V $72 \bullet \mathrm{PAW}{ }^{*} n^{\prime} i:\left(\sim n^{\prime}, e:\right) 247$

DREAM (VB.) - PAW *po:wV ( b) 291

DRESS (VB.) - PNA *we:dV ( w', t’) 372

DRINK - PAW *hak ${ }^{\text {ww } E \sim ~ * ~} k^{\text {sw }} \partial h E \approx{ }^{*} 2 a h k^{\text {ww } E}$ 'to drink; water' 144

DRY (ADJ.) - PAW * $k^{w} a: r k A$ 'dry' 175

DRY (VB.) - PNA *Ci(:) ( e [:]) 'to dry' 82

DUCK - PAW * $2 A w V N N^{w} E$ 'duck' 5

DWELL - PAW * ${ }^{*} w: K V 119$

EAR - PAW *hA:tV $\left(\sim t^{\prime}\right) 142 \bullet \mathrm{PAW} * 2 a m E-l V 221$

EARLY - PNA *nabV ( n', $\ddot{a}, p$ ') 'early' 242

EARTH - PAW *'⿳亠口 $A k^{w} V \approx{ }^{*} h A \check{c}^{\prime} k^{w} V 92 \bullet \mathrm{PAW}{ }^{*} m^{\prime} e: \approx{ }^{*} 2 e: m$ ' $V$ 'earth, land' 238

EAT - PAW * m'a: $h V \approx{ }^{*} h a m$ 'V $234 \bullet$ PNA *nit: ( n') $253 \bullet \mathrm{PAW}{ }^{*} q^{\prime} a n_{3} V \sim{ }^{*}{ }_{\mathrm{G} a n z} V(\sim c, s)$ 'to eat, bite' 315

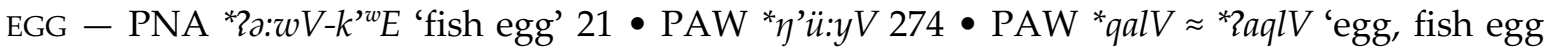

$308 \bullet$ PNA *2a: $w V\left(\sim w^{\prime}\right)$ 'egg, brood' 21

ELBOW - PNA *t'Omk'A( q’) 355

ELK - PAW *mu:wV $(\sim 0:)$ 'deer, elk' 230

EXTENDED - PAW * ${ }^{*} A: \eta k^{w} V\left(\sim k^{w}\right)$ 'straight, extended' 418

EYE - PAW *2A\&V 3

EYEBROW, EYELASH - PNA *čVXapV $(\sim \check{c}$ ', i) 'eyebrow, eyelash' 91

FACE - PAW *2A:sV 4 PNA *2i:ńgE $30 \bullet$ PNA *2O:čk'E 'head, face’ 36

FAR - PAW ${ }^{*}$ GAyV $126 \mathrm{a}$

FAST - PAW *yixA 'quick, fast' 405

FAT (N.) - PAW ${ }^{*} B^{w} 0: l V(\sim \dot{i}) 132 \bullet$ PNA ${ }^{*} \eta O k^{w} A\left(\sim \eta\right.$ ', $\left.q^{w}, X\right)$ 'fat, grease' 265

FEAR - PAW ${ }^{*} k E l V 160 \bullet$ PNA ${ }^{*} c^{\prime} \partial q^{\prime w} E \sim{ }^{*} 3 \partial q^{\prime w} E 78$ 
FEATHER $-\mathrm{PAW}{ }^{*}$ mi $\chi E \approx$ * im $\chi E$ 'hair, feather' 226

FIND OUT - PAW * walx ${ }^{w} E(\sim) 363$

FIRE - PAW ${ }^{*} 2 a \eta V\left(-k^{\text {ww }} E\right)$ 19 $\bullet \mathrm{PAW}{ }^{*} m E$ : 'to flame, fire' 220

FISH - PAW *̌̌u: 'fish, salmon' 420

FISH (KIND OF) - PAW * Gu:lV ( t) 124

FISH WITH LINE AND HOOK - PNA *kerčk'w $A\left(\sim q^{w}\right) 158$

FLAME (VB.) - PAW * $m E$ : 'to flame, fire' 220

FLAT - PAW * $p A l$ ' $V$ 'thin and flat' 277

FLEE - PNA * $2: m V(\sim m$ ') 15

FLESH - PAW *di:s ${ }^{w} V \sim{ }^{*} d i: G^{w} V(\sim \ddot{a}:)$ 'meat, flesh' 101

FLOOD (VB.) - PAW * po:lV ( ₹) 289

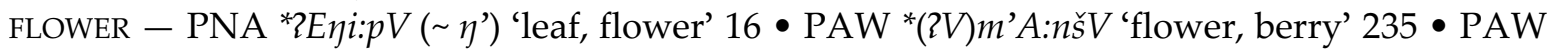

* $p$ Vlayq'A 'leaf, flower' 299

FLY (N.) - PNA *ping ${ }^{w} E(\sim e)$ 'fly, gnat' 284

FLY (VB.) - PAW * n'o:lV 249

FOAM - PNA *bü:PTV $\left(\sim p^{\prime}\right) 71$

FOG - PAW *2VwO:nV $(\sim \eta)$ 'cloud, fog' 54

FOLD (VB.) - PAW ${ }^{*} k{ }^{\text {w }} \dot{i}: 3 V$ 'to bend, fold' $186 \bullet$ PAW * $q$ 'V:ncV 322

FOOT - PNA *2Vč'kE ( q,X) 'foot, leg' $39 \bullet$ PAW *či:t’V(-lV) 'foot, leg' 86・PAW * $g^{w} i: g^{w} V 117$

FORK - PNA *waTVrk'ańV ( w’) 366

FOUR - PAW * $n$ 'i-y'E:wV, * $m V-y^{\prime} e: w V 408$

FOX - PNA * $\chi^{w} \ddot{a}: g^{w} A\left(\sim x^{w}-\right) 402$

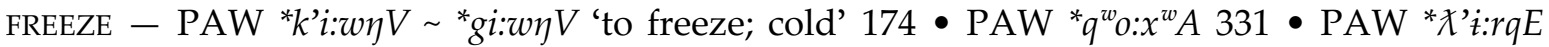
208

FRUIT - PAW *ma:lV ( ̈̈:) 'berry, fruit’ 217

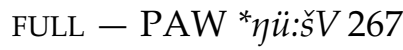

FUR GAME (KIND OF) - PAW *ni:K ${ }^{w} V 243 \bullet$ PAW * $\eta^{\prime} \dot{t}: 271$

FUR - PAW * $\lambda \ddot{u}: \chi V \sim{ }^{*} x^{\prime} \ddot{\prime}: \chi V(\sim q$ ') 'skin, fur' 203

GALL - PAW *tijV $(\sim e)$ 'liver, gall' 341

GIVE $-\mathrm{PAW}{ }^{*} c^{\prime} \mathrm{O} \gamma^{w} V \approx{ }^{*} 2 \mathrm{O}^{w}{ }^{w} V\left(\sim H^{w}\right) 95 \bullet \mathrm{PNA} * m i: \approx * 2 i: m V\left(\sim m^{\prime}\right) 225$

GNAT - PNA *ping ${ }^{w} E(\sim e)$ 'fly, gnat' 284

GO - PAW *ha: ( o:) $139 \bullet$ PAW *wi ( e) 'to walk, go' 375

GO AND DO - PAW * $\eta$ 'a: 'to go with, go and do' 269

GO ON ALL FOURS - PAW * $\gamma^{w} u l V$ 'to crawl, go on all fours' 120

GO OUT - PAW *bu: *pu: 'to go out, leave' 69

GO WITH - PAW * $\eta$ 'a: 'to go with, go and do' 269

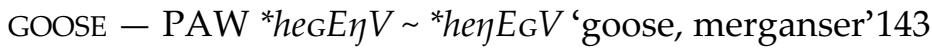

GREASE - PNA * $\eta O k^{w} A\left(\sim \eta\right.$ ', $\left.q^{w}, X\right)$ 'fat, grease' 265

GREEN - PAW * $q^{\prime}$ om $V\left(\sim q^{\prime w}\right) 319 \bullet$ PAW * $q^{w} \ddot{a}: l V \sim{ }^{*} G^{w} \ddot{a}: l V(\sim q)$ ‘blue, green' 325

HAIR - PAW *hapV(lV) 'hair (body, facial)' $145 \bullet$ PAW *mi $\chi E \approx *$ *im $\chi E$ 'hair, feather' 226

HALF - PAW ${ }^{*} q^{w} a K c$ ' $V$ 'half, one of a pair' 323

HAND - PAW *2i:kV ( k’) $23 \bullet \mathrm{PAW}{ }^{*} n^{\prime} \mathrm{OLK}\left({ }^{w}\right) V(\sim$ n') 'hand, arm' 250

HARD - PAW * $q^{w} A T k A$ 'hard, tough' 324

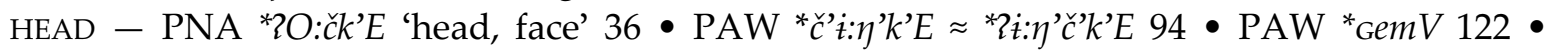

PAW *hü:xE 'head, nape' 155・PAW *t' ${ }^{*} q^{w} E \sim{ }^{*} t \dot{t} q^{w} E 353$

HEADDRESS - PNA *haGA ( $\ddot{a}, q$ ') 'cap, headdress' 133

HEAR - PAW ${ }^{*} m a r V \approx{ }^{*}$ am? $221 \bullet \mathrm{PAW}{ }^{*}$ no: $244 \bullet \mathrm{PAW}{ }^{*} q e: x^{w} A\left(\sim \chi^{w}\right) 312$

HEART - PAW *2epV 13 
HEAT - PAW * $p O \gamma\left({ }^{w}\right) V \approx * 20 p \gamma\left({ }^{w}\right) V$ 'to heat, burn' 292

HERON - PNA *wa:ncVKA ( w', n', $Q, X)$ 'heron, crane' 368

HOLD - PAW ${ }^{*} t e: X q^{{ }^{w}} E 340$

HOLE - PAW *ho VVq'A *hoq'V^A 151

HOLLOW - PAW ${ }^{*} \chi$ urG $^{w} E \sim{ }^{*} \chi u r g{ }^{w} E 400$

HOP ON ONE FOOT - PAW *X'imqA $(\sim e, \mathrm{G}) 207$

HORN - PAW *wi:LV 377

HOT - PAW * $k^{w} \ddot{a}: x^{w} V$ 'warm, hot' 176

HURRY - PNA *hü:mV ( m') 154a

I - PAW *ń 254

INALIENABLE POSSESSION (PREFIX) - PNA * $\eta V-\left(\sim \eta{ }^{\prime}\right) 268$

INTERROGATIVE STEM - PAW ${ }^{*} g^{w} V 118 \bullet$ PAW * $n a \approx * 2 a n V 241 \bullet$ PNA * $t V 346 \bullet \mathrm{PAW}^{*} w V\left(\sim w^{\prime}\right)$

$381 \bullet$

INTESTINES - PNA *yizwV ( y', a, w') 'body, intestines' 404

$\mathrm{JUMP}-\mathrm{PAW}{ }^{*} d i x^{w} A(\sim 0) 104 \bullet \mathrm{PAW}{ }^{*} k^{w} \partial 2 V \approx{ }^{*} 2 \partial k^{w} V 178 \bullet \mathrm{PAW}{ }^{*} t^{\prime} \mathrm{OrV} 357$

KICK - PAW ${ }^{*}$ timQV $(\sim e) 342$

KIDNEY - PNA *2i:LV 28

KILL $-\mathrm{PAW}{ }^{*} \chi V l V \approx * 2 V l \chi V 400 \mathrm{a}$

KNEE - PAW * ${ }^{\prime}$ 'iqE $304 \cdot \mathrm{PAW}{ }^{*} \chi V t V 401 \mathrm{a}$

KNEEL - PAW * ${ }^{\prime} \operatorname{og}^{w} E 209$

KNIFE - PAW *̌̌ $[e:] G^{w} A$ 'spear, point, knife' 419

KNOW - PAW *2O $\chi V d A g\left({ }^{w}\right) V\left(\sim t^{\prime}, k^{\prime}\right)$ 'to know how' $35 \bullet$ PAW ${ }^{*} k^{w} e: m V$ 'to know, understand'

177

LAME - PAW *yOgE ( k') 'to limp, lame’ 407

LAND - PAW *m'e: $\approx{ }^{*} 2 e: m$ ' $V$ 'earth, land' 238

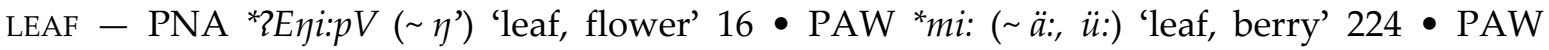

*pVlayq'A 'leaf, flower' 299

LEAK - PAW ${ }^{*} c o: x^{w} E \sim{ }^{*} c ̌ c: x^{w} E$ 'to leak, soak' 76

LEAVE - PAW *bu: * $p u$ : 'to go out, leave' 69

LEG - PNA *2Včk $k E(\sim q, X)$ 'foot, leg' $39 \bullet$ PAW *či:t’V(-lV) 'foot, leg' 86 PAW ${ }^{*} g^{w} i: g^{w} V 117$

LICHEN - PAW ${ }^{*} k^{\prime w} e: T q^{w} V\left(\sim q^{\prime w}\right) 184 \bullet$ PNA *wa:XK'V( w', ä:, $\left.Q^{w}\right)$ 'moss, lichen' 369

LICK - PAW *hi:tV ( e:) 'tongue; to lick' 148

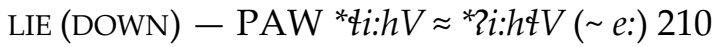

LIGHT - PNA * $k^{w} o n V\left(\sim q^{w}, n\right.$ ') 'light; day' 180

LIMP - PAW *yOgE ( k') 'to limp, lame' 407

LIP - PNA*2i:ptV 'lip, tip of tongue' 31

LIQUID - PAW *w'e: $p V \sim{ }^{*} p e: w$ ' $V$ 'water, liquid' 384

LIVER - PAW ${ }^{*} q^{\prime w} o \eta w V \sim{ }^{*} q^{w}$ o $o w V$ 'liver, bowels' $334 \bullet$ PAW ${ }^{*} r^{\prime} a: q^{\prime w} A \approx{ }^{*} z a: r^{\prime} q^{\prime w} A(\sim$ o:) $338 \bullet$

PAW *tig $V$ 'liver, gall' 341

LOAD (VB.) - PAW * m'A:w’V 236

LONG - PAW * gilV ( a) 113

LOOK - PAW *n'e:(wV) 'to see, look' 256

LOOK FOR - PAW * ${ }^{*}: x E \approx * 2 e: \rtimes x E$ 'to look for, watch' 204

LOOSE - PAW ${ }^{*} k$ 'E:š $V 170$

LOUSE - PAW *hi:rxk'E 149

LUNGS - PNA *hapV $(\sim \ddot{a}) 133$

MAIN - PNA *mangA ( m', ä, k', q') 'big, main' 214

MAN - PAW * $2 \ddot{u}: t O q^{\text {ww } E} 38$ 


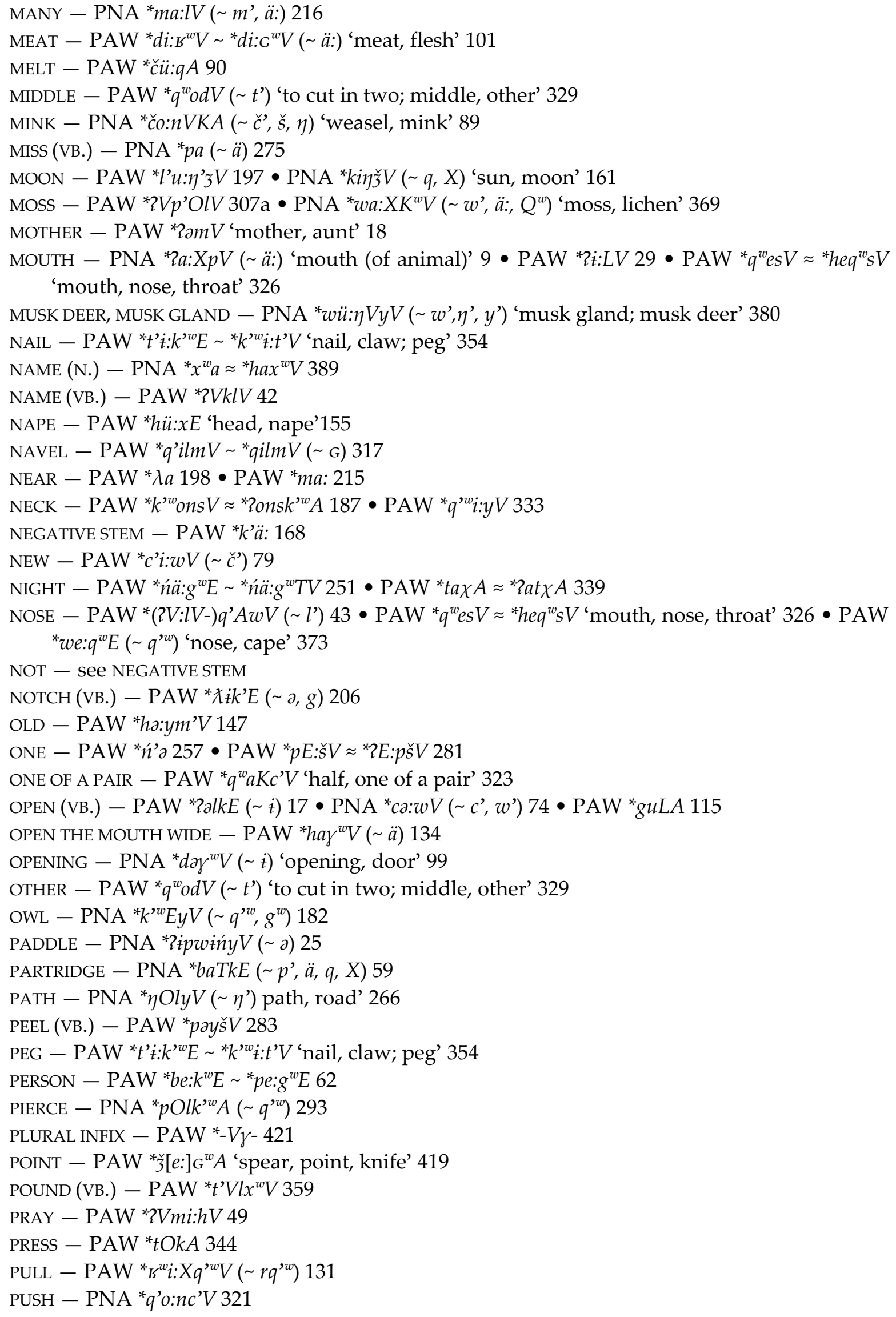




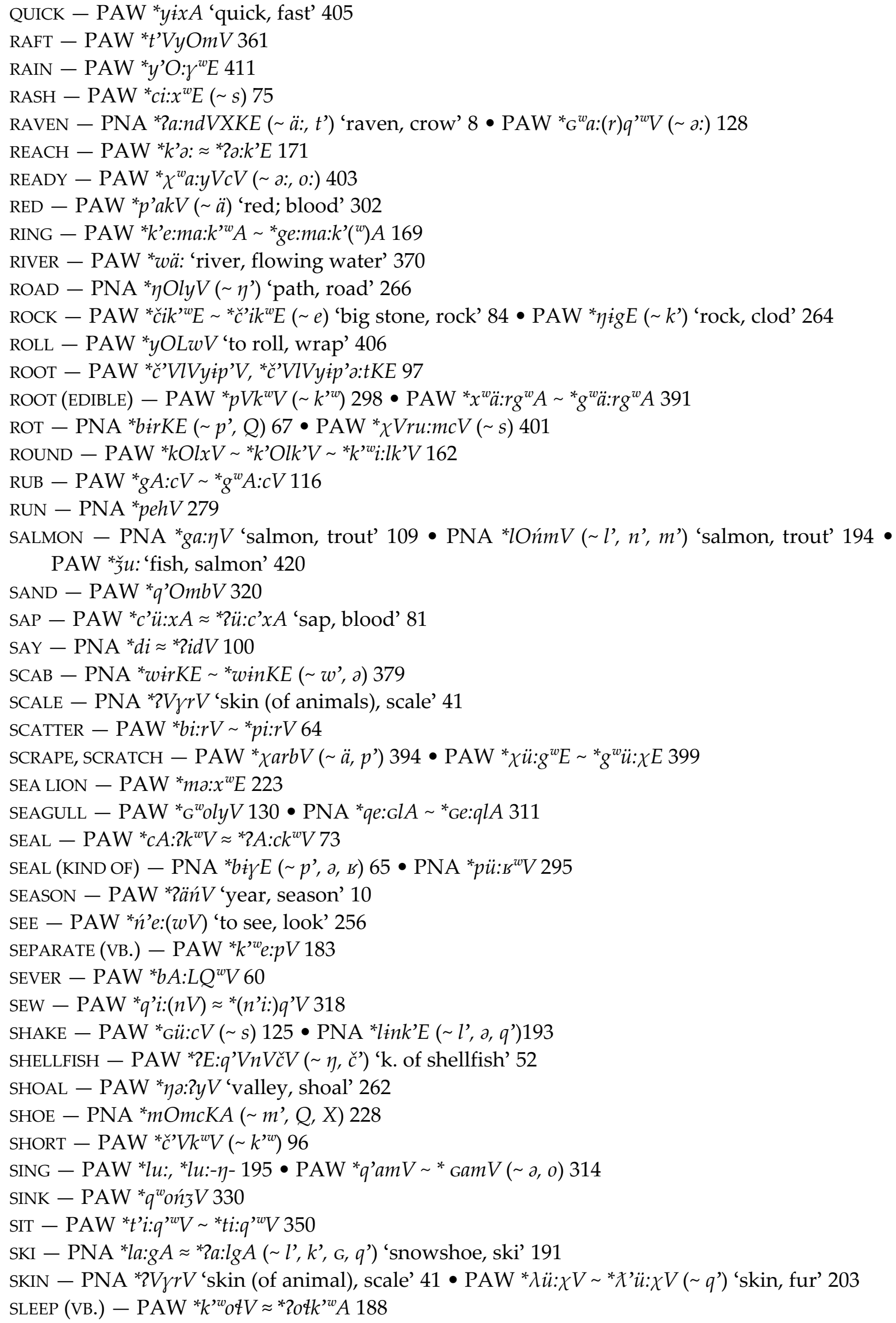


SLIDE (VB.) - PAW * $l V x E$ 'to slip, slide' 195a

SLIP - PAW *čo:2xE 88 • PAW *lVxE 'to slip, slide’ 195a • PNA *wiXca:rV ( w', e, q', c’) 376

SLOW - PNA * $b \ddot{a}: d V\left(\sim p^{\prime}, t^{\prime}\right) 61$

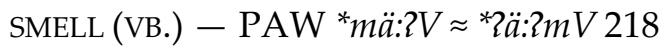

SMOKE (PRODUCE OR USE) - PAW * w'e:šq' $V$ 'to produce or use smoke' 385

SNAIL - PAW * $q^{\prime w} i \eta V$ 'snake, snail' 332

SNAKE - PAW ${ }^{*} q^{\prime w}$ i $\eta V$ 'snake, snail' 332

SNOW - PAW * $\eta A \mathrm{G} A(\sim q$ ') 258

SNOWSHOE - PNA *la:gA $\approx$ *2a:lgA ( l', k', G, q') 'snowshoe, ski' 191

SOAK - PAW ${ }^{*} \operatorname{co:}: x^{w} E \sim{ }^{*} c ̌ c: x^{w} E$ 'to leak, soak' 76

SPEAK - PAW *Ga: $4 V 121$

SPEAR - PAW *qa ${ }^{*} l A(\sim \ddot{)}) 309 \bullet \mathrm{PAW} *$ ऊ̌[ $[e:] G^{w} A$ 'spear, point, knife' 419

SPIRITUAL POWER - PAW ${ }^{*} \lambda i: g^{w} E 201 \bullet$ PNA * $m V N V C V\left(\sim m^{\prime}, N^{\prime}\right) 232$

SPLIT - PAW *padV $\left(\sim i, t^{\prime}\right) 282 \bullet \mathrm{PAW}{ }^{*} p V_{\boldsymbol{B}} V 301$

SPOON - PNA *2Vmiy $X^{w} E\left(\sim m^{\prime}, K^{w}\right) 50$

SPOTTED - PNA *t'arV $(\sim \ddot{a}) 347$

SPREAD - PAW *pirV $(\sim$ a) 288

SQUEAK - PAW * $k$ ' ${ }^{(w)} E k A$ 'to squeak, creak' 181

SQUIRREL - PNA * 2 Vlyak'w $A\left(\sim q^{\text {ww }}\right) 45$

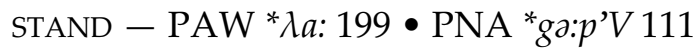

STAR - PNA * $20: n ́ k^{w} E\left(\sim q^{w}, X^{w}\right) 33$

STICK IN - PNA *3aKE $(\sim \ddot{a}, X) 413$

STONE - PAW ${ }^{*}{ }^{\prime} i k^{\prime w} E \sim{ }^{*}{ }^{*}$ ' $i k^{w} E(\sim e)$ 'big stone, rock' 84

STONE SUITABLE FOR MAKING TOOLS - PNA * $\left.{ }^{*} \dot{i} L V-l V k{ }^{\prime}{ }^{w}\right) E(\sim$ ) 287

STOOP - PAW ${ }^{*} k^{w}$ OmV 179

STRAIGHT - PAW *̌̌ A: $y k^{w} V\left(\sim k^{\prime w}\right)$ 'straight, extended' 418

STRETCH - PNA *či:pV *pi:čV $(\sim \check{s}) 85$

STRONG - PNA *dO:nXE ( t', K) 106

SUCK - PAW *nowV $\approx{ }^{*}$ ?onwV 'to suck; breast' 246

SUFFER - PAW *y'e: $\chi E \approx * 2 e: y$ ' $\chi E$ 407a

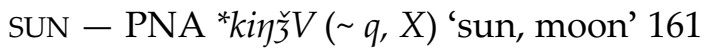

SUSPECT - PAW ${ }^{*} g o: l ’ V 114$

SWALLOW (VB.) - PAW ${ }^{*} \eta^{\prime} i: q^{\text {ww}} V 273$

SWELL - PAW *bu: *pu: 'to blow (with mouth); swell' 70

SWIM - PAW *ma:rV 222

TAIL - PAW * $\eta^{\prime} \partial: g E\left(\sim k^{\prime}\right) 270$

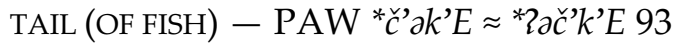

TELL - PNA * $d i \approx *$ *idV 100

THAT - SEe DEMONSTRATIVE STEM

THICK (CLOTH) - PNA *KVdibV $\left(\sim t^{\prime}, p^{\prime}\right) 167$

THIN (FLEXIBLE OBJ.) - PAW ${ }^{*} p O: k V\left(\sim b, k^{\prime}\right) 294$

THIS - SEe DEMONSTRATIVE STEM

THINK - PNA *2o:lV ( l') 20

THOU - PAW * $k V$ 'you (sg.), thou' 164

THREE - PAW ${ }^{*}$ gilV $\left(\sim \ddot{a}, l^{\prime}\right) 112$

THROAT - PNA *qü:rV $(\sim x, \chi) 313 \bullet \mathrm{PAW}{ }^{*} q^{w} e s V \approx{ }^{*} h e q^{w} s V$ 'mouth, nose, throat' 326

THROW - PNA *biKE ( p', a, Q, X) 66

THUNDER - PAW *ti:yV 211 
THUS - PNA *iilV $(\sim e) 22$

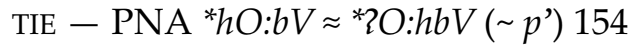

TIGHT (FABRIC) - PNA *KVdibV $\left(\sim t^{\prime}, p^{\prime}\right) 167$

TIME - PAW * ${ }^{*} a: G^{w} E 337$

TOGETHER - PAW * $\lambda$ orV 202

TONGUE - PAW *hi:tV ( e:) ‘tongue; to lick' $148 \bullet$ PNA*2i:ptV 'lip, tip of tongue' 31

TООТН - PAW * ${ }^{*} i: g E 123 \bullet \mathrm{PAW}{ }^{*} x E c V \approx{ }^{*} 2 \operatorname{ExcV}(\sim s) 388$

TOUCH - PNA *do:nKA ( t’) 105

TOUCH WITH THE HANDS - PAW * $m$ 'a 233

TOUGH - PAW * $q^{w} A T k A$ 'hard, tough' 324

TRACK, TRAIL - PNA * $y \ddot{a}: c V(\sim c$ ') 'track, trail' 261

TREE - PAW ${ }^{*} p i: x k^{\prime w} E$ 'tree, willow' $286 \bullet P A W{ }^{*} 3 i k^{\prime w} E 416$

TROUT - PNA *ga: $\eta V$ 'salmon, trout' $109 \bullet$ PNA *lOńmV ( l', n', m') 'salmon, trout' 194

TURN - PAW * $x^{w} i:$ tV 393

TWO - PAW *me: 219

UNDERSTAND - PAW * $k^{w} e: m V$ 'to know, understand' 177

URINATE - PAW *di: $\chi V$ 'to defecate, urinate' $102 \bullet$ PAW ${ }^{*} g a ̈ l q^{w} E \sim{ }^{*} k$ 'älq ${ }^{w} E 110$

USE - PNA * $i \dot{i} w V(\sim a, w$ ') 26

VALLEY - PAW * ya:?yV 'valley, shoal' 262

VOICE - PAW *we: * $2 e: w V 371$

VOMIT - PAW *2erV 14

VULVA - PAW * $y a: x^{\prime} x^{w} A 260$

WAIT - PAW *nowgE $\left(\sim k^{\prime}\right) 245$

WALK - PNA *be:lV $63 \bullet$ PAW *qa:rV $310 \bullet$ PAW *wi ( e) ‘to walk, go' 375

WARM - PAW * $k^{w} \ddot{a}: x^{w} V$ 'warm, hot' 176

WASH - PAW ${ }^{*} C^{\prime} u: b^{w} A\left(\sim \check{c}^{\prime}\right)$ 'to wash, clean' 80

WATCH - PAW * $\chi e: x E \approx * 2 e: \chi x E$ 'to look for, watch' 204

WATER - PAW ${ }^{*} h \partial k^{\prime w} E \sim{ }^{*} k^{\text {ww}} \partial h E \approx{ }^{*} \partial h k^{\prime w} E$ 'to drink; water' $144 \bullet$ PAW *wä: 'river, flowing wa-

ter' $370 \bullet \mathrm{PAW}{ }^{*} w ' e: p V \sim$ * $p e: w$ ' $V$ 'water, liquid' 384

WE - PAW * $m^{\prime} i(\sim e) 239$

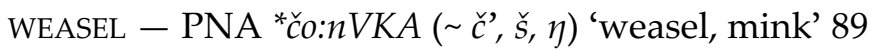

WHALE - PAW ${ }^{*}{ }^{w} i: 129$

WHAT - SE INTERROGATIVE STEM

WHISTLE (VB.) - PAW ${ }^{*} x^{w} i: y V 392$

WHO - SEe INTERROGATIVE STEM

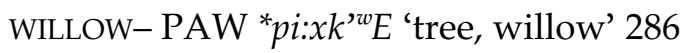

WIND - PAW *la:yVwV 'wind; to blow (wind)' 192

WITHER - PAW ${ }^{*} b a \sim{ }^{*} p a 58$

WOLF - PAW *2O:l'i: $k E\left(\sim k\right.$ ') $46 \bullet \mathrm{PAW}{ }^{*} k^{\prime w} \mathrm{OcV}(\sim s, \check{s})$ 'wolf, wolverine' 189

WOLVERINE - PAW ${ }^{*} k{ }^{\prime w} \mathrm{O} V(\sim s, \check{s})$ 'Wolf, wolverine' 189

WOMAN - PAW *tä $\eta V-k$ ' $\left({ }^{w}\right) V \approx{ }^{*}\left\{a ̈ t \eta V-k ’\left({ }^{w}\right) V 209\right.$ a

WORM - PAW ${ }^{*} k{ }^{\prime w} i l V \eta V(\sim a) 185$

WORRY - PAW * $q^{w} E: c V(\sim s) 327$

WRAP - PAW * $y O L w V$ 'to roll, wrap' 406

YAWN - PAW ${ }^{*} h a \gamma^{w} V(\sim \ddot{a}) 134$

YEAR - PAW *qäńV 'year, season' 10

YES - PAW *ha:?V *2a:hV 146

YOU (SG.) - PAW * $k V$ 'you (sg.), thou' 164 


\section{Language abbreviations and sources}

Ab. - Abenaki, acc. to O. Mudrak's comparative Proto-Algonquian database.

Am. - Amur Nivkh.

Arapaho - acc. to Salzmann 1983.

Blackfoot - acc. to Proulx 1989 and Hewson 1993.

Chem. - Chemakum, acc. to Powell 1993 and Boas 1892.

Cheyenne - acc. to Fisher, Leman, Pine, Sanches 2004 and Hewson 1993.

Cree - acc. to Hewson 1993.

Delaware - acc. to O’Meara 1996.

EOj. - Eastern Ojibwa, acc. to O. Mudrak's comparative Proto-Algonquian database.

Fox - acc. to Hewson 1993 and O. Mudrak's comparative Proto-Algonquian database.

Ha. - Haisla, acc. to Linkoln, Rath 1980.

He. - Heiltsuk, acc. to Linkoln, Rath 1980.

Kickapoo - acc. to Voorhis, 1988.

Kw. - Kwak'wala (Kwakiutl), acc. to Linkoln, Rath 1980.

Men. - Menominee, acc. to Hewson 1993 and O. Mudrak's comparative Proto-Algonquian database.

Miami - acc. to Baldwin, Costa 2005.

Mic. - Micmac (Mi'kmaq), acc. to O. Mudrak's comparative Proto-Algonquian database.

Natick - acc. to Aubin 1975.

NiY - "Nivkh of Yukaghir borrowings", the hypothetical Northern Sakhalin language. Forms are given acc. to O. Mudrak's comparative Yukaghir database jukaet.dbf.

Oj. - Ojibwa, acc. to Hewson 1993.

Oo. - Oowekyala, acc. to Linkoln, Rath 1980.

PA - Proto-Algonquian, acc. to Aubin 1975; Goddard 1974, 1979, 1982; Hewson 1993; Proulx 1984a, b, 1989, 1991, 1992, 1994 [with transliteration ${ }^{*} \Rightarrow{ }^{*}$; $\left.{ }^{*} x k,{ }^{*} x p \Rightarrow{ }^{*} t k,{ }^{*} t p ;{ }^{*} c{ }^{*},{ }^{*} c p>s k,{ }^{*} s p\right]$.

PAlg - Proto-Algic, acc. to Proulx 1984a, b, 1991, 1992, 1994. I have also added several PAlg roots, according to the rules of Proulx's reconstruction. I interpret the PAlg phonemes denoted by
Paul Proulx as ${ }^{*} T,{ }^{*} K,{ }^{*} L,{ }^{*} C,{ }^{*} \mathrm{C}$ as voiced ${ }^{*} d,{ }^{*} g$, ${ }^{*} L,{ }^{*} 3$, * . Proulx's ${ }^{*} S$ which only occurs in clusters is denoted as * $\gamma$; its reflexes are PA*2, Wi. $\varnothing$ and Yu. $s\left(<{ }^{*} r<{ }^{*} \gamma\right)$. This PAlg phoneme corresponds to velars in other Algonquian-Wakashan languages. The "normal" PAlg velar glide * $\gamma$ does not occur in consonantal clusters.

PAlt - Proto-Altaic, acc. to Starostin et al. 2003.

PAW - Proto-Algonquian-Wakashan, author's reconstruction.

PChi - Proto-Chumakuan, author's reconstruction.

PChiW - Proto-Chimakum-Wakashan, author's reconstruction.

PChK - Proto-Chukchi-Kamchatkan acc. to Mudrak 2000 and O. Mudrak's comparative database "Chukchi-Kamchatkan etymology" kamet.dbf (http://starling.rinet.ru).

PIt - Proto-Itelmen acc. to Mudrak 2000 and O. Mudrak's comparative database "Itelmen etymology" itelet.dbf (http://starling.rinet.ru).

PNA - Proto-Nivkh-Algic, author's reconstruction.

PNi - Proto-Nivkh, author's reconstruction according to materials in O. Mudrak's comparative Nivkh database nivget. dbf.

PS - Proto-Salish, acc. to Kuipers 2002.

PSC - Proto-Central Salish, acc. to Kuipers 2002.

PSI - Proto-Interior Salish, acc. to Kuipers 2002.

PW - Proto-Wakashan, acc. to Fortescue 2007.

PWN - Proto-Southern Wakashan, acc. to Fortescue 2007.

PWS - Proto-Northern Wakashan, acc. to Fortescue 2007 and Linkoln, Rath 1980.

Sakh. - Sakhalin Nivkh.

Shawnee - acc. to Hewson 1993.

Quil. - Quileute, acc. to Powell, Woodruff 1976.

Wi. - Wiyot, acc. to Teeter, Nichols 1993 and Proulx 1984a, b, 1989, 1991, 1992, 1994.

WOj. - Western Ojibwa, acc. to O. Mudrak's comparative Proto-Algonquian database.

Yu. - Yurok, acc. to Robins 1958 and Proulx 1985.

\section{References}

Aubin 1975 - George F. Aubin. A Proto-Algonquian dictionary. Ottawa, 1975.

Baldwin, Costa 2005 - Daryl Baldwin, David J. Costa. Miami-Peoria dictionary. Miami University, 2005.

Beck 1997 - David Beck. Mosan III: a problem of remote common proximity. 32 ${ }^{\text {nd }}$ International Conference on Salish and Neighboring Languages. 1997.

Fisher, Leman, Pine, Sanches 2004 - Louise Fisher, Wayne Leman, Leroy Pine Sr., Marie Sanchez. Cheyenne dictionary. Morrisville, 2004.

Fortescue 2007 - Michael Fortescue. Comparative Wakashan dictionary. München, 2007. 
Goddard 1974 - Ives Goddard. An outline of the historical phonology of Arapaho and Atsina. International Journal of American Linguistics. Vol. 40 (2). 1974, pp. 102-116.

Goddard 1979 - Ives Goddard. Comparative Algonquian. In: The languages of Native America: Historical and comparative assessment, eds. Lyle Campbell and Marianne Mithun. Austin, 1979, pp. 70-132.

Goddard 1982 - Ives Goddard. The historical phonology of Munsee. International Journal of American Linguistics. Vol. 48 (1). 1982, pp. 16-28.

Haas 1958 - Mary R. Haas. A new linguistic relationship in North America: Algonkian and the Gulf languages. Southwestern Journal of Anthropology. Vol. 14, pp. 231-264.

Hewson 1993 - John Hewson. A computer-generated dictionary of Proto-Algonquian. Canadian Museum of Civilization, 1993.

Kuipers 2002 - Aert Hendrik Kuipers. Salish Etymological Dictionary. Linguistics Laboratory, University of Montana, 2002.

Linkoln, Rath 1980 - Neville J. Lincoln, John C. Rath. North Wakashan Comparative Root List. Canadian Museum of Civilization Mercury Series, Canadian Ethnology Service Paper no. 68. Ottawa, 1980.

Mudrak 2000 - O. A. Mudrak. Etimologicheskij slovar' chukotsko-kamchatskikh jazykov. Moscow, 2000.

Nikolaev 2015 - Sergei L. Nikolaev. Toward the reconstruction of Proto-Algonquian-Wakashan. Part 1: Proof of the Algonquian-Wakashan relationship. Journal of Language Relationship. 13/1. Moscow, 2015. Pp. $23-61$.

O’Meara 1996 - John O’Meara. Delaware-English / English-Delaware dictionary. Toronto, 1996.

Powell, Woodruff 1976 - J.V. Powell, Fred Woodruff, Sr. Quileute dictionary. Northwest anthropological research notes. Memoir No. 3. Part 2. Moscow (Idaho), 1976.

Proulx 1984a - Paul Proulx. Proto-Algic II: Verbs. International journal of American linguistics. Vol. 50 (1). 1984 , pp. 59-94.

Proulx 1984b - Paul Proulx. Proto-Algic I: Phonological sketch. International journal of American linguistics. Vol. 50 (2). 1984, pp. 165-207.

Proulx 1989 - Paul Proulx. A sketch of Blackfoot historical phonology. International journal of American linguistics. Vol. 55 (1). 1989, pp. 43-82.

Proulx 1991 - Paul Proulx. Proto-Algic III: Pronouns. Kansas Working Papers in Linguistics. Vol. 16. University of Kansas, 1991, pp. 129-170.

Proulx 1992 - Paul Proulx. Proto-Algic IV: Nouns. Kansas Working Papers in Linguistics. Vol. 17, No. 2. University of Kansas, 1992, pp. 11-58.

Proulx 1994 - Paul Proulx. Proto-Algic V: Doublets and their implications. Kansas Working Papers in Linguistics. Vol. 19, No. 2. University of Kansas, 1994. Pp. 113-183.

Robins 1958 - Robert H. Robins. The Yurok Language: Grammar, Texts, Lexicon. University of California Publications in Linguistics. Vol 15. 1958.

Salzmann 1983 - Zdenek Salzmann. Dictionary of contemporary Arapaho usage. Wind River Reservation, Wyoming, 1983.

Starostin et al. 2003 - S.A. Starostin, A.V. Dybo, O.A. Mudrak. The etymological dictionary of Altaic languages. Leiden, 2003.

Teeter, Nichols 1993 - Karl V. Teeter, John D. Nichols. Wiyot Handbook I. Glossary and concordance. Winnipeg, 1993. Voorhis, 1988 - Paul H. Voorhis. Kickapoo vocabulary. Winnipeg, 1988.

С. А. Николаев. К реконструкции алгонкино-вакашского праязыка. Ч. 2: Алгонкиновакашские звуковые соответствия.

Вторая часть настоящей статьи, продолжающая исследование, опубликованное в одном из предыдущих номеров ВЯР, содержит: состав праалгонкино-вакашских фонем со ссылками на праалгонкино-вакашский сравнительный словарь (§2); сравнительный праалгонкино-вакашский словарь, который включает более четырехсот корневых реконструкций, снабженных релевантным правакашским, пранивхским и праалгийским материалом, причем словарь включает также пранивхско-алгонкинские корни (§3); индекс лексических значений праалгонкино-вакашских и пранивхско-алгонкинских корней (§4). Научная новизна статьи заключается в формальном доказательстве гене- 
тического родства между нивхским, алгийскими (алгонкино-ритванскими) и вакашскими языками стандартным компаративистическим методом, т. е. путем установления системы регулярных фонетических соответствий между словарями сравниваемых языков.

Ключевые слова: алгонкино-вакашские языки, алгийские языки, вакашские языки, чимакум-вакашские языки, вакашские языки, нивхский язык, историческая фонология, сравнительный словарь. 